\title{
DETERMINANTS OF SMALL BUSINESS REOPENING DECISIONS AFTER COVID RESTRICTIONS WERE LIFTED
}

\author{
Dylan Balla-Elliott \\ Zoë B. Cullen \\ Edward L. Glaeser \\ Michael Luca \\ Christopher T. Stanton \\ Working Paper 27362 \\ http://www.nber.org/papers/w27362
NATIONAL BUREAU OF ECONOMIC RESEARCH
1050 Massachusetts Avenue
Cambridge, MA 02138
June 2020, Revised September 2021

We thank the founders of Alignable for sharing data. The views expressed herein are those of the authors and do not necessarily reflect the views of the National Bureau of Economic Research.

At least one co-author has disclosed additional relationships of potential relevance for this research. Further information is available online at http://www.nber.org/papers/w27362.ack

NBER working papers are circulated for discussion and comment purposes. They have not been peer-reviewed or been subject to the review by the NBER Board of Directors that accompanies official NBER publications.

(C) 2020 by Dylan Balla-Elliott, Zoë B. Cullen, Edward L. Glaeser, Michael Luca, and Christopher T. Stanton. All rights reserved. Short sections of text, not to exceed two paragraphs, may be quoted without explicit permission provided that full credit, including $\bigcirc$ notice, is given to the source. 
Determinants of Small Business Reopening Decisions After COVID Restrictions Were Lifted Dylan Balla-Elliott, Zoë B. Cullen, Edward L. Glaeser, Michael Luca, and Christopher T.

Stanton

NBER Working Paper No. 27362

June 2020, Revised September 2021

JEL No. D22,E32,I15,L23

\begin{abstract}
The COVID-19 pandemic led to dramatic economic disruptions, including government-imposed restrictions that required millions of American businesses to temporarily close. We present three main facts about business decisions to reopen at the end of the lockdown, using a nation-wide survey of thousands of small businesses. First, the plurality of firms reopened within days of the end of legal restrictions, suggesting that the lockdowns were generally binding for businesses although a sizable minority delayed their reopening. Second, decisions to delay reopenings were not driven by public health concerns. Instead, businesses in high-proximity sectors planned to reopen more slowly because of expectations of stricter regulation rather than concerns about public health. Third, pessimistic demand projections played the primary role in explaining delays among firms that could legally reopen. Owners expected demand to be one-third lower than before the crisis throughout the pandemic. Using experimentally induced shocks to perceived demand, we find that a $10 \%$ decline in expected demand results in a 1.5 percentage point $(8 \%)$ increase in the likelihood that firms expected to remain closed for at least one month after being legally able to open.
\end{abstract}

Dylan Balla-Elliott

University of Chicago

dballaelliott@uchicago.edu

Zoë B. Cullen

Rock Center 210

Harvard Business School

60 N. Harvard

Boston, MA 02163

and NBER

zcullen@hbs.edu

Edward L. Glaeser

Department of Economics

315A Littauer Center

Harvard University

Cambridge, MA 02138 and

NBER

eglaeser@harvard.edu
Michael Luca

Harvard Business School

Soldiers Field

Boston, MA 02163

and NBER

mluca@hbs.edu

Christopher T. Stanton

210 Rock Center

Harvard University

Harvard Business School

Boston, MA 02163

and NBER

christopher.t.stanton@gmail.com 


\section{INTRODUCTION}

The COVID-19 pandemic led to economic disruptions that have not been seen since the Great Depression (Baker et al., 2020; Bartik et al., 2020; Forsythe et al., 2020). Government-imposed restrictions or lockdowns, including regulations on which businesses could operate, forced millions of businesses throughout the United States to temporarily close. At the time of the lockdowns, there was some optimism that lifting regulations would result in a speedy recovery. For example, then-President Trump tweeted that if policymakers were to "reopen our country," then businesses would rapidly come back online because "our people want to return to work." At the same time, important barriers to reopening may have existed, even absent restrictions. An important input for understanding the efficacy and need for regulation is understanding how small business owners responded both to pandemic-related risks and government-imposed operating restrictions. ${ }^{1}$

There are several factors that might have led a business to delay reopening after restrictions were lifted. First, business owners might have had concerns about their own health, as reopening may have exposed them or their employees to COVID-19. Second, the pandemic may have led to supply chain disruptions and coordination challenges. Third, business owners might have expected regulations to continue or to snap back into place after lapsing. Fourth, even before any government interventions, many households had begun self-isolating to reduce the risk of transmission of COVID (Couture et al., 2020; Glaeser et al., 2021; Gupta et al., 2020; Sears et al., 2020), leading to demand reductions that predated the lockdowns. Businesses might have expected lower demand to continue after restrictions were lifted, which in some cases might provide insufficient margin to cover the fixed and variable costs of even limited operations.

In this paper, we investigate businesses' reopening decisions, and factors that slowed the reopening process. To do this, we analyze responses from a survey of tens of thousands of small business owners conducted by the small-business network Alignable in early May of 2020. An in-

\footnotetext{
${ }^{1}$ The pandemic has led to some unusual patterns when compared to typical business cycles. Moscarini \& PostelVinay (2012) show that small businesses are less sensitive to standard negative aggregate productivity shocks. The pandemic recession appears to differ from business cycle fluctuations they consider. We find small businesses are hurt by anticipated demand-side factors, including lockdowns, in-person restrictions, and lower demand, due to contagion fears.
} 
formation provision experiment on customer demand projections embedded in the survey allows us to recover causal estimates of the link between expected demand and intentions to reopen. To understand other factors influencing business operations, we merge the survey-experiment results with O-NET data on workplace conditions, crowd-sourced data on industry attributes, and county-level data on COVID prevalence and related covariates. We also explore actual reopenings following the surprise lifting of operating restrictions in two states. Wisconsin and Florida lifted restrictions after a State Supreme Court order and an executive order, respectively. ${ }^{2}$ Through the summer and fall, we conducted follow-up surveys to trace whether owners' projections about reopening could be corroborated.

Overall, we find that regulations were often a binding constraint for firms' operating decisions. Just under $60 \%$ of owners reported an intention to open within a few days of the lifting of legal restrictions. Our follow-up surveys and difference-in-differences analyses show that lifting regulations resulted in owners reopening more quickly. Our results suggest that governments were setting more stringent guidelines for reopening, relative to what many businesses would have selected - which is consistent with the fact that the government is better positioned to make decisions that account for the externalities of higher foot traffic.

A minority of businesses chose to delay reopening, even beyond the mandated closure. Eighteen percent of firms reported intentions to delay reopening at least one month after the end of restrictions on their operations, and this estimate is likely a lower bound. This rises to thirty percent if we exclude firms that were open at the time of the survey. Why did these businesses expect additional delay? Our second main finding is that expectations of prolonged low demand played an important and causal role in explaining delayed reopenings. Overall, the demand projections were grim. Heading into the summer of 2020, the average firm in our sample expected that demand for its services would be 35.3 percent of pre-crisis levels the following fall. ${ }^{3}$ These demand projections correlate with political preferences: Republican vote share strongly and positively predicts

\footnotetext{
${ }^{2}$ The executive order extended "full phase one" reopening to all counties. This reopening included the statewide reopening of indoor dining, retail, gyms, and libraries and museums at $50 \%$ capacity.

${ }^{3}$ Unfortunately, we do not have price data, unlike Jaravel \& O'Connell (2020), so we focus on the share of customers returning, relative to before the crisis.
} 
higher levels of projected future demand. Other factors, such as health concerns and supply chain concerns, played a more minor role in delaying reopening. For example, only $5 \%$ of firms that were not fully open at the time of the survey cited supply concerns as a barrier that would prevent reopening. Furthermore, the interaction between local COVID case loads with measures of physical proximity to coworkers or customers, owner age, or share of high-risk older customers do not offer additional explanatory power for the timing of individual business reopenings.

We use an instrumental variables approach to establish a causal relationship between expectations of low demand and and plans to delay reopening. We shift demand projections using a survey experiment that presented aggregated projections about similar businesses' anticipated future demand to a subset of owners. We expected that receiving this information would cause owners to update their own beliefs, as observing information about overall demand may be hard to ascertain for individual owners. Optimistic owners receiving the information rationally shifted beliefs downward, while pessimistic ones had rosier forecasts after receiving the information treatment. Comparing owners with similar initial beliefs, but with different information treatments, reveals that delayed reopening hinged on customer demand. Over the longer term, consumer demand is correlated with the firm's reported expected probability of surviving until the end of the year.

Our evidence from early in the pandemic suggests owners were eager to return to work, despite salient reports on health risks and an uncertain disease progression. This raises important questions: did small business owners believe they could adapt practices to operate safely? Were they desperate for operating revenue? Did stimulus packages encourage reopening before owners would have otherwise chosen to open? We shed light on these questions in this paper. We asked owners whether they would choose to open or close over two weeks if they received a grant. We randomized the size of the grant and whether it included a requirement that the business remain closed. When the grant was not conditional on closing, around three-quarters of business owners chose to open, regardless of the grant size, even when the grant was close to 0 or as large as $\$ 50,000$. Hence we find no evidence that additional funds helped "tide over" businesses, allowing them to cover fixed costs while remaining closed to weather the health risks of the pandemic. When the grant 
was conditional on closing, half of small business owners would remain closed for an additional two weeks in exchange for a modest sum of $\$ 2,500$, but a quarter would reject $\$ 25,000$ to reopen immediately. This indicates that, for about a quarter of businesses, opening was perceived to be extremely valuable. For most firms, the benefits of reopening for two weeks were limited but of higher value than being closed. These results suggest that stimulus packages with modest incentives to change operating status, such as the Payroll Protection Program's incentives to continue active employment, likely shifted the decisions of these firms on the margin.

Absent health concerns, a risk-neutral employer might weigh the expected profit of opening and the carrying costs of closing temporarily versus shutting down. Conditional on remaining open in some fashion, the firm would also consider the financial returns to mitigating health hazards. These calculations would depend on firm expectations about customer demand and employee productivity, given risks of contagion. However, owners making decisions may be just as likely as consumers to fear contagion personally and may make decisions with these personal fears in mind. Moreover, recent research on "behavioral firms" (DellaVigna \& Gentzkow, 2019) highlights the ways in which firms may also make systematic mistakes.

The literature on the 2020 pandemic seems to confirm that consumer demand in many industries fell dramatically because of COVID-19, and many firms closed (Abu-Rayash \& Dincer, 2020; Alexander \& Karger, 2020; Baker et al., 2020; Brinkman \& Mangum, 2020; Chetty et al., 2020; Cintia et al., 2020; Coibion, Gorodnichenko, \& Weber, 2020; Couture et al., 2020; Dunn, Hood, \& Driessen, 2020; Glaeser, Gorback, \& Redding, 2020; Goolsbee \& Syverson, 2020; Huang et al., 2020; Kevin Linka, Alain Goriely, \& Ellen Kuhl, 2021; Sheridan et al., 2020; Soucy et al., 2020; Velde, 2020). Yet there is little clarity about whether firms shuttered because of reduced demand or other issues, including suppliers' fears of contracting disease or bankruptcy. Bartik et al. (2020) provided an early survey of small businesses that found that 45 percent of their sample was not in operation around April 1, 2020. Closure rates were much higher for businesses that dealt in faceto-face services, like the arts, than in information services, like finance. Similarly, Fairlie (2020) found that the "number of active business owners in the United States plummeted by 3.3 million 
or $22 \%$ over the crucial two-month window from February to April 2020.”

Chetty et al. (2020) also examine business closures, which they measure as a business with zero credit card payments over multiple days, effectively combining temporary and permanent closures. They estimate that lockdowns explain almost 15 percent of the variation in business closures over time and space, which is modest but far more than the variation these regulations explain for spending or employment. They do not try to distinguish whether the businesses closed because of reduced demand or concerns for worker safety. Papanikolaou \& Schmidt (2020) study the default probabilities implied by the premium firms must pay in their borrowing. They find both that employment dropped more during the pandemic in industries that cannot easily switch to remote work, and that markets expected more defaults in those industries. They interpret this as a labor supply shift, due to the pandemic, but it is difficult to differentiate between consumer demand and labor supply using their measure. de Vaan et al. (2020) find that the closing decisions of national brands also influenced the closing decisions of community establishments nearest the establishments of the parent brand, suggesting local social learning.

Our paper contributes to this literature by assessing the importance of consumer demand, supplyside factors, and the extent to which business owners internalize the risk of contagion when choosing whether to reopen. Weighing these factors can help inform policy decisions about whether to regulate businesses and how best to channel resources to them. For example, our results suggest that stimulus packages that boost consumer spending can encourage the reopening of small businesses. The results also suggest that the voluntary behavior of small businesses is unlikely to help mitigate health risks, absent sweeping regulation, as health concerns generally did not prevent businesses from planning to reopen. And the results further suggest that expectations about depressed consumer demand caused some firms to delay reopening even after regulations had been lifted.

\section{DATA SOURCES}

The small business owner data used in our analysis was collected through surveys conducted by Alignable Inc. Alignable is the largest network and community of small business owners in North 
America. We combine the survey data with Alignable's business profiles, O-NET details about physical proximity of working conditions at the industry level, and data on geographic variation of COVID-19 cases obtained from The New York Times. Together, these data help illuminate the factors driving business decisions about whether to reopen.

In this section, we describe the Alignable survey, its representativeness compared to Census data, and detail the other data sources used in the analysis.

\subsection{About Alignable and the Alignable Small Business Survey}

The Alignable platform has approximately 5 million registered small businesses across North America. Each week, Alignable distributes a survey link through email to its members. This link allows the company to merge the individual responses of participants to data from their user profiles.

Our primary sample comes from one wave of Alignable surveys that focused on business reopening, with the link emailed to users on May 9, 2020. This survey received 35,069 total responses to at least one question. 27,263 respondents completed all core questions that form the bulk of the analysis. The core questions contained several modules. The first module collected information about the current operational status of the business (fully open, partially open, temporarily closed, permanently closed) and any potential dependencies with other businesses that may have affected their decision to fully open or their ability to remain fully open. The second module asked about expectations about the return of their customers. To obtain an estimate of conditions on the ground, independent of the operational status of the business, owners were asked about the share of customers that would return in the event that they were fully open on a specified date in the future. That date was randomized over survey respondents, allowing us to trace out owners' expectations about the pandemic over varying horizons. To further separate the evolution of the pandemic from individual circumstances and trace out dependencies between businesses, an additional question asked about the expected reopening of other businesses. In the third module, respondents were asked about when they expected legal restrictions impacting their business to be lifted, and when they would be most likely to re-open fully if they were not fully open at the time of the survey. A 
final question asked about the likelihood that the business would be operational come December 2020.4

In the middle of the survey, before questions regarding expected demand and expected reopening and survival, a subset of respondents were shown information about how prior survey respondents had projected demand. The message read "based on your profile, location, and concerns, our polls show that similar businesses anticipate $[\mathrm{X} \%]$ of customers will return by [date]. The variable $X$ was calculated using data from the first 16,038 respondents. One-third of the respondents after the first batch received this message." ${ }^{5}$ The complete survey tool is available in the appendix. Table 1 Panel A provides more detail about the data and the measures collected from the main May 9 survey.

We supplement this survey wave with questions from other survey waves. From earlier and later waves, we can construct a time series of business operational status and demand using responses from 190,600 unique business owners from March to September 2020. We merge in demographic details about the owner's age and industry collected by Alignable in later surveys. We also include data on industry classification that comes from respondents entering their industry in a text box that would auto-complete to the text of four- and six-digit NAICS industry descriptions. We also use a question, delivered toward the end of May in an external survey conducted by Harvard Business School, to assess how participants would evaluate trade-offs between cash and health considerations. We presented users with a hypothetical grant, in amounts we randomized between $\$ 2,500$ and $\$ 50,000$. The grant could be one of two types: either the grant stipulated that the business would have to remain closed for two weeks to receive the grant, or the grant did not have conditions for receipt. We then asked users whether they would remain closed over the next two weeks under their particular hypothetical grant condition.

\footnotetext{
${ }^{4}$ A module tracking responses to CARES Act PPP status came prior to the final question about long-term business operations prospects, causing drop off to 17,098 completed responses for this last question.

${ }^{5}$ One-third of respondents saw a different message, but its mapping to a concept like demand is less clear.
} 


\subsection{Comparison of Survey Responses with U.S. Census Data}

One challenge in conducting surveys of businesses is the potential for selection bias. This sample is selected in two ways: (1) they are firms that have chosen to join Alignable, and (2) they are Alignable firms that have chosen to take surveys. Bartik et al. (2020) provide a variety of diagnostic checks for a survey of Alignable businesses conducted from late March to early April to assess its representativeness and shed light on sample selection. The sample provides broad coverage across the United States, industries, and business size (within small businesses). Roughly speaking, the sample matches Census data reasonably well along the dimensions of industry and geography, but the sample skews toward smaller businesses, relative to the full set of US small businesses. A crossvalidation against a phone survey suggests that these surveys reasonably estimate business closure, though the random phone survey suggested the survey might overrepresent closed businesses. ${ }^{6}$ This is consistent with expectations of Alignable executives, who believe that owners of permanently closed businesses will be less likely to respond to surveys.

Validation exercises of the May 9 survey wave reach similar conclusions to those of Bartik et al. (2020), indicating that the survey has nearly representative coverage by firm size and geography (see Appendix Figure A1). Appendix Figure A2 displays how closures co-vary with the local COVID caseload and unemployment rate.

\subsection{Other Data Sources}

Table 1 Panel B provides details about outside data sources that we merged with the Alignable data. We supplement the survey data with detailed characteristics about the industries of businesses at the four-digit NAICS level. We determine the extent that each industry can serve online customers and the likely age distribution of those customers, by posting a description of each industry on Amazon's Mechanical Turk and asking questions related to the nature of the industry and its customers. The

\footnotetext{
${ }^{6}$ As a test of selection into taking surveys, Bartik et al. (2020) reports the results of randomly calling 400 business owners using the contact information collected by Alignable at registration. The current status of these 400 business owners, open or closed, matches the ratio of open versus closed in a prior survey wave. This suggests that the survey responses are unlikely to understate the degree of businesses being permanently closed, at least conditional on having registered with Alignable.
} 
first question asked is, "how easy or common would it be for this business to provide services or goods online?" The second question is, "how likely is it for customers of this business to fall in each age bracket (listed below)?" We offer answers that correspond with 0-10 percent, 10-25 percent, 25-75 percent, and greater than 75 percent. Five unique individual Mechanical Turk responses were collected for each industry code and description. We average responses from these individuals at the industry level. The table presents the raw responses, while later analysis uses Z-Scores for these variables to ease interpretation.

We collect information at the occupational level about the proximity of employees with each other and with customers the O-NET proximity variable "To what extent does this job require the worker to perform job tasks in close physical proximity to other people?" The underlying encoding of the proximity measure ranges from "I don't work near other people (beyond $100 \mathrm{ft}$ )" as the lowest category to "Very close (near touching)" as the highest category. We follow Mongey \& Weinberg (2020) by merging the O-NET version 24 proximity variable to the Occupational Employment Statistics (OES) data collected by the BLS. The OES data provides a mapping between occupation codes and NAICS industries. We take the employment weighted average of proximity by four-digit NAICS code. ${ }^{7}$ Data about coronavirus cases at the county level were collected by The New York Times. While coverage is extensive, some counties were grouped together. ${ }^{8}$

Subsequent surveys help with validation exercises and confirm these early responses. Alignable asked about operations status at a monthly frequency starting at the end of July. We use the July, August, and September waves of these surveys to validate our early responses. These surveys asked respondents about the share of customers returning in the previous month as well as the current operating status of their business. Using a unique account ID, we can match respondents in our main survey wave in May to the later surveys. While these surveys are designed as repeated cross-sections, not as panels, in practice we observe more than 3,000 of the initial respondents in

\footnotetext{
${ }^{7}$ Examples of high proximity industries are retail establishments, personal care (i.e., barber \& beauty shops), and restaurants. In contrast, low proximity industries are insurance agents, legal services, designers/architects, and credit intermediaries.

${ }^{8}$ For example, a single value for New York City is reported, comprising New York, Kings, Queens, Bronx and Richmond Counties. The data are available at github.com/nytimes/covid-19-data
} 
at least one of the subsequent surveys.

\section{ANALYTICAL FRAMEWORK}

To fix ideas about the drivers of reopening, we consider the following simplified framework. A business owner's decision to open is a function $g($.$) of consumer demand c_{t}$, supplier availability $s_{t}$, owner or employee health concerns $h_{t}$, and government regulations $\theta_{t}$. A government lifts mandatory business closures for firms when COVID prevalence, $x_{t}$, is below a threshold. The thresholds may depend on how operations contribute to contagion. For simplicity we consider two types of business, high and low proximity, associated with two different regulatory thresholds, $\tau^{\text {high proximity }}$ and $\tau^{\text {low proximity }}$ respectively. Let $\theta_{t}$ be an indicator for whether the business remains below the threshold and hence is allowed to be open. Let $y_{t}$ be an indicator for whether a business is actually open.

Each of $c_{t} ; s_{t} ; h_{t}$; and $\theta_{t}$ is a function of COVID prevalence, $x_{t}$, and other factors outside the model. Our model predicts that certain characteristics of the business and owner will exacerbate the reopening response to local COVID prevalence. For example, if health concerns drive reopening decisions, we predict that personal characteristics of the owner and business, namely owner age, customer age, and the proximity of employees interacted with local COVID prevalence will be highly correlated with reopening decisions. If customer demand channels are pivotal for the reopening decision, the model predicts that the risk characteristics of customers, namely age and in-person contact, will interact with local case prevalence to predict reopening. If supplier availability or downstream businesses clients enter the reopening calculus, the case prevalence local to those businesses will interact with the proximity conditions in those businesses or essential business status to predict the reopening decision of the businesses we study.

Hence we write expected demand for direct-to-consumer (B2C) firms as a function of the interaction of local case loads with customer age and the demand for business-to-business (B2B) firms as a function of the status of downstream businesses, which may in turn depend on COVID case loads

and regulations in their local environment, $c\left(x_{t}\right.$, \{customer risk factors $\left.\}\right)$ or $c\left(\bar{Y}_{t}\left(\bar{X}_{t}, \overline{\mathrm{T}}_{t}^{\text {proximity }}\right)\right)$, 
where $\bar{Y}_{t}$ and $\bar{X}_{t}$ and $\overline{\mathrm{T}}_{t}^{\text {proximity }}$ refer to the open-status of downstream businesses and their local health and regulatory conditions respectively. The decision function is then

$$
y_{\text {type }, t}^{\text {proximity }}=g\left(c_{\text {type }}(.) ; s\left(x_{t}\right) ; h\left(x_{t}\right) ; \theta\left(x_{t} ; \tau^{\text {proximity }}\right)\right)
$$

where type indicates whether the firm is direct-to-consumer or business-to-business, and $c_{\text {type }}($. is the corresponding consumer demand function for $\mathrm{B} 2 \mathrm{C}$ firms, $c\left(x_{t}\right.$, \{customer risk factors $\left.\}\right)$ or B2B firms, $c\left(\bar{Y}_{t}\left(\bar{X}_{t}, \overline{\mathrm{T}}_{t}^{\text {proximity }}\right)\right)$. To gather evidence about the importance of the health channel $x_{t}$ in determining the choice to reopen, we make use of our theoretical prediction that the relevance of the local COVID caseload increases with the health risk factors of the owner and employees. In other words, if the owner's direct health concerns drive the reopening decision, then the expected time to reopen should rise with the age of the owner and rise faster with high levels of local exposure to the coronavirus. If the owner is concerned about the health of customers or liability for their health, then the expected time to reopen should rise with the share of customers in the high risk demographic groups, and rise faster when local exposure to the coronavirus is high. We estimate the equation

$$
\begin{aligned}
Y_{i}= & \beta_{1}(\text { Owner-Age } \times \text { COVID case load })+ \\
& \beta_{2}(\text { Share Older Customers } \times \text { COVID case load })+\gamma X_{i}+\epsilon_{i}
\end{aligned}
$$

We estimate this linear function using ordinary least squares regressions. We then check the sensitivity to using OLS on censored outcomes. ${ }^{9}$ We proxy for COVID-19 prevalence in the outside population with COVID-19 cases per capita in the county in which the business is located.

\footnotetext{
${ }^{9}$ For open firms, the time to reopening is censored from below at zero. For the closed firms, the time to reopening is censored above because the latest date for reopening they could report was September or later. To address censoring, Appendix Table A3 presents results using a Tobit regression. The results are similar in sign, but the Tobit coefficients when including all businesses are often larger in magnitude.
} 
We jointly address exposure to co-workers and customers by using a measure of workers' physical proximity to others, based on O-NET data. For most firms in our sample, the owner's age is available in Alignable's administrative data. Customer age is measured through the MTurk survey instrument detailed in Section 2.

To test whether firms fail to reopen because of problems further back in their supply chain, we directly ask whether respondents have (or anticipate having) supply problems or problems with downstream businesses and whether those problems have delayed (or will delay) their reopening.

To test the causal role of government regulation on reopening decisions, we can use sharp changes in regulations that occurred in mid-May, between two survey rounds, to identify how businesses changed their behavior and beliefs when restrictions were suddenly lifted. In Wisconsin, a State Supreme Court decision suddenly lifted restrictions on May $14{ }^{10}$. In Florida, an executive order issued by Governor DeSantis on May 14 (effective May 18) accelerated and standardized reopening statewide. We use a difference-in-difference model to compare the changes between survey rounds (running from May 9 to May 13 and then from May 14 through June 1) in Florida and Wisconsin to the changes in the other states. ${ }^{11}$

We estimate the following equation, where $Y_{i}$ is the reopening decision of business owner $i$, or the projected demand of business owner $i$.

$$
Y_{i}=\delta\left(\text { Reopened State }_{i} \times \text { Post }\right)+\beta_{1} \text { Post }+\beta_{2} \text { Reopened State }_{i}+\gamma X_{i}+\epsilon_{i}
$$

Post is an indicator equal to one for responses after the shocks to regulations. Reopened State ${ }_{i}$ is an indicator equal to one for responses in states that experience the surprise reopening. ${ }^{12} X_{i}$ contains separate vectors of fixed effects for states and four-digit NAICS industries, and $\epsilon_{i}$ captures

\footnotetext{
${ }^{10}$ The decision was announced late in the evening of May 13.

${ }^{11}$ While the later survey remained open until the following survey was distributed, over $95 \%$ of responses were collected by May 18 .

${ }^{12}$ We will estimate three versions of this model: in the first, Wisconsin and Florida are both treated. In the second and third versions, we consider Wisconsin only and Florida only, respectively. In the specification examining only the effect in Wisconsin, respondents from Florida are omitted from the regression (and vice versa) to avoid biasing the estimates.
} 
shocks outside the model that we assume are orthogonal to the surprise reopening. Our coefficient of interest is $\delta$, which identifies the effect of the surprise regulatory changes on outcomes.

To further help us identify the importance of the demand channel, we isolate factors that shift perceptions of future customer demand and yet are orthogonal to COVID prevalence. For example, perceptions of future demand can be influenced by the projections of similar business owners (de Vaan et al., 2020), a dimension we vary experimentally. The survey asked all survey respondents that were not permanently closed at the time of the survey to report their expectations regarding demand. After collecting several thousand responses, we could calculate the average expected demand in each region for various types of businesses. ${ }^{13}$

We then randomly assigned the remaining respondents to the control or to one of two treatment arms. In the treatment arms, the survey revealed projected changes in demand or reopening plans by similar respondents. ${ }^{14}$ Respondents were then asked about their own beliefs about demand and finally about their predicted behavior around reopening. Respondents in the control group were asked for the demand projections without being shown any information. For individuals whose initial beliefs were below those of similar businesses in the industry by region conditioning set, the revelation pushes beliefs upward. For those with more pessimistic beliefs, the revelation pushes beliefs downward. Overall, beliefs for treated firms should be less diffuse after treatment. As a result, we use the gap between the aggregated information displayed and the initial beliefs as our instrument.

We can express the process by which the information treatment changes demand projections with a Bayesian learning model. In a simple framework, the mean of the posterior belief is a

\footnotetext{
${ }^{13} \mathrm{We}$ created groups of business by pooling respondents of the same business type (serving business customers or consumers) who gave similar answers to our survey questions about downstream and upstream business dependencies, who operated in the same region of the United States, and who were asked about the same date in the future.

${ }^{14}$ The precise wording of the messages were: "Based on your profile, location, and concerns, our polls show that similar businesses anticipate $\left[X_{1}\right] \%$ of customers will return by [date]." and "Before continuing, we want to share some interesting information. Based on your profile, location, and concerns, our polls show that $\left[X_{2}\right] \%$ of similar businesses expect to be fully open by [future date]." Date in this case is the same date used for subsequent questions about expected demand. These estimates are derived from a subset of the earliest responses to the survey. We used these early responses to estimate these demand signals that were then randomly shown to an experimental subset of the main body of survey respondents. For the sake of statistical power, we pool both treatment arms.
} 
weighted average between the signal and the mean of the prior belief:

$$
D_{i}^{\text {post }}=\alpha \cdot D_{i}^{\text {signal }}+(1-\alpha) \cdot D_{i}^{\text {prior }}
$$

where the parameter $\alpha$ is the learning rate. The parameter $\alpha$ ranges from 0 (respondents completely ignore the signal) to 1 (respondents fully update their beliefs to exactly match the signal), and depends on the relative precision between the prior belief and the signal (Hoff, 2009). ${ }^{15}$

Initial beliefs are elicited through a related set of questions at the beginning of the survey before the information is shared. Because these earlier questions allow us to infer demand expectations (but do not ask about them directly), we combine the questions that precede the information treatment in a linear model, estimated with ordinary least squares, to predict beliefs for the exact question about return customers. The prediction model is estimated only using an early batch of respondents who did not receive any information and who are excluded from the remaining analysis.

Using 16,038 early respondents who were not shown the information treatment, we estimate the model

$$
\hat{D}_{i_{\text {training }}^{\text {prior }}}^{\text {pa }} X_{i_{\text {training }}}+\epsilon
$$

We use this $\hat{\boldsymbol{\beta}}$ to estimate the implied prior beliefs $\hat{D}_{i}^{\text {prior }}=\hat{\boldsymbol{\beta}} X_{i}$ using the full matrix $\mathrm{X}$ for the experimental sample. This yields a sample analog $\hat{D}_{i}^{\text {prior }}$ of the prior belief distribution in equation 4.

This prediction and the Bayesian learning model combine to provide the first stage of this instrumental variables model. Since we experimentally provide the information treatment to only

\footnotetext{
${ }^{15}$ This form of updating characterizes a Bayesian model in which both the prior and posterior distributions are normal with known variance. In our setting with an unknown variance and a variable (demand) that is bounded at zero, an exponential likelihood model is more appropriate. To build intuition, we interpret the first-stage coefficients in the simplified normal-normal setting; interpretation of the parameter $\alpha$ becomes more complicated if beliefs are not normally distributed (e.g., follow an exponential distribution).
} 
some of the sample, we can write the first stage of the instrumental variables specification as

$$
D_{i}^{\text {post }}=\gamma T_{i}\left(D_{i}^{\text {signal }}-\hat{D}_{i}^{\text {prior }}\right)+\lambda\left(D_{i}^{\text {signal }}-\hat{D}_{i}^{\text {prior }}\right)+\beta X_{i}+\epsilon_{i}
$$

where $T_{i}$ is an indicator that evaluates to one if the respondent received the information treatment and $X_{i}$ is a vector of controls, including the projected prior $\hat{D}^{\text {prior }}$. In this model, $\gamma$ captures the Bayesian learning parameter, after $\lambda$ nets out spurious updating (i.e., mean reversion) among respondents who never receive a signal. In the second stage, we can use the exogenous component of the shift in the posterior belief distribution to identify the causal effect of changes in demand projections on reopening plans. This second stage equation is then

$$
Y_{i}=\eta D_{i}^{p o s t}+\beta X_{i}+\xi_{i}
$$

where $Y_{i}$ is our outcome of interest, (i.e., expected months until reopening, an indicator for a lag of at least one month between expected reopening and the expected lifting of restrictions, and finally the probability that the business expects to be open in December 2020) and $X_{i}$ is the vector of control variables. In the baseline specification, $X_{i}$ contains controls for the projected prior $\hat{D}^{\text {prior }}$, the share of similar businesses that are open, current operating status, an indicator for whether the business is essential, and the future date to which the demand projections correspond. Additionally, we nonparametrically adjust for time trends in the composition of respondents within the survey by including controls for the time of the response. In an alternative specification, we add industry level controls for physical proximity, ease of doing business online, and the share of customers over 65, as well as county level controls for COVID cases per capita, population density, Republican vote share in the 2016 election, and the age of the owner. We cluster standard errors at the business type by region cell, which is the cell at which the information signal $[X]$ is defined. 


\section{RESULTS}

At the time of the survey (May 9, 2020), 32\% of surveyed small businesses were fully open (offering the same products and services as before the pandemic), 34\% were partially open (offering more limited products and services than before the pandemic), $32 \%$ had closed temporarily (offering no products and services for a temporary period), and the remaining $2 \%$ had closed permanently with no plan to reopen. ${ }^{16}$ In Figure 1, we show how the operational status of businesses at the time of the survey vary with respect to industry characteristics, location characteristics, and owner characteristics that are each intended to capture contagion risk experienced by the employees, customers, and owners. ${ }^{17}$ Most of these contagion-related characteristics are uncorrelated with operating status, including the share of sales that can be carried out online, and share of elderly customers at high risk of serious illness. While measurement error could mask a correlation, the modest relationship between business operating status and health factors is replicated across a number of alternative proxies, with two exceptions. The first is proximity status at the industry level, known to be highly correlated with regulation. High-proximity industries account for a full two-thirds of temporarily closed businesses but only 37\% of fully open businesses. In Panel A of Appendix Figure A4, we show that this gap persists through later survey rounds in the summer and early fall. We also see a correlation with the age of the owner and permanent closures. Closed businesses are more than $25 \%$ more likely to have an owner over 65 , potentially a category of owners who were considering retirement when the pandemic began.

\footnotetext{
${ }^{16}$ In the survey received by business owners, the question asking about business status specified that fully open and partially open are respectively defined as "offering the same" and "offering more limited" products or services than before COVID. We point out that an alternative definition of partially open could have been premised on employment. However, Kurmann, Lale, \& Ta (2020) show that businesses very quickly regained employment after reopening. In our sample, fully open businesses were at $101 \%$ of their pre-pandemic employment and partially open businesses were at $93 \%$. Even if we exclude the top $1 \%$ of firms, then fully open businesses were at $97 \%$ of their pre-pandemic employment and partially open businesses were at $92 \%$.

${ }^{17}$ Please refer to Section 2 for detailed definitions of each data source represented in this graph.
} 


\subsection{Are Regulations Binding?}

To distinguish between the effects of restrictions per se and the effects of the underlying factors that drive both restrictions and the reopening decisions, we focus on the roughly $66 \%$ of businesses that are temporarily closed or partially open. We elicit beliefs regarding their reopening timeline, future regulations (and their expiration), and future demand.

Figure 2 shows the joint distribution of firm expectations about when all lockdown regulations will end (x-axis) and when they expect to fully reopen their businesses (y-axis). The share of firms along the diagonal gives us the share of business owners who said that they would reopen fully at the moment that they were legally allowed to do so. The entries above the diagonal represent those business owners who expected to wait. ${ }^{18}$ The majority expect to reopen as soon as they can do so. However, there is also a large minority of owners that anticipates a gap between the expected end of the lockdowns and the expected time of reopening. ${ }^{19}$

Respondents in high and low proximity industries faced different regulatory hurdles at the time of the survey. Panel A of Figure 3 shows the cumulative share of firms in a given industry that expect to open fully on or before a given date. About 70 percent of firms in low proximity industries said they were legally allowed to open by the time of the survey (May 9th) in contrast to only 43 percent of high proximity firms. Respondents expected regulatory barriers to partially converge over the summer. Roughly $90 \%$ of firms in low proximity industries expected restrictions preventing them from reopening to expire by July, compared to roughly $82 \%$ of high proximity firms.

For the purpose of our empirical analysis, we underscore that legal restrictions at the time of the survey and expectations about the evolution of these restrictions are correlated with - but not perfectly determined by-local COVID conditions. In our framework, different regions choose

\footnotetext{
${ }^{18}$ Somewhat surprisingly, there are also firms that expect to be fully open before the restrictions on fully opening end. We believe that this reflects the gray area around the words "restrictions" and "fully." For example, a state order that mandated social distancing in retail establishments can be interpreted as a limitation on the ability to fully open. Yet the same business owner who expected that limitation to persist through July might choose to think of himself as being fully open at the time of the survey or at some other point before July.

${ }^{19}$ For all survey respondents that listed August as their expected date of deregulation, at least 23 percent expected to take some time before reopening. Fifteen percent of firms that expected the restrictions to end by early June also expected to remain at least partially closed until July. Thirty-one percent of business owners who expected lockdowns to end in late June expected that they would remain closed until July.
} 
different thresholds $\tau_{t}$ for the imposition of restrictions. Among other explanatory variables, local politics (proxied by share of Republican votes in the 2016 presidential election) explains substantial variation in threshold choices, holding fixed local pandemic conditions. In Appendix Figure A3, we explore heterogeneity across states in the expected length of the lockdowns and show that, despite large differences, the average gap between when firms expect lockdowns to end and when they expect to reopen is between one and two weeks.

Focusing on the surprising changes in regulations in Florida and Wisconsin, the timing of which is arguably orthogonal to local conditions, we corroborate our other findings about regulation's impact on the timing of business reopenings. In Table 2, we present evidence that the abrupt lifting of restrictions increased the share of open businesses in these states by an additional 5.6 percentage points (15\%). We also see a statistically significant but economically small increase in customer demand projections, conditional on reopening, by 0.4 percentage points $(<1 \%)$, relative to the national trend. In this way, we see that that the surprise regulatory reopening caused a meaningful subset of firms in the affected states to reopen but without a corresponding increase in demand projections. This suggests that the regulations bind per se, not that business owners think that regulations directly reduced demand or communicated information about the safety of patronizing these businesses to consumers. ${ }^{20}$

To explore the trade-offs of reopening versus remaining closed for an additional two weeks, we asked owners what they would choose to do under hypothetical scenarios. They were either asked about a scenario where they received an unconditional cash grant, or they received a scenario where the cash grant was conditional on remaining closed for two weeks. In both scenarios, we randomized the size of the grant. We show the results graphically in Figure 5. Around three-quarters of businesses chose to open with any sized grant when there was no condition to accepting the grant. When the grant was conditional on closing, half of small businesses would remain closed for an

\footnotetext{
${ }^{20}$ This is consistent with the literature on consumer behavior that finds a strong relationship between spending and health considerations, with regulations playing a smaller role (Chetty et al., 2020; Dunn, Hood, \& Driessen, 2020; Goolsbee \& Syverson, 2020; Velde, 2020). As mentioned in Section 1, it is now well documented that the fall in mobility and consumer activity preceded formal restrictions (Abu-Rayash \& Dincer, 2020; Huang et al., 2020; Soucy et al., 2020).
} 
additional two weeks in exchange for a modest sum of $\$ 2,500$, but a quarter of firms would reject $\$ 25,000$ to reopen immediately. This indicates that for about a quarter of businesses, opening as soon as possible was extremely valuable. For most firms, the benefits of reopening for two weeks were limited but still of value. Finally, we found no evidence that additional funds helped "tide over" businesses, allowing them to cover fixed costs while closed to weather the health risks of the pandemic. Small businesses were no more likely to remain closed when offered unconditional grants of any size: that is, the gradient of reopening with respect to the size of the grant offered is flat.

\subsection{Will Health Fears Deter Reopening?}

We now examine the correlation between expected time to reopening and health related variables. It is challenging to fully capture health concerns on the part of owners. We attempt to do this by proxying for health risks using such variables as the level of COVID-19 cases, employee proximity, and owner and customer age. While these proxies are all imperfect, they help provide insight into the role of health risk.

Table 4 provides our core results. We estimate equation 2, looking at firm expectations about reopening, future restrictions, and reopening, conditional upon restrictions being lifted.

In regressions (1) and (5), we explore the expected time, in months, to fully reopen. Regressions (2) and (6) focus on expectations about how many months it would take for restrictions on fully reopening to be lifted. Regressions (3) and (7) estimate the impact of health-related variables on expected time to reopening, controlling for the expected number of months until the full lifting of restrictions.

Regressions (1) through (4) include our entire sample of firms. Regressions (5) through (8) include only those firms that were not currently open. Both samples have benefits and disadvantages. Using the entire sample for a table that is focused on barriers to reopening includes many zeros, as those firms had already either reopened or never been closed. But using the closed subsample is also problematic, because the sample of firms that were closed looks quite different in low and 


\section{high COVID counties.}

In the first column of Table 4, we look at the overall correlates of expected time to reopening. The specification includes firms that were already open and does not control for expectations about the lifting of current restrictions. The first row shows that businesses expected to be closed longer in counties where the number of COVID cases was higher. Using population-weighted statistics, the difference between the 90th and 10th percentile of log deaths per capita is 2.85 , implying an opening delay of about seven days between hard-hit and less affected counties.

The next two rows show the impact of worker proximity alone and then the interaction between worker proximity and COVID-19 prevalence in the county. Employee proximity is a significant predictor of delayed reopening. A one standard deviation increase in this variable is associated with a 0.24 month, or 7.5 day, delay in reopening. Perhaps more surprisingly, there is no interaction between COVID-19 prevalence and employee proximity. We hypothesized that employee proximity would be more problematic in high COVID environments, but there is little evidence that this interaction entered into firms' expectations about reopening. Panel B of Figure 3 presents the cumulative distributions of total time to reopening by industry. Patterns resemble the patterns regarding time to restrictions being lifted in Panel A, with low proximity industries opening sooner.

The fourth and fifth rows look at owner age and the interaction with COVID prevalence. We expected that reopening would be less attractive to older owners, who face greater mortality risk from COVID, and that this effect would be larger in high COVID environments. But older owners did not seem to expect to delay reopening, and there is no significant interaction between age and the prevalence of the pandemic.

The sixth and seventh rows look at customer age and interactions with COVID prevalence. We expected to find that firms with older customers would have been more likely to delay their opening, either because of reduced demand from skittish customers or out of concern for customers or legal liability. The coefficient goes in the opposite direction, where owners of firms that served older customers expected that they were more likely to open sooner. One possible explanation for this fact is that firms serving older customers specialize in products, including health services, that are 
more likely to face robust demand. We also do not find a positive interaction between customer age and the COVID rate in the county.

The eighth row shows that essential businesses expect that they will open 0.3 months (or nine days) sooner than non-essential businesses. The ninth row shows the ease of operating online. This variable does predict an earlier reopening, but the effect is relatively small.

The last two rows show the impact of our two other county level variables: density and the Republican vote share in 2016. Density is negatively associated with time to reopening, either because of health-related concerns or because of regulation. Republican vote share is even more strongly negatively related to time to reopening.

The second column attempts to separate expectations about regulation alone from other firm beliefs about their own decisions. The outcome variable in this column is the number of months until all restrictions on business for this firm are lifted. Somewhat remarkably, almost all of the coefficients are quite close to the coefficients estimated in the first column. For example, a 100 percent increase in the number of COVID cases per capita is associated with a 0.08 month increase in the amount of time until all restrictions are lifted. The similarity of slopes with respect to health concerns and other factors suggests that a constant offset between lifting restrictions and reopening fits the data quite well. For example, a one standard deviation increase in physical proximity is associated with a 0.3 month increase in the expected time until restrictions are lifted. The coefficient is larger but similar to Column 1 .

One modest difference between the two columns is that owner age is negatively associated with the expected time until restrictions are lifted. That effect withstands county fixed effects, which is shown in Appendix Table A4, so it does not reflect any spatial correlation between owner age and local regulatory regimes. Older owners may have been in industries that were less subject to local regulation, or they may have just been more optimistic. Overall, the second regression shows that our proxies for health concerns, when they matter for delays at all, seem to matter just as much for prognostications about the end of regulation. Consequently, health fears may figure little in deterring firms' reopening patterns. To test this hypothesis, the third column examines 
expectations about reopening, controlling for the expected time until restrictions are expected to be lifted. The coefficients in this column can be interpreted as telling us whether particular variables predict delays after reopening becomes legally feasible.

If firms intended to delay reopening because of health fears for either their workers or customers, then we would expect many of these coefficients to be significant both statistically and in magnitude. Yet we find that almost none of them are. Both the COVID-case and physical-proximity coefficients retain statistical significance, but they are much smaller in size. The COVID-case coefficient drops by about 75 percent between regressions (1) and (3). The coefficient on employee proximity drops by 85 percent.

Figure 4 shows the gap in post-lockdown reopening between high and low proximity industries. There is no visible difference in time to reopening after lockdowns end. As we have already seen, this fact does not imply that there is no delay after the restrictions end. There is a delay, but the average delay seems to be essentially independent of the duration of the restrictions and relates only loosely to the health-related factors that we have explored. Instead, regulations appear to explain most of the variation in reopening times.

Policymakers and public health officials should take note of a key distinction between the role of regulations in binding consumer and business behavior. The difference between the reopening plans of high and low proximity businesses was driven by differences in the expected duration of restrictions. The reopening plans of high and low proximity businesses are essentially identical once we adjust for these differences in when owners expected to be able to reopen. This contrasts with how consumers responded; travel, for example, fell before restrictions were implemented. Further, local case prevalence can explain travel reductions, even after controlling for regulations (Brinkman \& Mangum, 2020).

In this way, individual contagion concerns complemented government restrictions to limit travel to locations with the highest caseloads. We don't find evidence of this same kind of complementarity among business owners. That is, owners of high-proximity businesses did not analogously plan to delay reopening beyond the legal requirements. Policymakers should note that this suggests 
legal restrictions were the mechanism by which business owners expected health concerns to affect their reopening plans.

Regression (4) of Table 4 considers an indicator for a reopening time greater than one month from the lifting of restrictions. At the mean, $17.7 \%$ of the sample reports their planned date of fully reopening will occur more than four weeks after the date they believe restrictions will end. This estimate is likely a lower bound because we cannot calculate this lag for firms that believe restrictions will end after August. Over 80 percent of firms anticipate reopening within a month of being able to do so, but a significant share anticipate drawn out delays before fully reopening. There are only two significant variables, essential business and Republican vote share, suggesting that much of the variation in long delays is unrelated to health concerns.

Regression (5)-(8) repeat these regressions looking only at those firms that were closed or partially open at the time of the survey. These firms are a selected sample, and the selection depends on COVID cases at the county level. A larger share of businesses were not fully open in counties with high levels of COVID. Panel A of Appendix Figure A2 shows the relationship between the share of businesses that were open and the level of COVID at the county level across counties with more than 110 businesses in our sample. Over 40 percent of firms were fully open in the counties with low COVID rates. Less than 20 percent of firms were open in the counties near New York City that had the highest COVID rates. This selection may explain why the relationship between the level of COVID cases and predicted time to reopening is weaker among firms that were then closed. In the high COVID counties, most firms were closed, and many of these firms had attributes that would facilitate reopening. In the low COVID counties, the firms well suited for being open were already open, and consequently only the most vulnerable firms are closed. This selection problem inhibits interpretation of all of the county-level variables in this later sample.

Only a few variables are significant in regression (5). Owners of firms with older customers expected they would open sooner. Those in essential industries expected they would open sooner. And those in counties with a higher Republican vote share also expected to open sooner.

The sixth regression again examines beliefs about when regulations would end. Those same co- 
efficients again predict expectations about deregulation. Owners of essential businesses expected regulations to end more quickly. Owners with older customers and those in more Republican counties also expected regulations would end sooner.

In the seventh regression, we look at the correlates of expected time to reopening, conditional on expectations about legal restrictions. The patterns in this regression are broadly similar to those before, except physical proximity and the measure of local pandemic severity become insignificant for explaining the lag among these businesses. These patterns continue to hold in column 8 , where $28 \%$ of the businesses that were not fully open anticipated having delays in reopening greater than one month. The primary difference between this and other columns is that the coefficient on local COVID caseload is much smaller than in any other outcome, underscoring that the set of businesses in this regression are selected based on differences in county characteristics.

This table and the related figures tell a clear story that health concerns matter greatly for regulation but much less so for firms' behavior post-regulation. Firms with older customers expected to reopen sooner rather than later. Greater COVID-19 prevalence predicts expected regulatory delay but not economically significant differences in firm choices, absent regulation. We interpret this as suggesting that firms opening behavior might suggest there are health concerns, but digging deeper suggests these patterns arise because of regulations.

Another piece of evidence that supports this view is shown in Figure 5. We gave respondents a hypothetical question about whether they would be willing to remain closed if they received either an unconditional grant or a grant conditional upon remaining closed. We randomly varied the size of the hypothetical grant. If owners wanted to remain at home because of health fears, then we would expect the unconditional grant to have a large impact that increased with the size of the grant, as larger grants would allow owners to consume or pay their bills without the need to access cash flows generated from their businesses. Reopening decisions were invariant to the size of the cash grant, which we interpret to suggest that owners minimally traded off liquidity concerns with worries about well-being. ${ }^{21}$

\footnotetext{
${ }^{21}$ These findings contrast with other work that shows commuting often slowed dramatically before lockdown regulations were implemented, suggesting that some firms stopped in-person work before being forced to do so. On
} 
This suggests there is substantial residual variation in reopening times that is not captured by average health risk, conditions on the ground (cases, density), industry characteristics (proximity, essential), or attitudes (GOP vote share). While regulation explains a substantial portion of the reopening variability, much remains. We explore two additional hypotheses in the next section: coordination with other businesses in the ecosystem and reductions in (or uncertainty about) demand.

\subsection{Reopening and Coordination Between Customers and Suppliers}

Figure 6 illustrates the complementary nature of businesses throughout the United States. The top panel asks those business owners who were currently open "Although you are currently open, if these other businesses closed, would it affect your ability to remain open? (Select the category that matters most.)" Thirty-six percent of owners of open businesses said their ability to remain open would be impacted if their customers closed. A business' survival naturally depends on demand for its services or products. Suppliers mattered less than customers among this group, but both were important. A smaller share also cited the importance of businesses that refer them customers. If we add together the businesses that refer and the business customers, we find that almost 50 percent of firms emphasized downstream linkages. That share is almost double the 25 percent of firms that highlighted upstream linkages.

This difference between upstream and downstream connections is also shown in the bottom panel of Figure 6. This panel shows the responses to a question that was asked only of firms that were temporarily closed or partially open: "are you waiting on other businesses to open before fully opening yourself?" Somewhat surprisingly, more than half of our small business owners said no. Most of currently closed businesses did not require any coordination with other businesses. Sixty-five percent of respondents to this question were in consumer-facing businesses, helping to explain these results. For the business-to-business respondents presented with this question, it is likely that their business customers were already open at the time of the survey.

the reopening question, our analysis would point to more firms reopening quickly, but our analysis may be putting more weight on small firms that had lower capacity for telecommuting or were less exposed to potential health-related lawsuits. 
Nonetheless, almost half of business owners did note that they were waiting on other businesses. The largest category in this group was firms waiting on business customers. Together, more than 20 percent of respondents said that they were waiting for either customers and businesses that refer customers to them. This represents more than 40 percent of the dependency in this sample.

Another 20 percent said that they were waiting on businesses that were similar to theirs to open. While we might usually think that the reopening of competing businesses would depress demand for a particular enterprise, the respondents seemed to take the opening of competitors as a signal that demand had returned. There might also have been some advantage to waiting and learning from the reopenings of peers (de Vaan et al., 2020).

Only 5 percent of respondents cited the need to wait until suppliers had reopened. This share does not mean that suppliers are unimportant. The top panel confirmed that, if supply relationships ended, then this could stifle a business. Instead, this means that currently closed firms were not

worried as much about supply, presumably because upstream firms were more likely to be open or because global supply chains allowed them to source from somewhere else. If upstream suppliers produced goods in lower density factories, then it was likely easier for them to stay open.

These results confirm the importance of linkages for reopening but also suggest that slightly more than half of closed firms in May 2020 could reopen without any other firm reopening as well. The results suggest that downstream linkages seem likely to be most important. For that reason, we now turn to the firm's forecasts about future demand and the impact of future demand on projected reopening behavior.

\subsection{Forecasting Post-Crisis Demand}

We start with the firms' forecasts about future demand. The survey asked owners to predict what share of their pre-COVID demand would return. The future date was one of six randomized dates ranging from early May to September 2020. The exact wording was: "If you are fully open in [date], what share of your customers do you expect at that time, compared to before the crisis? 
Please provide your best guess." Response options were top-coded at "greater than 90 percent." 22

On average, across all industries, demand was expected to return to $65 \%$ of its pre-COVID level by September. Appendix Table A7 reports both the share of firms that expected their demand to fully return (90 percent or more of their pre-crisis levels) and reports the mean level of demand predicted, again relative to pre-crisis levels. ${ }^{23}$

Face-to-face sectors, including educational services, retail trade and restaurants and accommodation, all expected large decreases in demand through September. For example, accommodation and food service providers expected their demand to be 58 percent of its pre-crisis level in September. Similarly, arts, entertainment, and recreation only expected demand to be at 55 percent of pre-crisis levels by September.

In contrast, finance and insurance appears to be the sector with the smallest reductions in demand - with financial firms expecting demand to return to 70 percent of pre-crisis levels by September. More broadly, industries that deliver information-intensive products tended to be more optimistic about future demand.

Before we examine whether these drops in projected demand can explain slow rates of planned reopening, we turn to a more systematic exploration of the correlates of predicted drops in demand.

Table 5 shows predictors of demand expectations for all businesses (column 1) and businesses that were not fully open (column 2). The regressions pool results for projected demand across future months and include a control for the reference month that was contained in the survey question. To separate the impact of regulations from other factors, we control for the months until reopening restrictions were lifted. In both columns, the length of delay until the lifting of restrictions is associated with lower levels of expected demand. One more month of restrictions is associated with 17.4 percent lower projected demand in the entire sample and a 13 percent reduction in projected demand in the sample that was currently not fully open.

One interpretation of the correlation between the expected length of restrictions and the reduc-

\footnotetext{
${ }^{22}$ Our estimates may miss some reallocation of demand because of top-coding of survey responses (Barrero, Bloom, \& Davis, 2020). Table A7 allows an assessment by examining the share of responses indicating demand would exceed $90 \%$ of its pre-pandemic level.

${ }^{23}$ Appendix Table A8 shows a more granular industry breakdown.
} 
tion in projected demand could be that firms anticipated that consumers would switch to alternative suppliers and products if the delay lasted longer. In this case, the lost demand might be recouped across different sectors of the economy, even though a specific firm had lost customers. An alternative interpretation is that restrictions were correlated with reduced demand because both reflect omitted factors, such as aspects of the health crisis not captured by our COVID case measure.

With the exception of employee proximity, most of our health related variables are not correlated with projected demand. The level of COVID cases itself is unrelated to the expected drop in demand. Owner age is uncorrelated with projected future demand, while customer age is positively correlated. Presumably, this reflects the tendency of older customers to have more stable consumption patterns and to purchase services, like healthcare, that they are likely to need going forward.

A notable exception is businesses where employee proximity is higher. A standard deviation increase in proximity reduces demand forecasts by roughly 8 percent across specifications. There is also a negative interaction effect with COVID cases, and magnitudes are larger for businesses that were not fully open. Comparing these magnitudes for demand reductions in high proximity businesses to these businesses' reopening plans suggests that, despite the potential for demand to decline, owners intended to reopen high proximity businesses to serve a smaller customer base. These workplaces appear able to operate at a smaller scale than their pre-pandemic levels, possibly because the opportunity cost of operating (a service provider's outside option) deteriorated.

Two other industry-specific variables also predict demand. Projected demand is 11 or 12 percent higher for essential businesses than for non-essential ones. If demand were not top-coded at "greater than 90 percent", we might have detected an even larger boost in projected demand for essential businesses.

There is also a greater drop in projected demand for businesses than can be performed online. One interpretation is that the business owners in our sample expected that they would lose their customers to online competitors. An alternative view is that ease of online delivery captures relatively non-essential services. 
Two place-based variables predict expected future demand. Future demand is generally higher in denser areas, possibly because these markets will facilitate finding a new group of customers. Future demand relates strongly to the share of Republican voters in 2016.

\subsection{The Impact of Demand on Reopening}

We now turn to the impact that projected demand has on future reopening intentions. To identify the causal effect of demand projections on reopening plans (generally and conditional on restrictions lifting) and long-term business viability, we use experimental variation in information provision about future demand.

We turn to the estimation of equations 6 and 7, our IV approach, using experimental variation in information provision about future demand. Panel B of Table 6 displays the first-stage regression. The instrument, which is the interaction between receiving information in the survey and the difference in the logarithm of the signal and the constructed prior belief, has a strong positive impact on predicted demand. A 10 percent larger gap between the signal and prior, leads just under a 2 percent increase in the owner's projected demand. This shows the posterior beliefs move in the direction of the signal. Throughout this table, we present results with a standard set of controls germane to the instrumental variable specification in particular. We also add columns with an additional set of controls from the more expansive OLS specification in Table 4. Results are stable across these two alternative specifications.

Columns 3-10 show reduced form estimates, where the various outcomes (lags to reopening, lags to reopening with restriction date fixed effects, indicators for long lags, and indicators for longrun prospects) are regressed directly upon the instrument. These results are again stable across specifications. The reduced form coefficients show the importance of the instrument, presumably through the demand channel, on these outcomes.

Panel A presents the two-stage least squares estimates of the causal effect of changes in projected demand. In column 1, we estimate that a 10 percent increase in projected demand decreases the time to reopen by 0.088 months or roughly 2.7 days. This point estimate is stable when we 
include additional controls for a range of industry (proximity, ease of conducting business online, etc.) and geography (COVID cases, population density, GOP vote share, etc.). However, when we include fixed effects for the projected date that restrictions will be lifted, the coefficient falls to 0.53 , meaning that a 10 percent increase in projected demand will reduce planned time to open by about 1.6 days.

The estimates in columns 1-4 reflect changes in the average planned time to reopen caused by shifts in demand projections. However, these means necessarily obscure differences across various margins. Columns 5-6 examine lags of greater than one month. Here a 10 percent increase in demand reduces the probability of a long delay in reopening by about 1.6 percentage points or an 8 percent reduction relative to the mean. This highlights the long tail of reopening times and suggests that pessimistic owners are influenced by changes in their demand projections.

In column (7), we look at the probability of being operational by the end of 2020 as our dependent variable. A $10 \log$ point increase in the share of customers expected to return increases the expected probability of survival by 3.1 percentage points. In other words, a 20 percent increase in projected demand increases expected survival probability by six percentage points on average. Given that the mean failure rate is 21 percent, a drop from 21 to 15 percent is economically highly significant.

While we are interested in the impact of expectations of demand on reopening and survival decisions, providing information on demand can also indirectly affect beliefs about regulation. To account for this, we control for expectations of regulation, which we collected after the information intervention as well. Columns 3 and 4 show that expectations of demand seem to have a large and direct impact on reopening decisions, even after controlling for expectations about regulation.

\subsection{The Impact of Demand and Other Variables on Survival}

One of the most important questions about COVID-related lockdowns is whether a temporary period of firm closure leads to permanent elimination of thousands or millions of American businesses. Consequently, we now examine whether any of our variables predict survival until December 2020. 
We have already estimated the impact of projected demand on expected survival in the last two columns of Table 6 , but we have not linked this survival rate with any of our other variables. In both exercises, projected demand relates positively with long-run projected survival rates, often substantially so. Although tracing out actual survival ex-post is notoriously difficult, these projected survival rates have been shown to correlate with follow-up phone audits done by Bartik et al. (2021).

In Table 7, we build in the correlation between our core set of additional variables and the expected probability of survival until December. The first two rows look at the impact of projected demand and months until the end of restrictions are anticipated. Projected demand positively predicts survival expectations, but the estimated coefficient is smaller than in all of the two-stage least squares estimations.

The most striking and important fact is that the length of expected restrictions is strongly negatively associated with the anticipated probability of survival. As the expected restriction duration increases by one month, the expected probability of survival drops by 2.6 percentage points. This fact does not mean that restrictions are wrong, but it does suggest that the economic cost of longer lockdowns, especially as experienced by small entrepreneurs, is likely to be large. ${ }^{24}$

Three other variables are significant in every specification. Essential businesses were between 1.3 and 2.1 percentage points more likely to survive in expectation. This gap could reflect the advantage of being able to continue in business throughout the crisis, or it could reflect more stable demand for essential businesses. Firms with higher worker proximity were less likely to report optimism about survival. A one standard deviation increase in worker proximity is associated with at least a 1.7 percentage point decrease in the expected probability of survival. This may reflect the expected difficulty of operating in a high contact work environment. Finally, businesses with older customers have higher expectations of survival, possibly because this customer base was more stable. None of the other variables have reliable correlations with the projected probability

\footnotetext{
${ }^{24}$ Past work, since at least Hamilton (2000), suggests that many small businesses are likely to be fragile even in good times. Related work studies how business owners respond to shocks over their careers (Catherine, 2019; Dillon \& Stanton, 2017; Hincapié, 2020).
} 
of survival.

\subsection{Reliability of Demand and Reopening Projections}

Subsequent surveys help with validation exercises and confirm these early responses. In the subsequent Alignable series, cross-sections of small business owners were surveyed at the end of July, August, and September. These surveys asked about the share of customers returning in the previous month as well as the current operating status of their business. Using a unique account ID, we can match respondents in our main survey wave in May to the later surveys. While these surveys are designed as repeated cross-sections, not as panels, in practice we observe more than 3,000 of the initial respondents in these later surveys.

In Panel A of Table A5, we compare demand projections to the retrospective realized demand when resurveyed. Respondents with the most optimistic demand projections - those projecting more than $90 \%$ of their pre-COVID customers returning by the date in question - report relative demand of $93 \%$ in July, $87 \%$ in August, and $89 \%$ in September. In these waves, roughly $85 \%$ to $90 \%$ of these respondents report being fully open.

In contrast, respondents with the lowest demand projections - those anticipating less than $10 \%$ of their pre-COVID demand-report $44 \%, 50 \%$, and $37 \%$ of their customers returning in July, August, and September, respectively. While these figures are significantly higher than 10 percent, only roughly $30 \%-40 \%$ of these businesses were open when resurveyed. Since we only observe retrospective demand for businesses that were open in the preceding month, we don't see the counterfactual demand level for the majority of these businesses that are still closed later in the summer. In this way, these demand estimates come from the best performing third of these businesses. Even conditional on being open when surveyed, demand in this group is roughly half of the realized demand for respondents projecting over $90 \%$ of their customers returning.

In Panel B, we can compare the projected reopening date to the share of businesses that are open in each successive survey round. At each survey round throughout the summer, respondents who projected reopening by early May were two to three times as likely to have been open than their 
counterparts who projected remaining closed through September or later. While there is a strong gradient, small business owners do appear to be optimistic in their reopening estimates. When we resurveyed respondents in July, $80 \%$ of respondents who projected reopening in early May were open, but only $25 \%$ of those who projected reopening in September were open. However, this means that, even in the most optimistic group, $20 \%$ of business owners who projected being open in May remained closed in July; by September, as case loads began to rise, $28 \%$ of respondents who projected reopening in early May were closed. By September, only 35\% of businesses who projected reopening in August were open.

The reopening projections have strong explanatory power; the reopening regressions displayed in Panel B are linear probability models that regress an indicator for being open on a vector of indicators that correspond to each possible reopening date; the $R^{2}$ statistics range from 0.71 to 0.73. While these projections correlate well with realized reopenings, the projections appear to systematically underestimate delays in reopening.

In Appendix Table A6, we show that differential attrition as a function of the variables of interest is minimal. The industry distribution is broadly similar in the baseline and re-sampled wave. There is a statistically significant but economically small shift away from finance $\&$ insurance and professional services ( two percentage points in each category) and toward retail $(+2 \mathrm{pp})$ and other services $(+1.5 \mathrm{pp})$. The geographic mix remains broadly stable.

We do see a slight shift in the composition of the small business owners with respect to the business status in May when we compare the subset who replied to the later survey to the full survey, but these shifts are modest. The share of businesses that were fully open in May is roughly three percentage points higher in the subset that can be matched to a later round. However, these changes are qualitatively small: businesses fully open in May were $31.6 \%$ of the baseline sample and $34.8 \%$ of the validation sample; partially open businesses shift in the opposite direction from $34 \%$ of the main sample to $32 \%$ of the validation sample.

The composition with respect to the share of customers has similarly small shifts. Perhaps counterintuitively, business owners projecting fewer than $10 \%$ of their customers returning make 
up a slightly larger share of the validation sample than the full sample $(13.7 \%$ relative to $10 \%$ in the baseline), and there is a similar shift in the opposite direction for businesses projecting 50\%-75\% relative demand ( $22.3 \%$ relative to $25.1 \%$ in the baseline). These differences in weights are too modest to threaten the qualitative results of this exercise.

Additionally, we validate that the Alignable measures on business operations are correlated with administrative data on labor market performance. Panel B of Appendix Figure A2 plots the share of business that were currently open against the county level unemployment rate, indicating that the impact is not being felt equally nationwide. The striking correlations suggest the Alignable measures accurately portray economic activity at a granular level. Of course, as mentioned above, part of the county differences are driven by differences in regulations.

A final important driver of behavior and expectations is the partisan environment. People living in strongly Democratic or strongly Republican areas of the country made decisions based on different information about the underlying health risks posed by the virus (Bursztyn et al., 2020). We find that county-level Republican vote share in the 2016 election is very strongly correlated with all of the outcomes of interest. In Figure 7, we show that Republican vote share is associated with expectations of earlier reopening, removal of restrictions, and shorter gaps between reopening and when it is legal to do so. It is striking that this result is robust to controls for population, population density, COVID prevalence, state and granular industry (NAICS four digit). By considering the time to reopen conditional on it being legal to do so, the estimates of the delay in Panel C even adjust for differences in the regulatory environment. This raises important questions that are beyond the scope of this paper. How much this effect reflects attitudinal differences of business owners in these counties? How much is driven by differences in customer demand caused by different attitudes among local consumers? And how much is driven by misinformation about health risks, rather than different levels of risk tolerance? Understanding how partisan and ideological commitments interact with public health interventions is of vital importance for policymakers. 


\section{CONCLUSION}

The Alignable Survey of Small Business Owners provides a snapshot of small business behavior and expectations during the COVID-19 crisis. Firms gradually reopened, but those in some places reopened faster than those in others.

Although restrictions influenced the reopening decision, many businesses expected to delay reopening when restrictions were lifted. The average business in our sample expected to be closed two weeks longer than the restrictions lasted, although some businesses expected to be closed for months after they were legally allowed to reopen. When considering future regulations, policymakers will likely seek to understand both average behavior and sources of heterogeneity. Were owners responding to health concerns for themselves, changes in demand, or other factors? Which of these arise due to regulations themselves, and which of these would remain absent restrictions on behavior?

The delay in reopening did not appear to relate to health concerns, at least for the small businesses in the survey. The lag between the predicted end of restrictions on operations and the predicted time for reopening is not correlated with any of our measures of health risk. Neither older customers nor older owners predicted longer delays after the end of restrictions. And while COVID case prevalence predicted the presence of restrictions on operations into the future, COVID cases per capita did not predict delays in opening after restrictions on operations were lifted. These facts suggest that small firms' reopenings were driven more by their economic needs to survive than by their worries about public health.

Several other findings underscore the importance of demand projections and interdependencies among businesses for owners' reopening decisions. We use an information provision experiment to show that the reopening decision depends on expectations about demand. If downstream businesses don't open, then this will ripple through the network of firms. ${ }^{25}$ Adding to the headwinds businesses face, this crisis was - and continues to be - both a health crisis and an economic crisis. Businesses expected demand for their services to be greatly depressed for many months, likely justifying some

\footnotetext{
${ }^{25}$ See Akbarpour et al. (2020) for a discussion of other aspects of networks related to reopening policy.
} 
of the government aid to businesses, which aimed to allow them to weather lower projected demand while health risks to consumers lingered.

Entrepreneurs can play an important role in post disaster situations. For example, ChamleeWright \& Storr $(2010,2014)$ document the role of social and commercial entrepreneurs in resilience to and recovery from Hurricane Katrina. Storr, Haeffele-Balch, \& Grube (2015) tell a wider tale of how entrepreneurs provide a protective ecosystem that enabled the recovery of New York after Hurricane Sandy and New Orleans after Katrina. Our findings examine the current ongoing COVID crisis and illuminate the barriers small businesses faced when deciding about reopening. 


\section{References}

Abu-Rayash, A., \& Dincer, I. (2020). Analysis of mobility trends during the COVID-19 coronavirus pandemic: Exploring the impacts on global aviation and travel in selected cities. Energy Research and Social Science, 68.

Akbarpour, M., Cook, C., Marzuoli, A., Mongey, S., Nagaraj, A., Saccarola, M., Tebaldi, P. ... Yang, H. (2020). Socioeconomic Network Heterogeneity and Pandemic Policy Response. NBER Working Paper No. 27374. Cambridge, MA: National Bureau of Economic Research. Retrieved December 31, 2020, from www.nber.org/papers/w27374.

Alexander, D., \& Karger, E. (2020). Do stay-at-home orders cause people to stay at home? Effects of stay-at-home orders on consumer behavior. Mimeo. Retrieved March 8, 2021, from www.chicagofed.org/publications/working-papers/2020/2020-12.

Baker, S., Bloom, N., Davis, S., Kost, K., Sammon, M., \& Viratyosin, T. (2020). The Unprecedented Stock Market Impact of COVID-19. NBER Working Paper No. 26945. Cambridge, MA: National Bureau of Economic Research. Retrieved December 31, 2020, from www.nber.org/papers/w26945.

Barrero, J. M., Bloom, N., \& Davis, S. (2020). COVID-19 Is Also a Reallocation Shock. Technical report, National Bureau of Economic Research, Cambridge, MA. NBER Working Paper No. 27137. Cambridge, MA: National Bureau of Economic Research. Retrieved December 31, 2020, from www.nber.org/papers/w27137.

Bartik, A. W., Bertrand, M., Cullen, Z., Glaeser, E. L., Luca, M., \& Stanton, C. (2020). The impact of COVID-19 on small business outcomes and expectations. Proceedings of the National Academy of Sciences of the United States of America, 117, 17656-17666.

Bartik, A. W., Cullen, Z., Glaeser, E. L., Luca, M., \& Stanton, C. (2021). The Targeting and Impact of Paycheck Protection Program Loans to Small Businesses. NBER Working Paper No. 27623. Cambridge, MA: National Bureau of Economic Research. Retrieved July 1, 2021, from www.nber.org/papers/w27623.

Brinkman, J., \& Mangum, K. (2020). The Geography of Travel Behavior in the Early Phase of the Covid-19 Pandemic. Mimeo. Retrieved March 30, 2021, from doi.org/10.21799/frbp.wp.2020.38

Bursztyn, L., Rao, A., Roth, C., \& Yanagizawa-Drott, D. (2020). Misinformation During a Pandemic. NBER Working Paper No. 27417. Cambridge, MA: National Bureau of Economic Research. Retrieved July 1, 2021, from www.nber.org/papers/w27417.

Catherine, S. (2019). Keeping Options Open: What Motivates Entrepreneurs? Mimeo. Retrieved December 31, 2020, from ssrn.com/abstract $=3274879$.

Chamlee-Wright, E., \& Storr, V. H. (2010). The role of social entrepreneurship in post-Katrina community recovery. International Journal of Innovation and Regional Development, 2, 149164. 
Chamlee-Wright, E., \& Storr, V. H. (2014). Commercial relationships and spaces after disaster. Society, 51, 656-664.

Chetty, R., Friedman, J., Hendren, N., Stepner, M., \& Team, T. O. I. (2020). The Economic Impacts of COVID-19: Evidence from a New Public Database Built Using Private Sector Data. NBER Working Paper No. 27431. Cambridge, MA: National Bureau of Economic Research. Retrieved March 8, 2021, from www.nber.org/papers/w27431.

Cintia, P., Pappalardo, L., Rinzivillo, S., Fadda, D., Boschi, T., Giannotti, F., ... \& Pedreschi, D. (2020). The relationship between human mobility and viral transmissibility during the COVID19 epidemics in Italy. Retrieved March 8, 2021 from arxiv.org/abs/2006.03141.

Coibion, O., Gorodnichenko, Y., \& Weber, M. (2020). Labor Markets During the COVID-19 Crisis: A Preliminary View. NBER Working Paper No. 27017. Cambridge, MA: National Bureau of Economic Research. Retrieved March 8, 2021, from www.nber.org/papers/w27017.

Couture, V., Dingel, J. I., Green, A., Williams, K. R., \& Handbury, J. (2020). Measuring movement and social contact with smartphone data: A real-time application to COVID-19. NBER Working Paper No. 27560. Cambridge, MA: National Bureau of Economic Research. Retrieved March 8, 2021, from www.nber.org/papers/w27560.

de Vaan, M., Mumtaz, S., Nagaraj, A., \& Srivastava, S. B. (2020). Social Influence in the COVID19 Pandemic: Community Establishments' Closure Decisions Follow Those of Nearby Chain Establishments. Mimeo. Retrieved December 31, 2020, from www.hbs.edu/faculty/Pages/item.aspx?num=59464.

DellaVigna, S., \& Gentzkow, M. (2019). Uniform Pricing in US Retail Chains. NBER Working Paper No. 23996. Cambridge, MA: National Bureau of Economic Research. Retrieved March 8, 2021, from www.nber.org/papers/w23996.

Dillon, E., \& Stanton, C. (2017). Self-Employment Dynamics and the Returns to Entrepreneurship. NBER Working Paper No. 23168. Cambridge, MA: National Bureau of Economic Research. Retrieved March 8, 2021, from www.nber.org/papers/w23168.

Dunn, A., Hood, K., Driessen, (2020). Measuring the Effects of the COVID-19 Pandemic on Consumer Spending Using Card Transaction Data. Mimeo. Retrieved December 31, 2020, from www.bea.gov/system/files/papers/BEA-WP2020-5_0.pdf.

Fairlie, R. (2020). The Impact of COVID-19 on Small Business Owners: The First Three Months after Social-Distancing Restrictions. NBER Working Paper No. 27462. Cambridge, MA: National Bureau of Economic Research. Retrieved March 8, 2021, from www.nber.org/papers/w27462.

Forsythe, E., Kahn, L., Lange, F., \& Wiczer, D. (2020). Labor Demand in the time of COVID19: Evidence from vacancy postings and UI claims. NBER Working Paper No. 27061. Cambridge, MA: National Bureau of Economic Research. Retrieved December 31, 2020, from www.nber.org/papers/w27061.

Glaeser, E. L., Gorback, C., \& Redding, S. J. (2020). How Much Does Covid-19 Increase with Mobility? Evidence from New York and Four Other U.S. Cities. NBER Working Paper No. 
27519. Cambridge, MA: National Bureau of Economic Research. Retrieved November 12, 2020, from www.nber.org/papers/w27519.

Glaeser, E. L., Jin, G. Z., Leyden, B. T., \& Luca, M. (2021). Learning from Deregulation: The Asymmetric Impact of Lockdown and Reopening on Risky Behavior During COVID $\square$ 19. Journal of Regional Science.

Goolsbee, A., \& Syverson, C. (2020). Fear, Lockdown, and Diversion: Comparing Drivers of Pandemic Economic Decline 2020. NBER Working Paper No. 27432. Cambridge, MA: National Bureau of Economic Research. Retrieved December 12, 2020, from www.nber.org/papers/w27432.

Gupta, S., Nguyen, T. D., Rojas, F. L., Raman, S., Lee, B., Bento, A., Simon, K. I., \& Wing, C. (2020). Tracking Public and Private Responses to the COVID-19 Epidemic: Evidence from State and Local Government Actions. NBER Working Paper No. 27027. Cambridge, MA: National Bureau of Economic Research. Retrieved December 12, 2020, from www.nber.org/papers/w27027.

Hamilton, B. H. (2000). Does entrepreneurship pay? An empirical analysis of the returns to selfemployment. Journal of Political Economy, 108, 604-631. Hincapié, A. (2020). Entrepreneurship Over the Life Cycle: Where are the Young Entrepreneurs? International Economic Review, 61, 617-681.

Hoff, P. D. (2009). A first course in Bayesian statistical methods. New York: Springer.

Huang, X., Li, Z., Jiang, Y., Li, X., \& Porter, D. (2020). Twitter reveals human mobility dynamics during the COVID-19 pandemic. PLoS ONE, 15.

Jaravel, X., \& O’Connell, M. (2020). Real-time price indices: Inflation spike and falling product variety during the Great Lockdown. Journal of Public Economics, 191, 104270.

Kurmann, A., Lale, E., \& Ta, L. (2020). The Impact of COVID-19 on U.S. Employment and Hours: Real-Time Estimates With Homebase Data. Mimeo. Retrieved March 17, 2021 from www.lebow.drexel.edu/sites/default/files/1588687497-hbdraft0504.pdf.

Linka, K., Goriely, A. \& Kuhl, E. (2021). Global and local mobility as a barometer for COVID-19 dynamics. Biomechanics and Modeling in Mechanobiology, 20, 651-669.

Mongey, S., \& Weinberg, A. (2020). Characteristics of Workers in Low Work-From-Home and High Personal-Proximity Occupations. Mimeo. Retrieved April 12, 2020 from bfi.uchicago.edu/workingpaper/characteristics-of-workers-in-low-work-from-home-and-high-personal-proximity-occupations/.

Moscarini, G., \& Postel-Vinay, F. (2012). The contribution of large and small employers to job creation in times of high and low unemployment. American Economic Review, 102, 2509-2539.

Papanikolaou, D., \& Schmidt, L. D. (2020). Working Remotely and the Supply-side Impact of Covid-19. NBER Working Paper No. 27330. Cambridge, MA: National Bureau of Economic Research. Retrieved December 31, 2020, from www.nber.org/papers/w27330.

Sears, J., Villas-Boas, J. M., Villas-Boas, S., \& Villas-Boas, V. (2020). Are We \#StayingHome to Flatten the Curve? Mimeo. Retrieved December 31, 2020, from www.medrxiv.org/content/10.1101/2020.05.23. 
Sheridan, A., Andersen, A. L., Hansen, E. T., \& Johannesen, N. (2020). Social distancing laws cause only small losses of economic activity during the COVID-19 pandemic in Scandinavia. Proceedings of the National Academy of Sciences of the United States of America, 117, 2046820473.

Soucy, J. P. R., Sturrock, S. L., Berry, I., Westwood, D. J., Daneman, N., MacFadden, D. R., \& Brown, K. A. (2020). Estimating effects of physical distancing on the COVID-19 pandemic using an urban mobility index. Mimeo. Retrieved March 8, 2021 from www.medrxiv.org/content/10.1101/2020.04

Storr, V. H., Haeffele-Balch, S., \& Grube, L. E. (2016). Community revival in the wake of disaster: Lessons in local entrepreneurship. Springer.

Velde, F. R. (2020). What Happened to the US Economy During the 1918 Influenza Pandemic? A View Through High-Frequency Data. Mimeo. Retrieved December 31, 2020 from ssrn.com/abstract=3587634. 


\section{Tables and Figures}

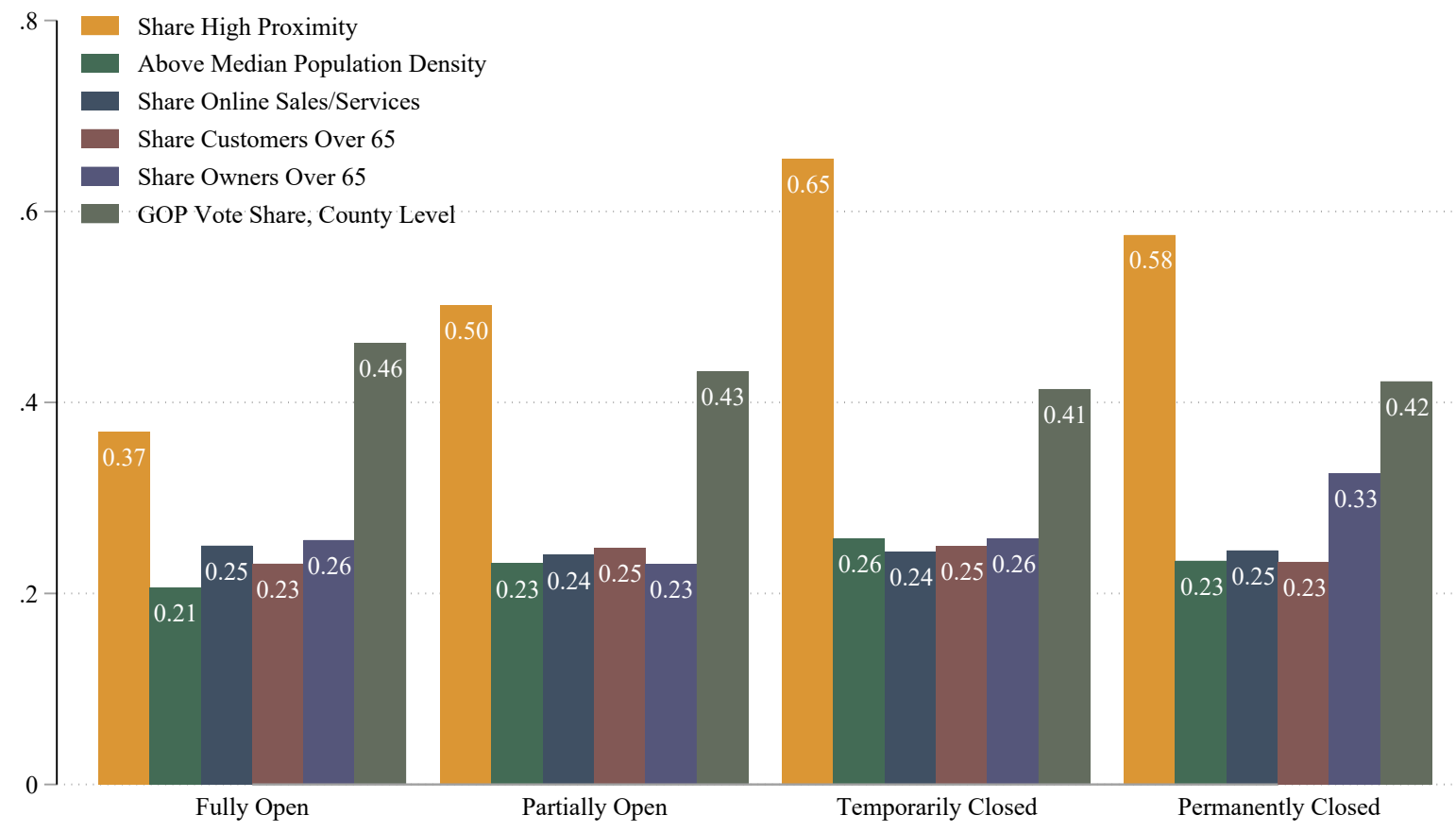

Figure 1. Characteristics of Businesses by Operational Status as of May 9, 2020.

This figure plots characteristics of different businesses based on their industry characteristics, location characteristics, or owner characteristics. Bars represent means and data are grouped by the operational status of the business as reported in the May 9, 2020 survey. Please refer to Section 2 of the corresponding paper for detailed definitions of each data source represented in this graph. 


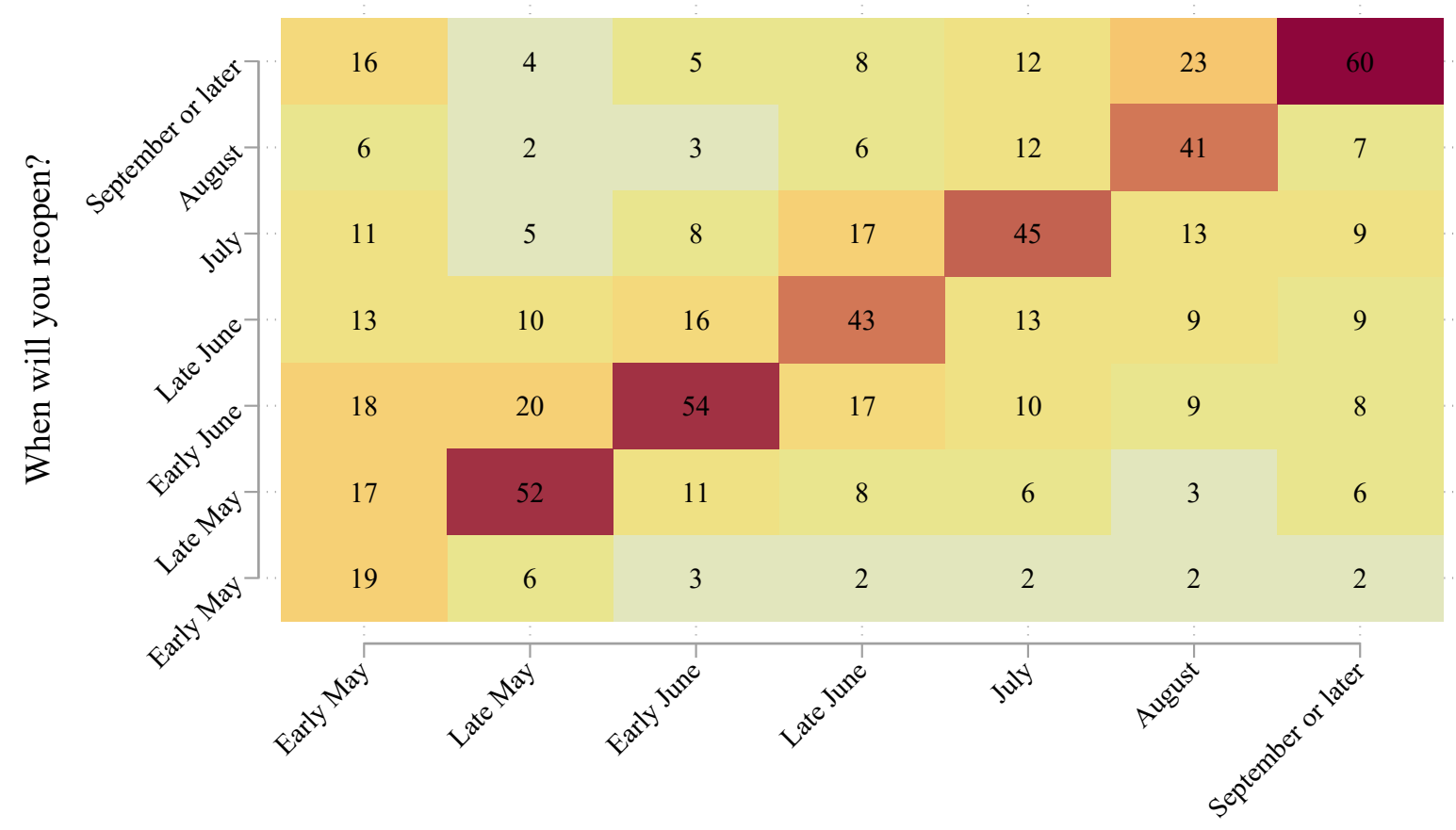

When Will Restrictions Be Lifted?

The percent of respondents in each cell is displayed, normalized within columns. Due to rounding, columns may not sum to 100.

Figure 2. Patterns in Regulation and Reopening at the Individual Business Level.

This figure displays when each business owner expects easing of legal restrictions around "fully reopening" (x-axis) and the expected date when they will "fully reopen" (y-axis). The x-axis is derived from the question "If there are legal restrictions on fully reopening your business, when do you expect them to be lifted?". Response possibilities ranged from "There are no legal restrictions." to "September or later". The y-axis is derived from the question "When will your business be fully open? Please provide your best guess." Responses possibilities ranged from "Early May" to "September or later". Businesses that were fully open were not asked the question and excluded from this figure. Numbers in each cell are the percent of responses within each column. 
Panel A: Share of Businesses Expecting to be Legally Able to Reopen

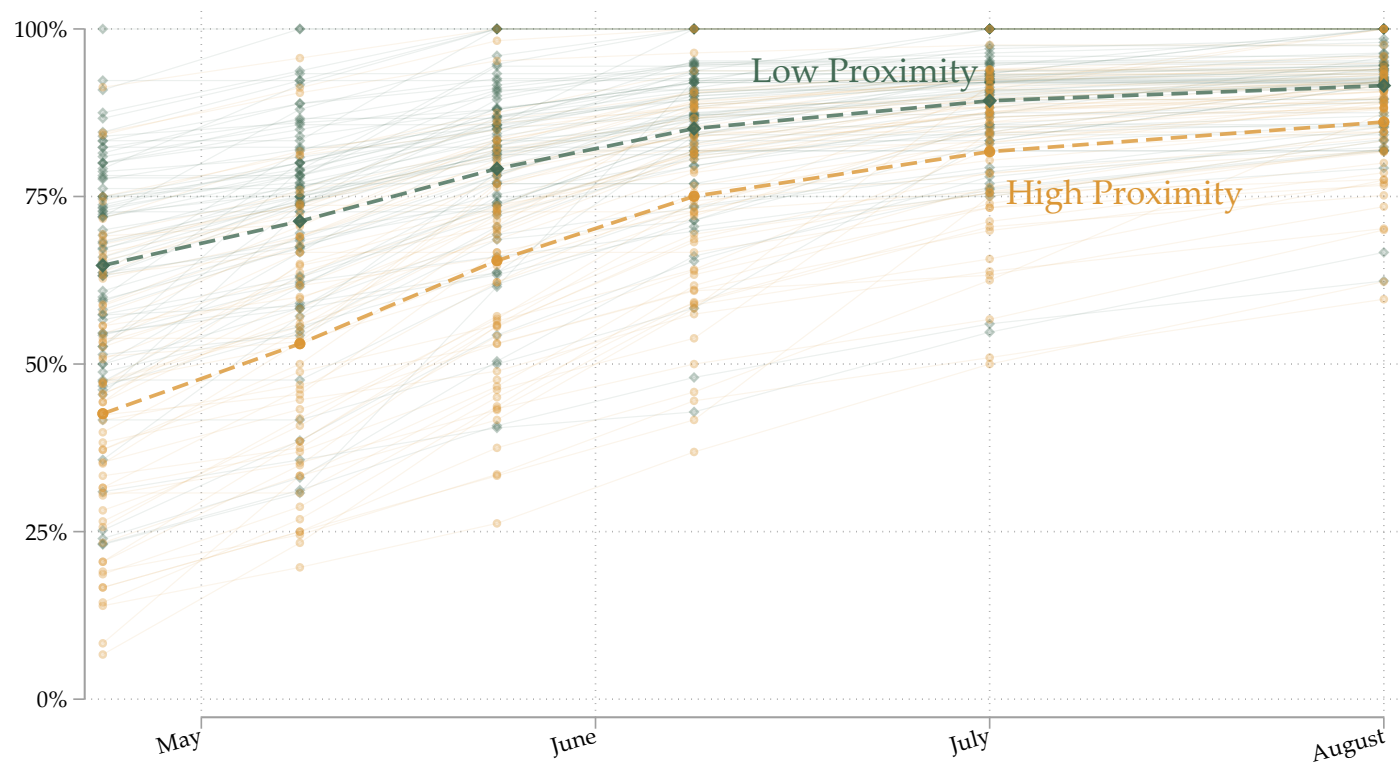

Panel B: Share of Businesses Expecting to be Fully Open

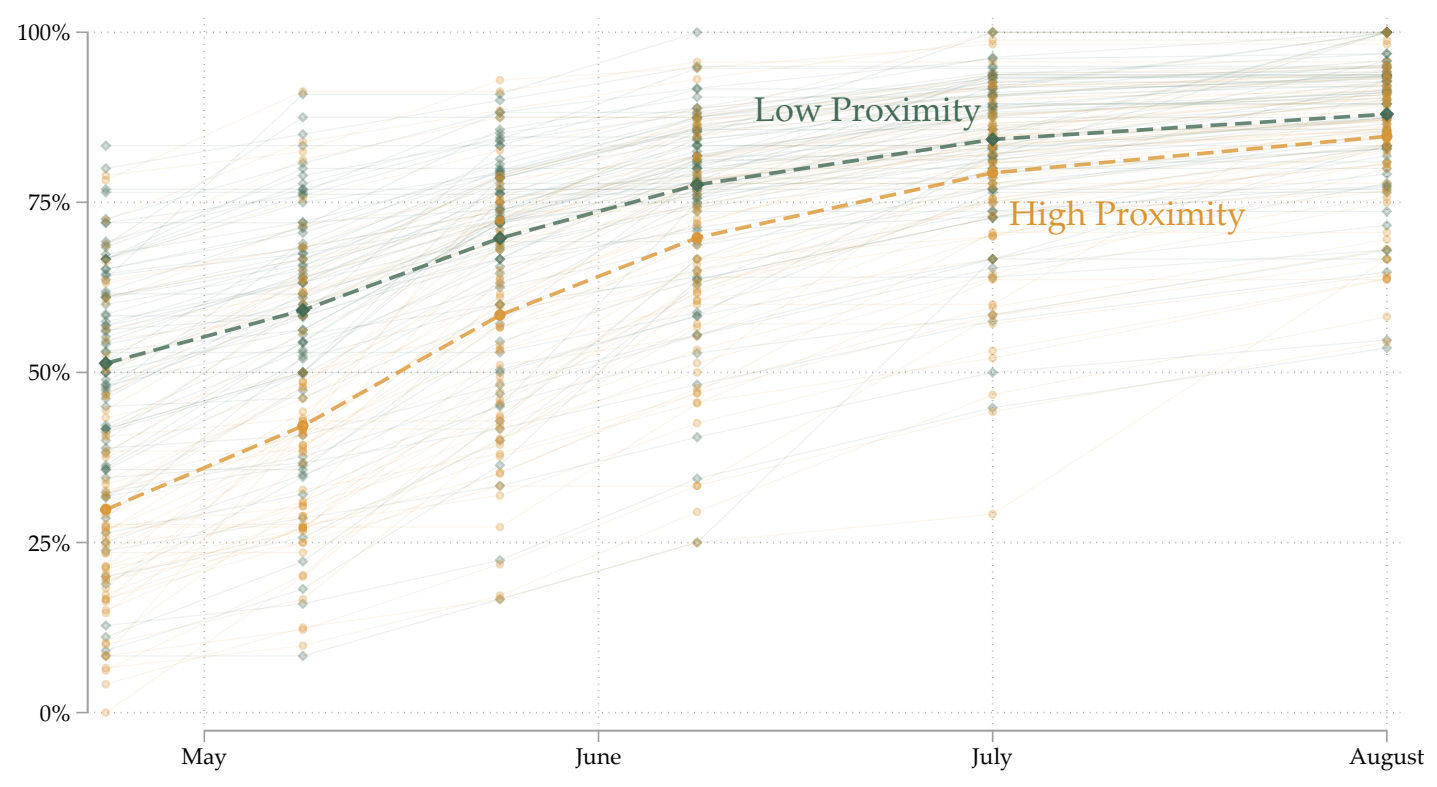

Figure 3. Average Share of Businesses Projected to Be Fully Open in Each Industry by Date.

Panel A plots the average share of businesses fully open or projected to be fully open at future dates. Each line represents a 4-digit NAICS code and is constructed using the cumulative distribution of individual responses to the question "When will your business be fully open? Please provide your best guess." Panel B plots the average share of businesses legally able or expected to be legally able to reopen open at future dates. Fully open businesses are included in both panels and are coded as open and legally able to open in the first period. High proximity businesses, in yellow, are those above the median according to the proximity score. Green indicates low proximity businesses. 


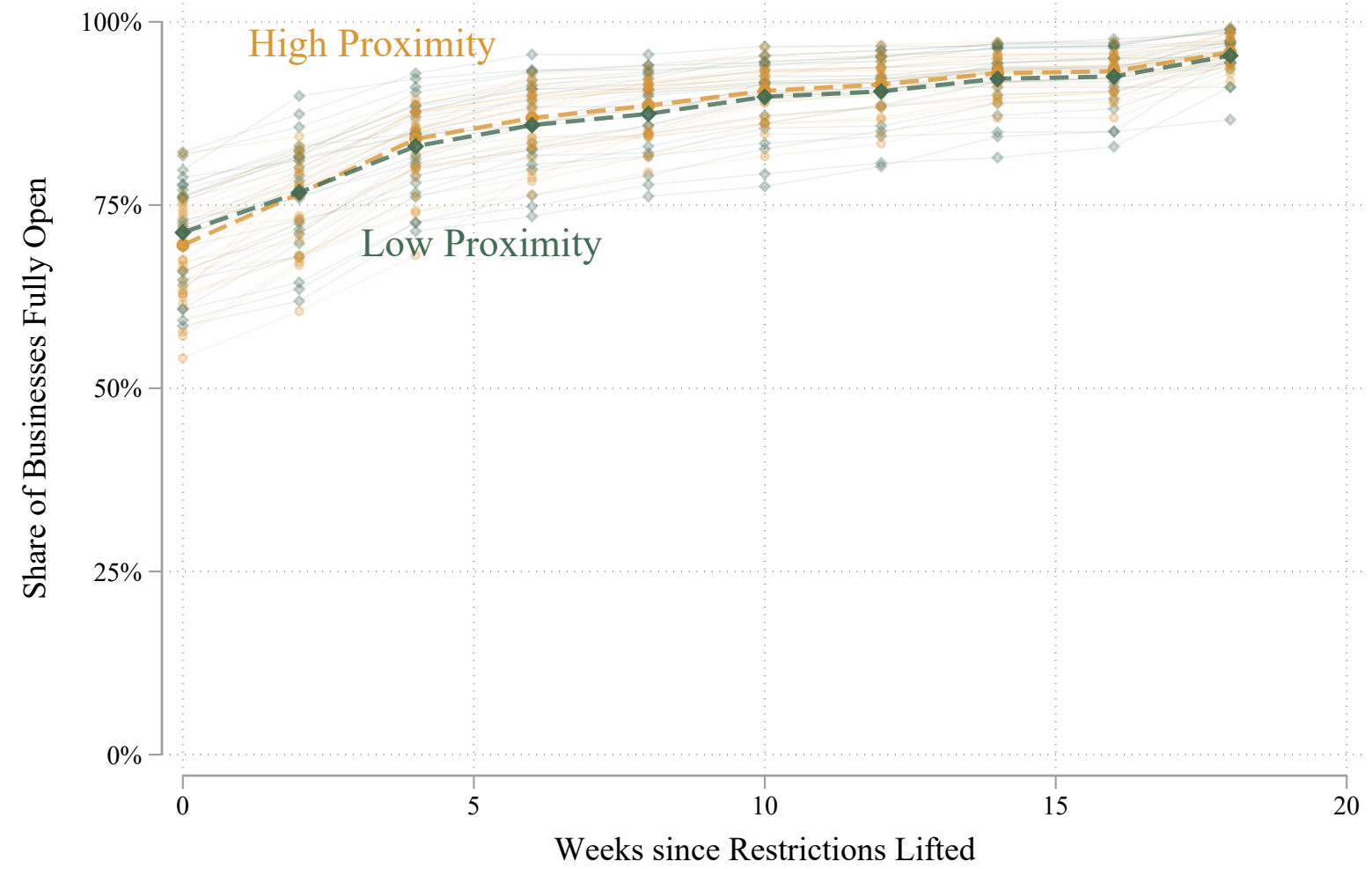

Figure 4. Average Share of Businesses Reopening in Each Industry, Represented as Elapsed Weeks after Restrictions are Lifted.

This figure plots the lag time in reopening between when respondents plan to reopen and when they are legally allowed to do so. This is calculated as the difference between respondents' projected reopening date and their perceived date by which legal restrictions on operations will be lifted. Businesses that are fully open are included at 0 . 


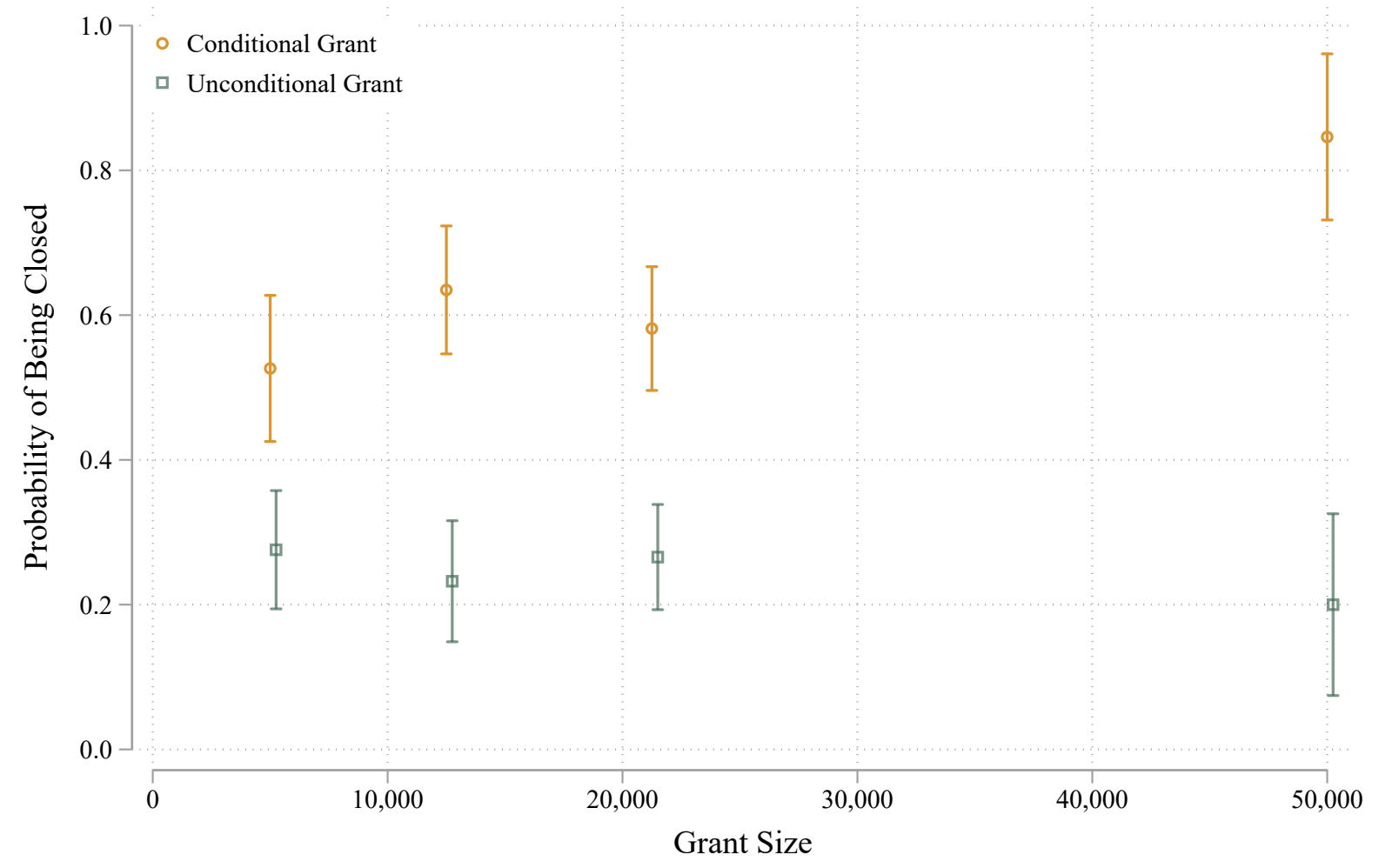

Figure 5. Estimates of How Cash On Hand and Conditional Cash On Hand Change the Decision to Remain Closed.

This figure plots how answers to a question about willingness to stay closed over the next 2 weeks changes as a function of different hypothetical amounts of cash on hand. This is captured by "grant size" on the x-axis, which comes from two parallel questions. Half of respondents (Unconditional Grant) were asked "Suppose we could extend you a cash grant of [Grant Size]. Would you choose to open over the next two weeks?" The other half of respondents (Conditional Grant) were asked "Suppose we could extend you a cash grant of [Grant Size] but only on the condition that you remained closed for the next two weeks. Would you choose to open over the next two weeks instead of taking the cash grant?" The sample for this figure comes from the first wave of a panel survey of Alignable users conducted through Harvard Business School between May 20, 2020 and May 28, $2020(\mathrm{~N}=780)$. 
Panel A: Businesses that Are Fully Open in May 9 Survey

If these other businesses closed, would it affect your ability to remain open?

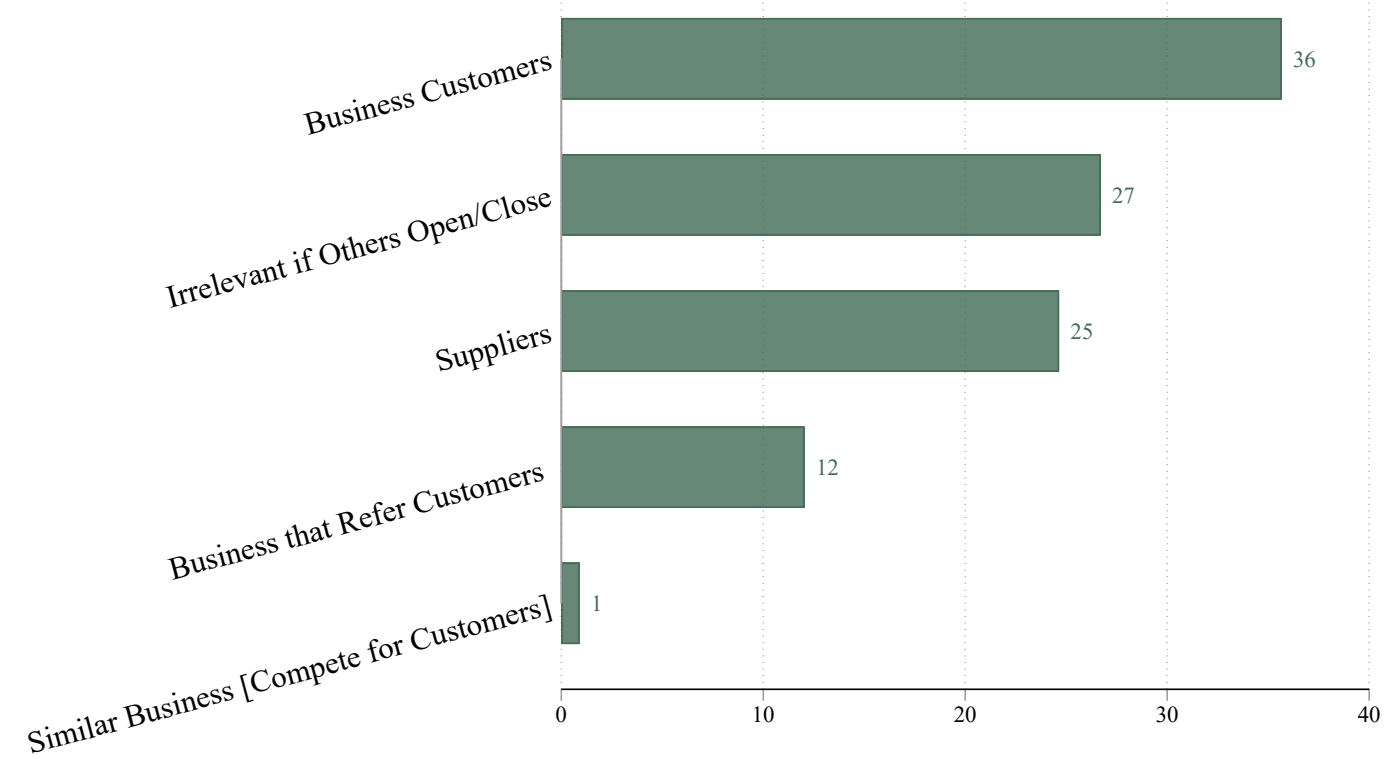

Panel B: Businesses that Are Partially Open or Temporarily Closed in May 9 Survey Are you waiting on other businesses to open before fully opening yourself?

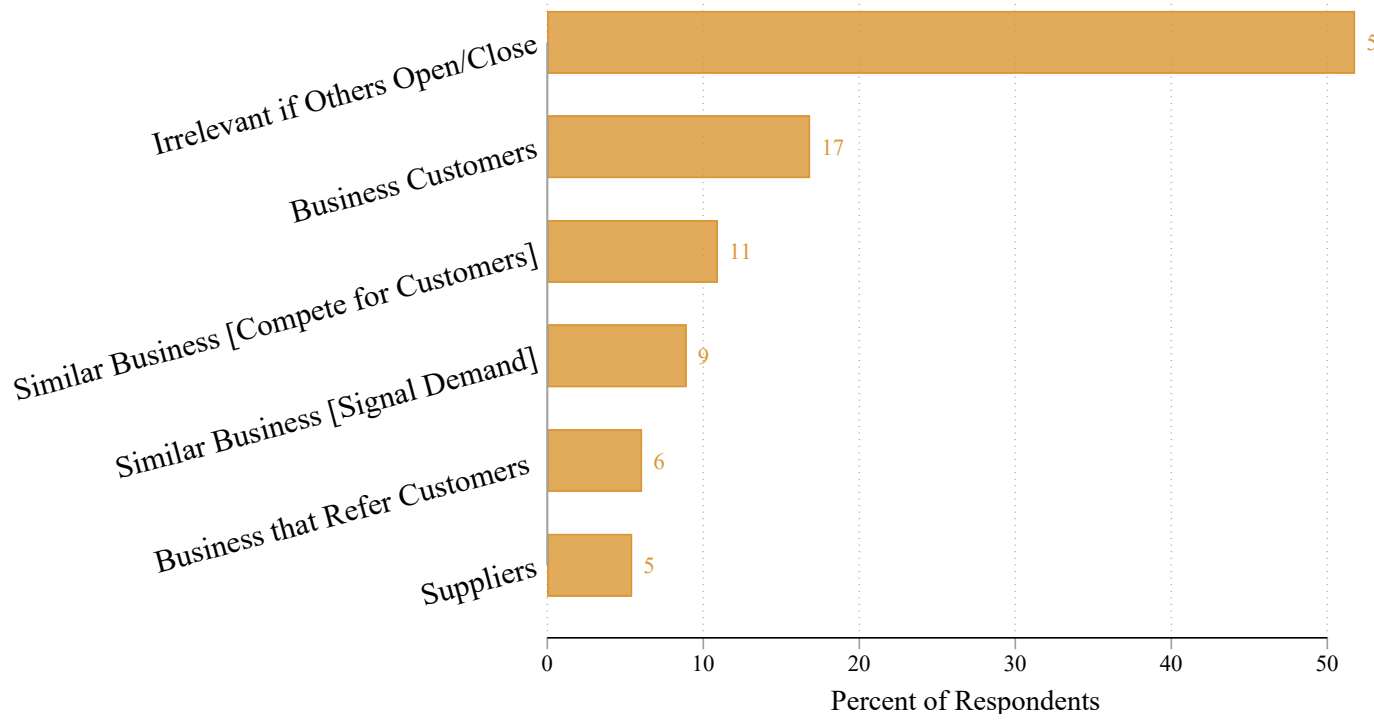

Figure 6. Reopening Decisions as a Function of Other Businesses' Actions.

This figure displays patterns of business dependency. Partially open or temporarily closed were asked "Are you waiting on other businesses to open before fully opening yourself? (Select the category that matters most.)." Fully open businesses were asked "Although you are currently open, if these other businesses closed, would it affect your ability to remain open? (Select the category that matters most.)". 


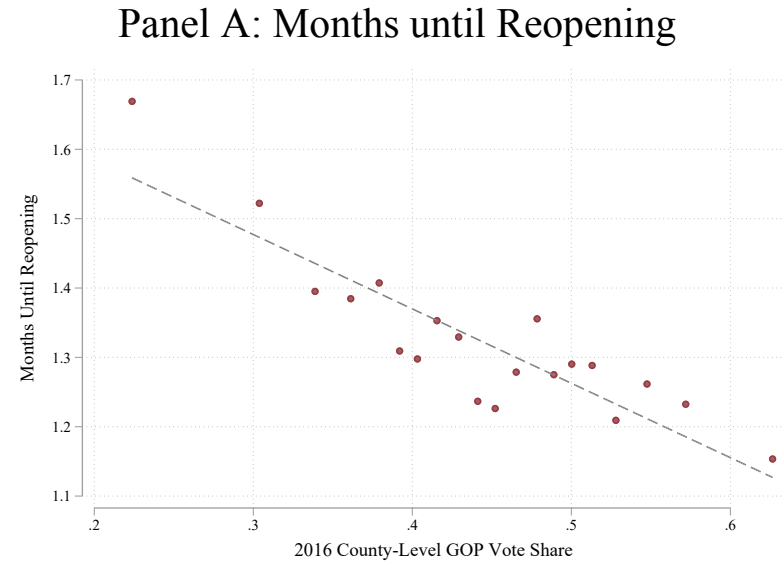

Panel C: Delay in Reopening Once Legal

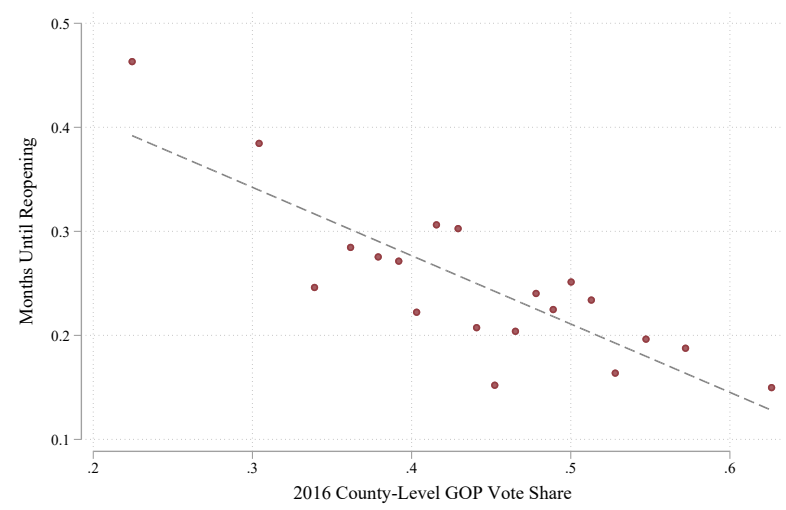

Panel B: Months until Restrictions Lifted

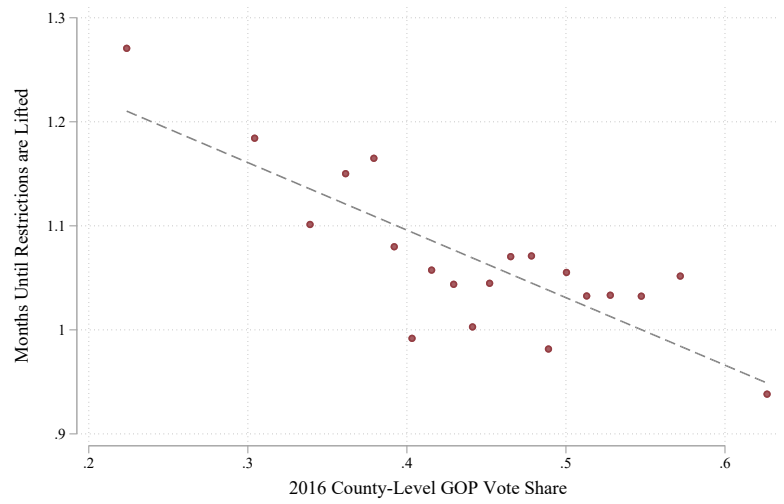

Panel D: Share Opening with No Lag

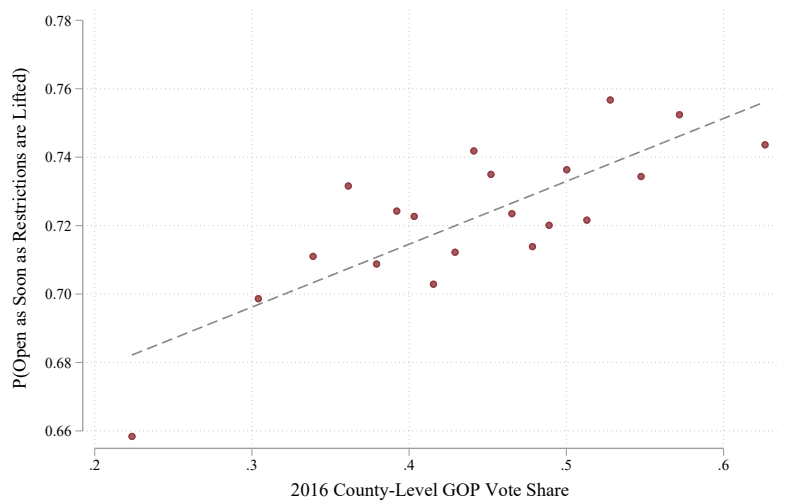

Figure 7. Effect of 2016 GOP Vote Share on Projected Time to Reopen and Time until Restrictions Lifted.

The $\mathrm{x}$-axis in every panel is the county-level GOP vote share in the 2016 Presidential election. Panel A plots the projected months until the business reopens. Panel B plots the projected months until restrictions are lifted. Panel C replicates Panel A, but nets out fixed effects for projected months until restrictions are lifted. Panel D plots the share of respondents who selected the same period for projected reopening date and the projected date by which restrictions will be lifted. All plots contain state and 4-digit NAICS fixed effects, and control for population, population density and COVID cases (all control variables have been transformed by the natural logarithm). 
Table 1. Summary Statistics on Data from Survey and Additional Sources

\begin{tabular}{|c|c|c|c|c|c|c|}
\hline & \multicolumn{6}{|c|}{ Panel A: Data from Alignable Survey } \\
\hline & Mean & Std. Dev. & 25th P'tile & 75th P'tile & $\min / \max$ & Obs. \\
\hline Mo. until Reopen & 1.33 & 1.49 & 0.00 & 1.75 & $0.00-4.50$ & 29,305 \\
\hline Mo. until No Restrictions & 1.06 & 1.42 & 0.00 & 1.75 & $0.00-4.50$ & 28,763 \\
\hline Lag $\geq 4$ wks & 0.18 & 0.38 & 0.00 & 0.00 & $0.00-1.00$ & 28,538 \\
\hline Share Returning Customers & 54.01 & 29.42 & 37.50 & 82.50 & $5.00-95.00$ & 27,571 \\
\hline N. Employees (Jan, 2020) & 10.63 & 32.77 & 1.00 & 7.00 & $0.00-500.00$ & 20,505 \\
\hline Fully Open in May 9 Survey & 0.32 & 0.46 & 0.00 & 1.00 & $0.00-1.00$ & 33,356 \\
\hline Partially Open in May 9 Survey & 0.34 & 0.47 & 0.00 & 1.00 & $0.00-1.00$ & 33,356 \\
\hline Temporarily Closed in May 9 Survey & 0.32 & 0.47 & 0.00 & 1.00 & $0.00-1.00$ & 33,356 \\
\hline Permanently Closed in May 9 Survey & 0.02 & 0.15 & 0.00 & 0.00 & $0.00-1.00$ & 33,356 \\
\hline \multirow[t]{3}{*}{$\mathrm{P}($ Open in December $)$} & 0.78 & 0.20 & 0.61 & 0.94 & $0.13-0.94$ & 17,105 \\
\hline & \multicolumn{6}{|c|}{ Panel B: Data from Additional Sources } \\
\hline & Mean & Std. Dev. & 25th P'tile & 75th P'tile & $\min / \max$ & Obs. \\
\hline COVID Cases per $1 \mathrm{k}$ & 4.45 & 5.83 & 1.12 & 5.33 & $0.00-71.52$ & 32,426 \\
\hline Emp. Physical Proximity & 3.48 & 0.44 & 3.08 & 3.83 & $2.16-4.42$ & 19,162 \\
\hline Likelihood Customers Over 65 & 24.26 & 13.91 & 12.50 & 30.50 & $5.00-87.50$ & 22,856 \\
\hline Ease Operating Online & 24.48 & 14.99 & 10.00 & 37.00 & $5.00-65.00$ & 22,856 \\
\hline Essential Business (DE \& MN) & 0.53 & 0.50 & 0.00 & 1.00 & $0.00-1.00$ & 22,883 \\
\hline GOP Vote Share (County) & 0.44 & 0.16 & 0.33 & 0.55 & $0.04-0.90$ & 33,117 \\
\hline Share Output $\rightarrow$ Intermed. Input & 0.53 & 0.35 & 0.15 & 0.91 & $0.00-1.00$ & 18,213 \\
\hline Share Business Buyers in Essential Ind. & 0.55 & 0.30 & 0.33 & 0.73 & $0.00-1.00$ & 20,995 \\
\hline
\end{tabular}

Notes: Panel A presents summary statistics for survey responses. "Mo. until Reopen" and "Mo. until No

Restrictions" are the perceived months until the business will be fully open, and the perceived months until it is legal to fully open, respectively. These figures are relative to the survey date of May 9. Responses were topcoded at "September or Later", which we top code at 4.5 months from early May. "N. Employees (Jan, 2020)" is the self reported number of employees, including the respondent, in January 2020. The four indicator variables regarding current status as of the May 9 survey correspond to the four options of the first question asked to respondents. For this reason, these variables have the most observations. " $\mathrm{P}(\mathrm{Open}$ in December)" is the numeric probability that a businesses remains open in December, 2020. We code these probabilities from a multiple choice question shown to respondents. This is the last question in the survey, which accounts for the fact that this variable has the fewest responses. The text provides more detail about survey completion rates.

Panel B presents summary statistics for data taken from outside sources. "COVID Cases per cap." is the county-level number of COVID cases per capita. "Emp. Physical Proximity" is the the weighted average of a 5 point occupational proximity scale over the industry-level (4-digit NAICS) distribution of occupations. "Likelihood Customers Over 65" and "Ease Operating Online" are derived from MTurk answers at the 4-digit NAICS level. (See appendix for the MTurk data collection tool.) "Essential Business (DE \& MN)" is an indicator variable that indicates if a businesses was considered essential in the guidelines made available in Deleware and Minnesota. "GOP Vote Share (County)" is the share of votes for the Republican Presidential candidate in 2016. "Share Output $\rightarrow$ Intermed. Input" is derived from the BEA 2012 Use table and is the share of total 3-digit industry output that used as intermediate inputs. "Share Business Buyers in Essential Ind." is derived from the same BEA series, as well as the "Essential Business (DE \& MN)" measure. This is the share of output that is used as an input by industries we identify as essential divided by the total output that is used as intermediate inputs. 
Table 2. Difference-in-Difference: Reopening and projected customers returning.

\begin{tabular}{|c|c|c|c|c|c|c|}
\hline \multirow{2}{*}{$\begin{array}{l}\text { Percentage: } \\
\text { After May } 14\end{array}$} & \multicolumn{3}{|c|}{ Business Fully Open } & \multicolumn{3}{|c|}{ Customers Returning } \\
\hline & $\begin{array}{c}14.79^{* * *} \\
(0.814)\end{array}$ & $\begin{array}{c}14.83^{* * *} \\
(0.821)\end{array}$ & $\begin{array}{c}14.80^{* * *} \\
(0.808)\end{array}$ & $\begin{array}{c}6.756^{* * *} \\
(1.019)\end{array}$ & $\begin{array}{c}6.513^{* * *} \\
(1.038)\end{array}$ & $\begin{array}{c}6.768^{* * *} \\
(1.030)\end{array}$ \\
\hline$\times$ Pooled WI \& FL & $\begin{array}{c}5.552^{* * *} \\
(0.441)\end{array}$ & & & $\begin{array}{l}0.482^{* *} \\
(0.235)\end{array}$ & & \\
\hline$\times$ Just WI & & $\begin{array}{l}3.114^{* *} \\
(1.138)\end{array}$ & & & $\begin{array}{c}0.104 \\
(0.204)\end{array}$ & \\
\hline$\times$ Just FL & & & $\begin{array}{c}6.092^{* * *} \\
(0.137)\end{array}$ & & & $\begin{array}{l}0.557^{* *} \\
(0.240)\end{array}$ \\
\hline$R^{2}$ & 0.11 & 0.11 & 0.11 & 0.17 & 0.17 & 0.17 \\
\hline $\mathrm{N}$ & 24,248 & 22,209 & 23,842 & 24,248 & 22,209 & 23,842 \\
\hline
\end{tabular}

Note: In this table, we present difference in difference estimates of the effect of unexpected changes in the regulatory environment on the share of businesses that are currently open and on demand projections in the future. In column 1, we present difference in difference results with Wisconsin and Florida pooled together to form the treatment group. In columns 2 and 3 we estimate the results separately for Wisconsin and Florida, respectively. To avoid biasing these DiD estimates towards zero, Florida is excluded from the regression in 2 and Wisconsin is excluded from column 3 to avoid contaminating the control group. We present analogous estimates of the effect of the regulatory change on demand projections in columns 4 to 6 .

We supplement the main survey data (collected from May 9 to May 13) with data from a later survey (collected from May 14 to June 1); since the policy changes were announced on May 13 (WI) and 14 (FL), the main survey is the pre-period, and the follow-up survey is the post-period. We reweight the post-period to match the pre-period at the 4-digit NAICS by county level, cells that do not include at least one observation in both surveys are dropped. Note that while the second survey remained open until the following survey was distributed, over $95 \%$ of responses were collected by May 18. Since the first survey was distributed starting on May 9th, the majority of responses are collected over a nine day period in early May. See equation 3 and the discussion for more information. 
Table 3. Factors contributing to differences in operational status

\begin{tabular}{lcccc}
\hline & $(1)$ & $(2)$ & $(3)$ & $(4)$ \\
& Fully Open & Partially Open & Temp. Closed & Perm. Closed \\
\hline Emp. Physical Proximity & $-0.1050^{* * *}$ & $-0.0156^{* *}$ & $0.1170^{* * *}$ & $0.0036^{* *}$ \\
& $(0.0046)$ & $(0.0059)$ & $(0.0048)$ & $(0.0016)$ \\
Owner Age & $0.0009^{*}$ & $-0.0009^{*}$ & -0.0004 & $0.0004^{* *}$ \\
& $(0.0005)$ & $(0.0005)$ & $(0.0005)$ & $(0.0002)$ \\
Customers Over 65 & $-0.0079^{* *}$ & $0.0128^{* * *}$ & -0.0029 & -0.0020 \\
& $(0.0032)$ & $(0.0047)$ & $(0.0031)$ & $(0.0012)$ \\
Essential Business & $0.1188^{* * *}$ & $0.0433^{* * *}$ & $-0.1581^{* * *}$ & $-0.0040^{* *}$ \\
& $(0.0067)$ & $(0.0093)$ & $(0.0093)$ & $(0.0019)$ \\
Ease Operating Online & $-0.0157^{* * *}$ & $-0.0087^{*}$ & $0.0237^{* * *}$ & 0.0007 \\
& $(0.0042)$ & $(0.0050)$ & $(0.0036)$ & $(0.0011)$ \\
$\ln$ (COVID cases per cap.) & $-0.0318^{* * *}$ & 0.0063 & $0.0256^{* *}$ & -0.0001 \\
& $(0.0090)$ & $(0.0040)$ & $(0.0100)$ & $(0.0008)$ \\
$\ln$ (Pop. Density) & $0.0154^{* *}$ & -0.0052 & $-0.0100^{*}$ & -0.0002 \\
& $(0.0058)$ & $(0.0033)$ & $(0.0056)$ & $(0.0007)$ \\
GOP Vote Share (County) & $0.3244^{* * *}$ & $-0.0842^{* * *}$ & $-0.2311^{* * *}$ & $-0.0091^{*}$ \\
& $(0.0508)$ & $(0.0311)$ & $(0.0544)$ & $(0.0052)$ \\
\hline DV Mean & 0.316 & 0.340 & 0.321 & 0.022 \\
DV SD & 0.465 & 0.474 & 0.467 & 0.147 \\
Residual SD & 0.451 & 0.472 & 0.450 & 0.147 \\
$R^{2}$ & 0.0593 & 0.0060 & 0.0702 & 0.0024 \\
N & 33,236 & 33,236 & 33,236 & 33,236 \\
\hline
\end{tabular}

Note: These columns correspond to answers to the question Are you currently open?. These options are collectively exhaustive and mutually exclusive. Employee Physical Proximity, Customers Over 65, and Ease Operating Online are converted to z-scores. Standard errors are in parentheses and clustered at the state level. ${ }^{*} p<0.1,{ }^{* *} p<0.05$, ${ }^{* * *} p<0.01$ 
Table 4. OLS: Contribution of various factors to the small business reopen decision

\begin{tabular}{|c|c|c|c|c|c|c|c|c|}
\hline & \multicolumn{4}{|c|}{ All Businesses } & \multicolumn{4}{|c|}{ Excluding Fully Open Businesses } \\
\hline & $\begin{array}{c}(1) \\
\text { Reopen }\end{array}$ & $\begin{array}{c}(2) \\
\text { Restrictions }\end{array}$ & $\begin{array}{c}(3) \\
\text { Reopen }\end{array}$ & $\mathrm{Lag} \stackrel{(4)}{\geq} 4 \mathrm{wk}$ & $\begin{array}{c}(5) \\
\text { Reopen }\end{array}$ & $\begin{array}{c}(6) \\
\text { Restrictions }\end{array}$ & $\begin{array}{c}(7) \\
\text { Reopen }\end{array}$ & $\mathrm{Lag} \stackrel{(8)}{\geq} 4 \mathrm{wk}$ \\
\hline $\ln$ (COVID cases per cap.) & $\begin{array}{c}0.0816^{* * *} \\
(0.0207)\end{array}$ & $\begin{array}{c}0.0799^{* * *} \\
(0.0258)\end{array}$ & $\begin{array}{c}0.0231^{* * *} * \\
(0.0080)\end{array}$ & $\begin{array}{l}0.0059^{*} \\
(0.0033)\end{array}$ & $\begin{array}{c}0.0217^{* *} \\
(0.0106)\end{array}$ & $\begin{array}{c}0.0427^{* *} \\
(0.0197)\end{array}$ & $\begin{array}{c}0.0113 \\
(0.0101)\end{array}$ & $\begin{array}{c}0.0001 \\
(0.0044)\end{array}$ \\
\hline Emp. Physical Proximity & $\begin{array}{c}0.2433^{* * *} \\
(0.0540)\end{array}$ & $\begin{array}{c}0.3011^{* * *} \\
(0.0688)\end{array}$ & $\begin{array}{c}0.0365 \\
(0.0273)\end{array}$ & $\begin{array}{c}0.0124 \\
(0.0088)\end{array}$ & $\begin{array}{l}-0.0016 \\
(0.0492)\end{array}$ & $\begin{array}{c}0.1109 \\
(0.0740)\end{array}$ & $\begin{array}{l}-0.0353 \\
(0.0340)\end{array}$ & $\begin{array}{l}-0.0078 \\
(0.0096)\end{array}$ \\
\hline$\times \ln ($ COVID cases p.c. $)$ & $\begin{array}{c}0.0012 \\
(0.0092)\end{array}$ & $\begin{array}{c}0.0005 \\
(0.0116)\end{array}$ & $\begin{array}{c}0.0021 \\
(0.0050)\end{array}$ & $\begin{array}{c}0.0005 \\
(0.0016)\end{array}$ & $\begin{array}{c}0.0037 \\
(0.0081)\end{array}$ & $\begin{array}{l}-0.0060 \\
(0.0129)\end{array}$ & $\begin{array}{c}0.0039 \\
(0.0064)\end{array}$ & $\begin{array}{c}0.0019 \\
(0.0018)\end{array}$ \\
\hline Owner Age & $\begin{array}{l}-0.0009 \\
(0.0024)\end{array}$ & $\begin{array}{c}-0.0052^{* * *} \\
(0.0015)\end{array}$ & $\begin{array}{c}0.0028 \\
(0.0022)\end{array}$ & $\begin{array}{c}0.0006 \\
(0.0006)\end{array}$ & $\begin{array}{c}0.0004 \\
(0.0033)\end{array}$ & $\begin{array}{c}-0.0060^{* * *} \\
(0.0018)\end{array}$ & $\begin{array}{c}0.0020 \\
(0.0029)\end{array}$ & $\begin{array}{c}0.0003 \\
(0.0008)\end{array}$ \\
\hline$\times \ln ($ COVID cases p.c. $)$ & $\begin{array}{c}0.0001 \\
(0.0002)\end{array}$ & $\begin{array}{c}-0.0001 \\
(0.0003)\end{array}$ & $\begin{array}{c}0.0002 \\
(0.0002)\end{array}$ & $\begin{array}{c}0.0000 \\
(0.0001)\end{array}$ & $\begin{array}{c}0.0000 \\
(0.0002)\end{array}$ & $\begin{array}{l}-0.0002 \\
(0.0003)\end{array}$ & $\begin{array}{c}0.0001 \\
(0.0002)\end{array}$ & $\begin{array}{l}-0.0000 \\
(0.0001)\end{array}$ \\
\hline Customers Over 65 & $\begin{array}{c}-0.1098^{* * *} \\
(0.0318)\end{array}$ & $\begin{array}{c}-0.0804^{*} \\
(0.0432)\end{array}$ & $\begin{array}{c}-0.0547^{*} \\
(0.0290)\end{array}$ & $\begin{array}{l}-0.0099 \\
(0.0116)\end{array}$ & $\begin{array}{c}-0.0800^{* *} \\
(0.0368)\end{array}$ & $\begin{array}{c}-0.0437 \\
(0.0625)\end{array}$ & $\begin{array}{c}-0.0789^{* * *} \\
(0.0276)\end{array}$ & $\begin{array}{c}-0.0171 \\
(0.0156)\end{array}$ \\
\hline$\times \ln ($ COVID cases p.c. $)$ & $\begin{array}{c}-0.0116^{*} \\
(0.0058)\end{array}$ & $\begin{array}{c}-0.0049 \\
(0.0073)\end{array}$ & $\begin{array}{c}-0.0082 \\
(0.0051)\end{array}$ & $\begin{array}{c}-0.0024 \\
(0.0019)\end{array}$ & $\begin{array}{l}-0.0027 \\
(0.0063)\end{array}$ & $\begin{array}{c}0.0066 \\
(0.0106)\end{array}$ & $\begin{array}{c}-0.0078 \\
(0.0048)\end{array}$ & $\begin{array}{l}-0.0026 \\
(0.0027)\end{array}$ \\
\hline Essential Business & $\begin{array}{c}-0.2995^{* * *} \\
(0.0257)\end{array}$ & $\begin{array}{c}-0.3244^{* * *} \\
(0.0278)\end{array}$ & $\begin{array}{c}-0.0727^{* * *} \\
(0.0161)\end{array}$ & $\begin{array}{c}-0.0268^{* * *} \\
(0.0044)\end{array}$ & $\begin{array}{c}-0.1204^{* * *} \\
(0.0291)\end{array}$ & $\begin{array}{c}-0.2264^{* * *} \\
(0.0293)\end{array}$ & $\begin{array}{c}-0.0480^{* *} \\
(0.0220)\end{array}$ & $\begin{array}{c}-0.0186^{* * *} \\
(0.0055)\end{array}$ \\
\hline Ease Operating Online & $\begin{array}{c}0.0452^{* * *} \\
(0.0129)\end{array}$ & $\begin{array}{c}0.0273^{* * *} \\
(0.0098)\end{array}$ & $\begin{array}{c}0.0250^{* *} \\
(0.0099)\end{array}$ & $\begin{array}{c}0.0049 \\
(0.0034)\end{array}$ & $\begin{array}{c}0.0215 \\
(0.0138)\end{array}$ & $\begin{array}{c}0.0057 \\
(0.0126)\end{array}$ & $\begin{array}{c}0.0256^{* *} \\
(0.0107)\end{array}$ & $\begin{array}{c}0.0033 \\
(0.0036)\end{array}$ \\
\hline $\ln ($ Pop. Density) & $\begin{array}{c}-0.0438^{* * *} \\
(0.0146)\end{array}$ & $\begin{array}{c}-0.0483^{* * *} \\
(0.0152)\end{array}$ & $\begin{array}{c}-0.0099 \\
(0.0070)\end{array}$ & $\begin{array}{l}-0.0025 \\
(0.0023)\end{array}$ & $\begin{array}{l}-0.0168 \\
(0.0122)\end{array}$ & $\begin{array}{c}-0.0358^{* *} \\
(0.0147)\end{array}$ & $\begin{array}{c}-0.0061 \\
(0.0091)\end{array}$ & $\begin{array}{l}-0.0005 \\
(0.0029)\end{array}$ \\
\hline GOP Vote Share (County) & $\begin{array}{c}-1.3075^{* * *} \\
(0.1109)\end{array}$ & $\begin{array}{c}-1.0939^{* * *} \\
(0.1671)\end{array}$ & $\begin{array}{c}-0.5701^{* * *} \\
(0.0652)\end{array}$ & $\begin{array}{c}-0.1694 * * * \\
(0.0243)\end{array}$ & $\begin{array}{c}-0.9870 * * * \\
(0.0930)\end{array}$ & $\begin{array}{c}-0.8572 * * * \\
(0.1627)\end{array}$ & $\begin{array}{c}-0.5966^{* * *} \\
(0.0963)\end{array}$ & $\begin{array}{c}-0.1556^{* * *} \\
(0.0364)\end{array}$ \\
\hline Restriction Expectation FE & No & No & Yes & Yes & No & No & Yes & Yes \\
\hline DV Mean & 1.309 & 1.053 & 1.309 & 0.177 & 2.076 & 1.670 & 2.076 & 0.281 \\
\hline DV SD & 1.489 & 1.409 & 1.489 & 0.382 & 1.386 & 1.456 & 1.386 & 0.449 \\
\hline Residual SD & 1.452 & 1.369 & 1.119 & 0.375 & 1.373 & 1.439 & 1.162 & 0.379 \\
\hline$R^{2}$ & 0.0479 & 0.0561 & 0.4352 & 0.0328 & 0.0192 & 0.0226 & 0.2979 & 0.2887 \\
\hline $\mathrm{N}$ & 28,449 & 28,449 & 28,449 & 28,449 & 17,932 & 17,932 & 17,932 & 17,932 \\
\hline
\end{tabular}

Note: Reopen is the expected months to reopen. Restriction is the estimated months until restrictions are lifted. Lag $\geq 4 w k$ is a indicator variable that evaluates to 1 if the firm's estimated reopening date is at least one month/four weeks after the estimated date restrictions are lifted. Businesses that were permanently closed at the time of the survey are excluded from these regressions; businesses that were fully open at the time of the survey are excluded from columns 5-8. Employee Physical Proximity, Customers Over 65, and Ease Operating Online are converted to z-scores. Restriction expectation fixed effects are included in the indicated models and are a vector of fixed effects corresponding to the date at which respondents believe that restrictions will be lifted. Standard errors in parentheses, clustered at county level. Note that the survey questions in which reopening and restriction beliefs are elicited is mid-way through the survey, thus in some columns we are able to have more observations than we have complete survey responses. ${ }^{*} p<0.1,{ }^{* *} p<0.05,{ }^{* * *} p<0.01$ 
Table 5. Contribution of Various Factors to Projected $\ln$ (Share Returning Customers)

\begin{tabular}{|c|c|c|}
\hline & $\begin{array}{c}(1) \\
\text { All Businesses }\end{array}$ & Excluding Fully Open Businesses \\
\hline Mo. until No Restrictions & $\begin{array}{c}-0.1740^{* * *} \\
(0.0048)\end{array}$ & $\begin{array}{c}-0.1298^{* * *} \\
(0.0046)\end{array}$ \\
\hline $\ln ($ COVID cases per cap.) & $\begin{array}{l}-0.0053 \\
(0.0088)\end{array}$ & $\begin{array}{l}-0.0008 \\
(0.0109)\end{array}$ \\
\hline Emp. Physical Proximity & $\begin{array}{c}-0.0757^{* * *} \\
(0.0252)\end{array}$ & $\begin{array}{c}-0.0792^{* * *} \\
(0.0237)\end{array}$ \\
\hline$\times \ln (\mathrm{COVID}$ cases p.c. $)$ & $\begin{array}{l}-0.0110^{* *} \\
(0.0044)\end{array}$ & $\begin{array}{c}-0.0167^{* * *} \\
(0.0044)\end{array}$ \\
\hline Owner Age & $\begin{array}{l}-0.0005 \\
(0.0017)\end{array}$ & $\begin{array}{l}-0.0011 \\
(0.0017)\end{array}$ \\
\hline$\times \ln ($ COVID cases p.c. $)$ & $\begin{array}{l}-0.0002 \\
(0.0002)\end{array}$ & $\begin{array}{l}-0.0002 \\
(0.0002)\end{array}$ \\
\hline Customers Over 65 & $\begin{array}{l}0.0661^{* * *} \\
(0.0209)\end{array}$ & $\begin{array}{l}0.0615^{* *} \\
(0.0273)\end{array}$ \\
\hline$\times \ln (\mathrm{COVID}$ cases p.c. $)$ & $\begin{array}{l}0.0074^{* *} \\
(0.0035)\end{array}$ & $\begin{array}{c}0.0047 \\
(0.0044)\end{array}$ \\
\hline Essential Business & $\begin{array}{l}0.1233^{* * *} \\
(0.0130)\end{array}$ & $\begin{array}{l}0.1115^{* * *} \\
(0.0185)\end{array}$ \\
\hline $\ln$ (Pop. Density) & $\begin{array}{c}0.0133 \\
(0.0080)\end{array}$ & $\begin{array}{c}0.0159 \\
(0.0109)\end{array}$ \\
\hline Ease Operating Online & $\begin{array}{c}-0.0376^{* * *} \\
(0.0069)\end{array}$ & $\begin{array}{c}-0.0404^{* * *} \\
(0.0093)\end{array}$ \\
\hline GOP Vote Share (County) & $\begin{array}{l}0.4275^{* * *} \\
(0.0554)\end{array}$ & $\begin{array}{c}0.4768^{* * *} \\
(0.0713)\end{array}$ \\
\hline DV Mean & 3.727 & 3.558 \\
\hline DV SD & 0.876 & 0.921 \\
\hline Residual SD & 0.798 & 0.844 \\
\hline$R^{2}$ & 0.1695 & 0.1609 \\
\hline $\mathrm{N}$ & 27,185 & 18,157 \\
\hline
\end{tabular}

Note: The outcome in all columns is the logarithm of projected demand, measured as the answer to the question "If you are fully open by randomized date, what share of your customers do you expect at that time, compared to before the crisis? Please provide your best guess". Employee Physical Proximity, Customers Over 65, and Ease Operating Online are converted to z-scores. Standard errors in parentheses, clustered at county level. ${ }^{*} p<0.1,{ }^{* *} p<0.05$, ${ }^{* * *} p<0.01$ 
Table 6. Instrumenting expected customer demand

\begin{tabular}{|c|c|c|c|c|c|c|c|c|c|c|}
\hline & & & \multicolumn{4}{|c|}{ Reopen } & \multicolumn{2}{|c|}{ Lag $\geq 4$ weeks } & \multicolumn{2}{|c|}{ Open Dec. } \\
\hline & & & (1) & (2) & (3) & (4) & (5) & (6) & (7) & (8) \\
\hline $\ln$ (Share Customers Returning) & & & $\begin{array}{c}-0.876^{* * *} \\
(0.187)\end{array}$ & $\begin{array}{c}-0.854^{* * *} \\
(0.193)\end{array}$ & $\begin{array}{c}-0.528^{* *} \\
(0.216)\end{array}$ & $\begin{array}{c}-0.531^{* *} \\
(0.210)\end{array}$ & $\begin{array}{l}-0.163^{*} \\
(0.083)\end{array}$ & $\begin{array}{l}-0.150^{*} \\
(0.082)\end{array}$ & $\begin{array}{c}0.310^{* * *} \\
(0.041)\end{array}$ & $\begin{array}{c}0.325^{* * *} \\
(0.043)\end{array}$ \\
\hline Restriction Expectation FE & & & No & No & Yes & Yes & Yes & Yes & Yes & Yes \\
\hline Additional Controls & & & No & Yes & No & Yes & No & Yes & No & Yes \\
\hline Kleibergen-Paap F stat & & & 8.4 & 9.6 & 8.4 & 9.5 & 8.4 & 9.5 & 8.7 & 9.7 \\
\hline Mean Dep. Var. & & & 1.38 & 1.38 & 0.19 & 1.37 & 0.19 & 0.19 & 0.79 & 0.79 \\
\hline Std. Dev. Dep. Var. & & & 1.49 & 1.49 & 0.39 & 1.49 & 0.39 & 0.39 & 0.18 & 0.18 \\
\hline $\mathrm{R}^{2}$ & & & 0.70 & 0.70 & 0.79 & 0.79 & 0.46 & 0.47 & 0.91 & 0.90 \\
\hline \multirow[t]{3}{*}{ Observations } & & & 16,357 & 16,357 & 16,265 & 16,265 & 16,265 & 16,265 & 13,395 & 13,395 \\
\hline & Fir & tage & \multicolumn{4}{|c|}{ Reopen } & \multicolumn{2}{|c|}{ Lag $\geq 4$ weeks } & \multicolumn{2}{|c|}{ Open Dec. } \\
\hline & (1) & (2) & (3) & (4) & (5) & (6) & (7) & (8) & (9) & (10) \\
\hline $\ln ($ Signal $)-\ln ($ Prior $) \times$ Shown Info & $\begin{array}{c}0.189^{* * *} \\
(0.044)\end{array}$ & $\begin{array}{c}0.187^{* * *} \\
(0.041)\end{array}$ & $\begin{array}{c}-0.239^{* * *} \\
(0.047)\end{array}$ & $\begin{array}{c}-0.236^{* * *} \\
(0.043)\end{array}$ & $\begin{array}{c}-0.144^{* *} \\
(0.054)\end{array}$ & $\begin{array}{c}-0.146^{* * *} \\
(0.048)\end{array}$ & $\begin{array}{l}-0.042^{*} \\
(0.022)\end{array}$ & $\begin{array}{l}-0.039^{*} \\
(0.021)\end{array}$ & $\begin{array}{c}0.080^{* * *} \\
(0.006)\end{array}$ & $\begin{array}{c}0.083^{* * *} \\
(0.005)\end{array}$ \\
\hline Restriction Expectation FE & No & No & No & No & Yes & Yes & Yes & Yes & Yes & Yes \\
\hline Additional Controls & No & Yes & No & Yes & No & Yes & No & Yes & No & Yes \\
\hline Mean Dep. Var. & 3.73 & 3.73 & 1.38 & 1.38 & 1.37 & 1.37 & 0.19 & 0.19 & 0.79 & 0.79 \\
\hline Std. Dev. Dep. Var. & 0.87 & 0.87 & 1.49 & 1.49 & 1.49 & 1.49 & 0.39 & 0.39 & 0.18 & 0.18 \\
\hline $\mathrm{R}^{2}$ & 0.34 & 0.34 & 0.52 & 0.52 & 0.63 & 0.63 & 0.39 & 0.39 & 0.10 & 0.11 \\
\hline Observations & 16,357 & 16,357 & 16,357 & 16,357 & 16,265 & 16,265 & 16,265 & 16,265 & 13,395 & 13,395 \\
\hline
\end{tabular}

Note: In Panel A, the dependent variable in Col. $(1,2,3,4)$ Reopen is the expected months to reopen. The model in Col. $(3,4)$ includes a fixed effect for the date restrictions are lifted. In Col. $(5,6) \mathrm{Lag} \geq 4 \mathrm{wk}$ is a indicator variable that evaluates to 1 if the firm's estimated reopening date is at least one month/four weeks after the estimated date restrictions are lifted. In Col. $(7,8)$ the dependent variable Open Dec. is the self-reported probability of being operational by December 31st, 2020. Controls across all regressions include the prior and the gap between the signal and the prior (log units), date fixed effects, the current status of business, and an indicator for classification as an essential business. In Panel B, the dependent variable in Col. (1) is the log expected demand, the response to the question "If you are fully open by randomized date, what share of your customers do you expect at that time, compared to before the crisis? Please provide your best guess." The instrument for expected demand is an information instrument shown to a random subset of participants before we elicit demand expectations. See equations 6 and 7 and the related discussion for more information about the econometric specification. Columns with additional controls contain the additional controls from the main OLS specification in Table 5, namely the natural logarithm of (1+COVID cases per capita), physical proximity, owner age, likelihood of having customers over 65 , ease of conducting business online, the natural logarithm of population density, and the county-level share of the vote that went to the Republican candidate in the 2016 presidential election. Restriction expectation fixed effects are included in the indicated models and are a vector of fixed effects corresponding to the date at which respondents believe that restrictions will be lifted. Standard errors are clustered at the region $\times$ business type level, which is the level at which the information treatment is assigned. ${ }^{*} p<0.1,{ }^{* *} p<0.05,{ }^{* * *} p<0.01$ 
Table 7. Factors Contributing to the Probability of Being Open in December, 2020

\begin{tabular}{|c|c|c|c|}
\hline & (1) & (2) & (3) \\
\hline Mo. until No Restrictions & $\begin{array}{c}-0.0257^{* * *} \\
(0.0011)\end{array}$ & & $\begin{array}{c}-0.0164^{* * *} \\
(0.0011)\end{array}$ \\
\hline $\ln ($ Share Returning Customers) & & $\begin{array}{c}0.0637^{* * *} \\
(0.0023)\end{array}$ & $\begin{array}{c}0.0567^{* * *} \\
(0.0024)\end{array}$ \\
\hline $\ln$ (COVID cases per cap.) & $\begin{array}{c}0.0013 \\
(0.0015)\end{array}$ & $\begin{array}{c}-0.0002 \\
(0.0015)\end{array}$ & $\begin{array}{c}0.0010 \\
(0.0015)\end{array}$ \\
\hline Emp. Physical Proximity & $\begin{array}{c}-0.0209^{* * *} \\
(0.0047)\end{array}$ & $\begin{array}{c}-0.0210^{* * *} \\
(0.0064)\end{array}$ & $\begin{array}{c}-0.0167^{* * *} \\
(0.0054)\end{array}$ \\
\hline$\times \ln ($ COVID cases p.c. $)$ & $\begin{array}{c}-0.0016^{* *} \\
(0.0008)\end{array}$ & $\begin{array}{c}-0.0009 \\
(0.0010)\end{array}$ & $\begin{array}{l}-0.0010 \\
(0.0009)\end{array}$ \\
\hline Owner Age & $\begin{array}{c}0.0001 \\
(0.0004)\end{array}$ & $\begin{array}{c}0.0002 \\
(0.0004)\end{array}$ & $\begin{array}{c}0.0001 \\
(0.0004)\end{array}$ \\
\hline$\times \ln ($ COVID cases p.c. $)$ & $\begin{array}{l}-0.0001^{*} \\
(0.0000)\end{array}$ & $\begin{array}{c}-0.0001 \\
(0.0000)\end{array}$ & $\begin{array}{l}-0.0001 \\
(0.0000)\end{array}$ \\
\hline Customers Over 65 & $\begin{array}{c}0.0140^{* * *} \\
(0.0045)\end{array}$ & $\begin{array}{l}0.0103^{* *} \\
(0.0045)\end{array}$ & $\begin{array}{l}0.0098^{* *} \\
(0.0044)\end{array}$ \\
\hline$\times \ln ($ COVID cases p.c. $)$ & $\begin{array}{c}0.0007 \\
(0.0008)\end{array}$ & $\begin{array}{c}0.0002 \\
(0.0008)\end{array}$ & $\begin{array}{c}0.0002 \\
(0.0008)\end{array}$ \\
\hline Essential Business & $\begin{array}{c}0.0211^{* * *} \\
(0.0029)\end{array}$ & $\begin{array}{c}0.0171^{* * *} \\
(0.0024)\end{array}$ & $\begin{array}{r}0.0126^{* * *} \\
(0.0027)\end{array}$ \\
\hline $\ln$ (Pop. Density) & $\begin{array}{l}-0.0003 \\
(0.0016)\end{array}$ & $\begin{array}{c}-0.0001 \\
(0.0013)\end{array}$ & $\begin{array}{l}-0.0006 \\
(0.0014)\end{array}$ \\
\hline Ease Operating Online & $\begin{array}{l}-0.0010 \\
(0.0013)\end{array}$ & $\begin{array}{c}0.0008 \\
(0.0013)\end{array}$ & $\begin{array}{c}0.0011 \\
(0.0013)\end{array}$ \\
\hline GOP Vote Share (County) & $\begin{array}{c}0.0162 \\
(0.0116)\end{array}$ & $\begin{array}{c}0.0042 \\
(0.0106)\end{array}$ & $\begin{array}{c}-0.0078 \\
(0.0098)\end{array}$ \\
\hline DV Mean & 0.792 & 0.792 & 0.792 \\
\hline DV SD & 0.185 & 0.185 & 0.185 \\
\hline Residual SD & 0.180 & 0.175 & 0.174 \\
\hline$R^{2}$ & 0.0593 & 0.1085 & 0.1224 \\
\hline $\mathrm{N}$ & 16,747 & 16,747 & 16,747 \\
\hline
\end{tabular}

Note: The outcome in all columns is the answer to the question "What is the likelihood of your business remaining operational by Dec. 31, 2020? Please provide your best guess.". Businesses that were permanently closed at the time of the survey are excluded from these regressions. Employee Physical Proximity, Customers Over 65, and Ease Operating Online are converted to z-scores. Standard errors in parentheses, clustered at county level. ${ }^{*} p<0.1,{ }^{* *}$ $p<0.05,{ }^{* * *} p<0.01$ 


\section{A. Appendix: Additional Figures and Tables}

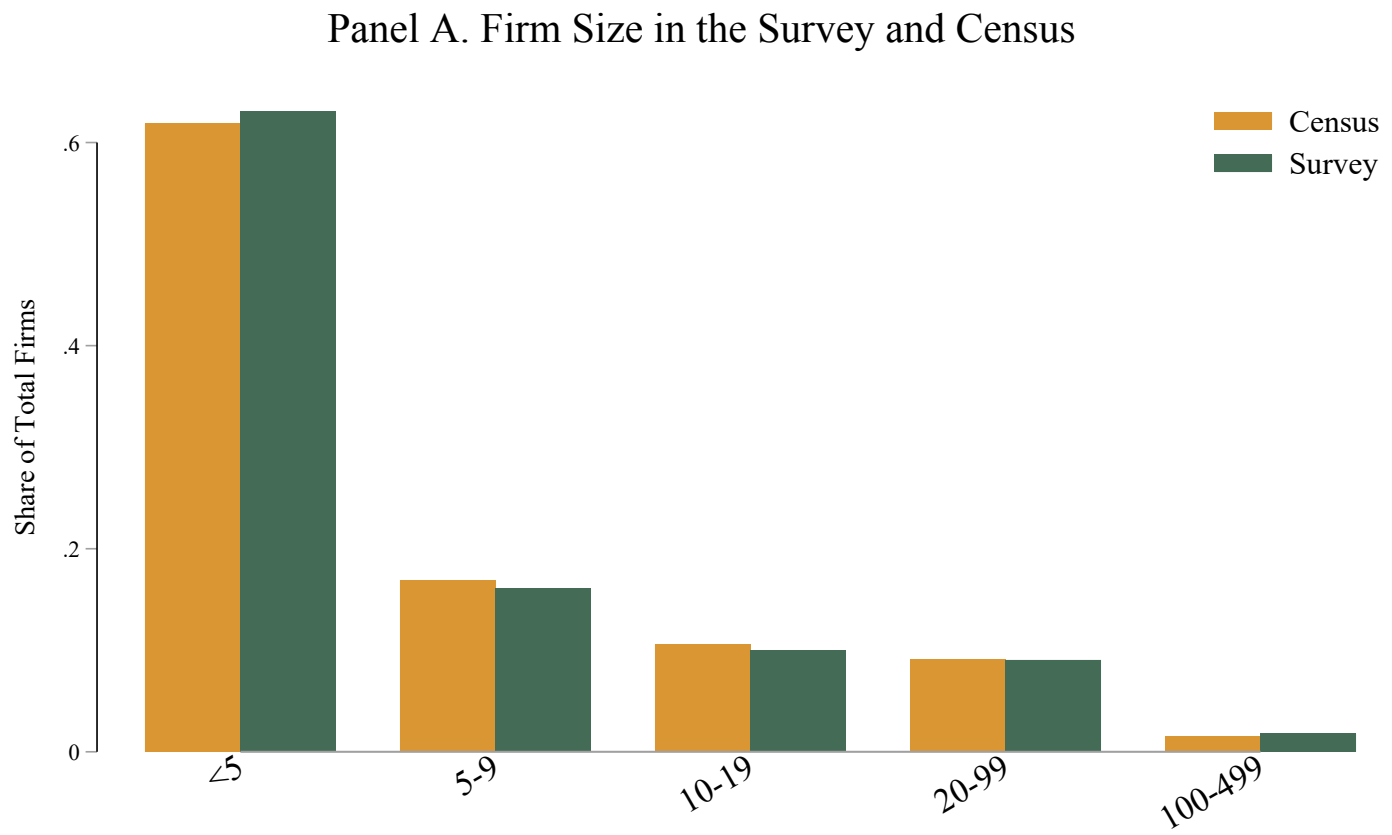

Panel B. Firm Locations in the Census and Survey

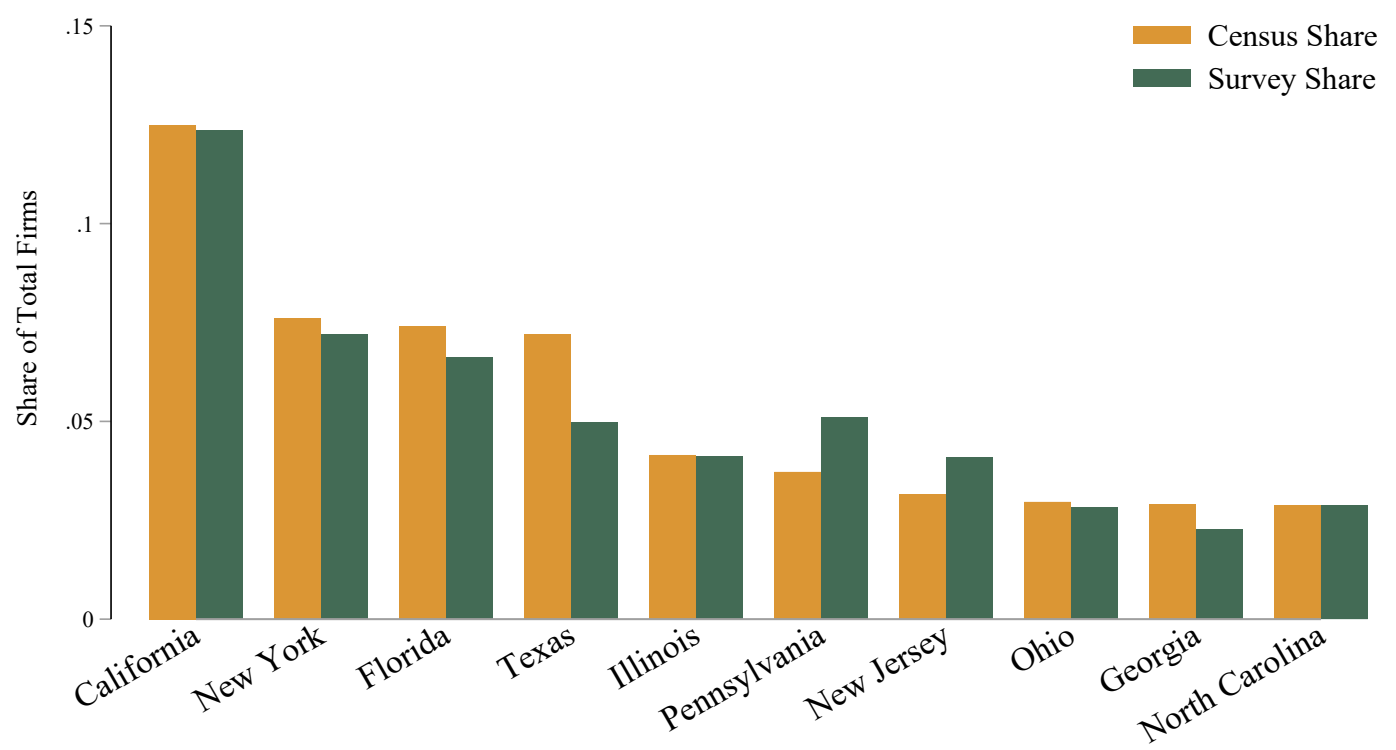

Figure A1. Firm Size and Location in the Survey and Census.

Note: This figure plots the share of firms in each employment category and state for the 2017 Census of US Businesses and the survey respondents for May 9, 2020. The sample size is 22,492 responses from May 9th survey wave with non-missing employment data and 34,941 responses with non-missing state data. 


\section{Panel A: Local COVID Prevalence}

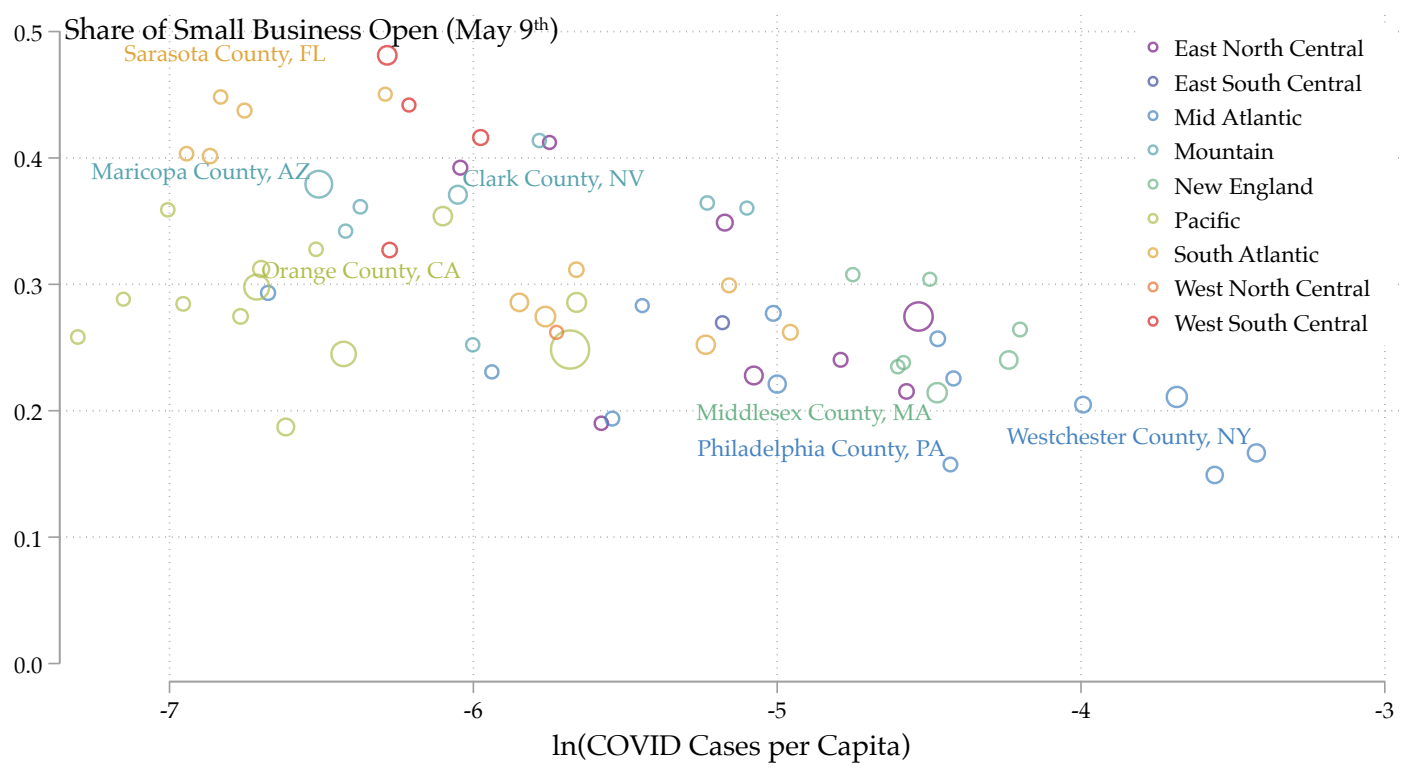

Panel B: Local Unemployment

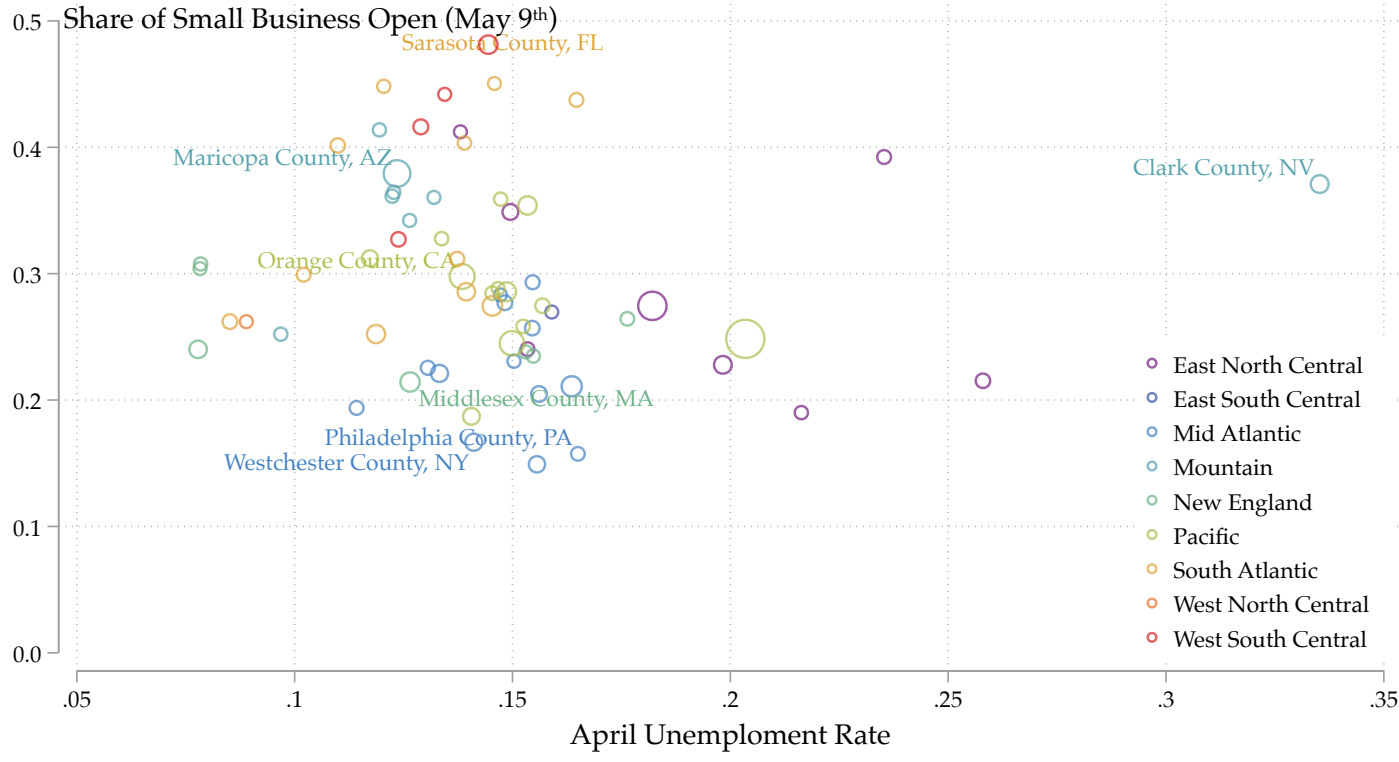

Figure A2. Share of Small Businesses Open by COVID Cases and Unemployment.

Note: This figure plots the share of firms that are fully open as of the May 9th survey wave against COVID cases per capita, and the unemployment rate, at the county level. Counties with fewer than 100 observations not plotted; rings representing counties with more responses are drawn larger than those representing counties with few responses. 


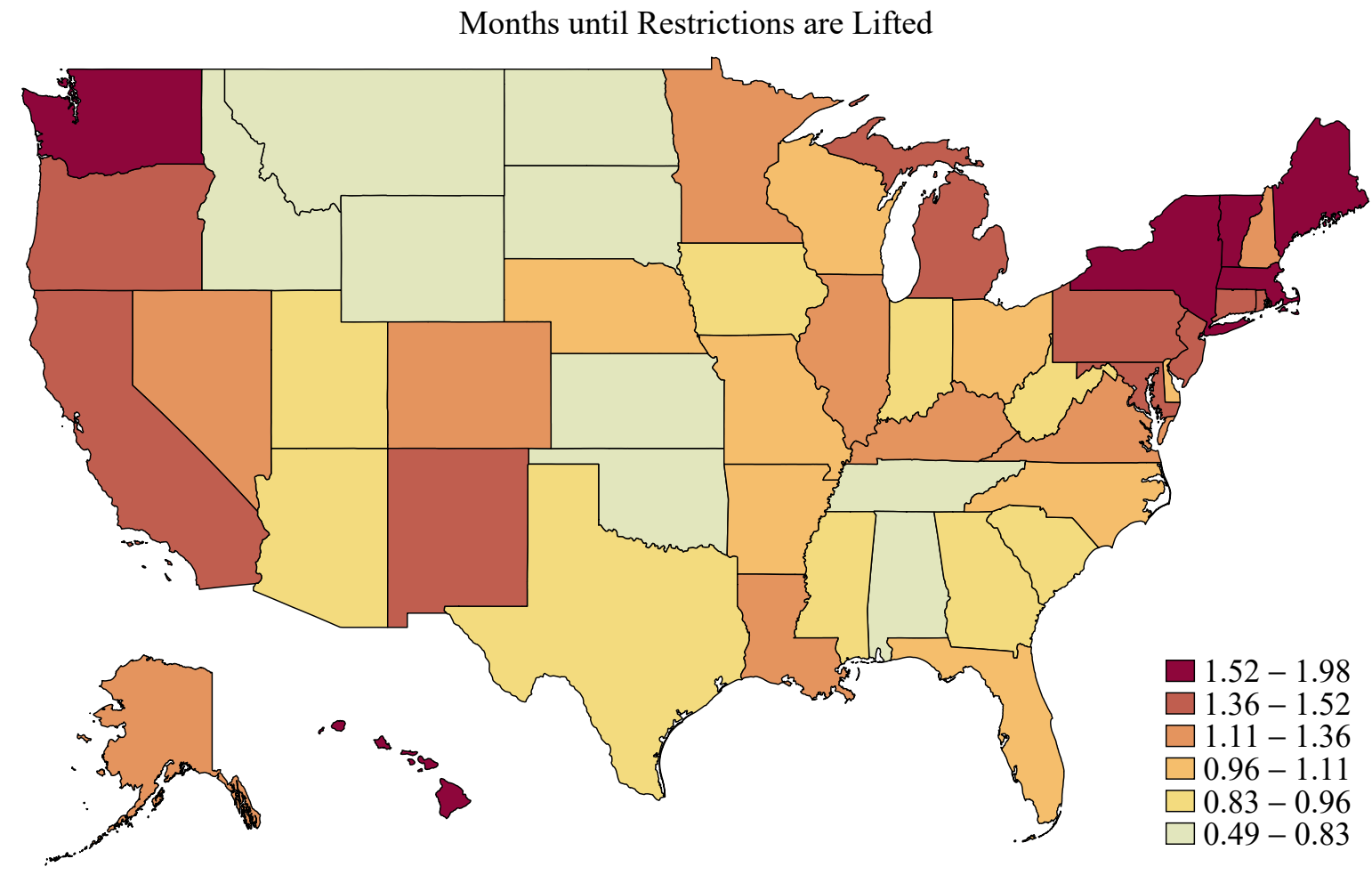

Figure A3. Perceived Months Until Restrictions Lifted, by State.

Note: This map presents the average perceived months until restrictions lifted, by state. 


\section{Panel A: Shares of Businesses that are Temporarily Closed by Above and Below Median Proximity}

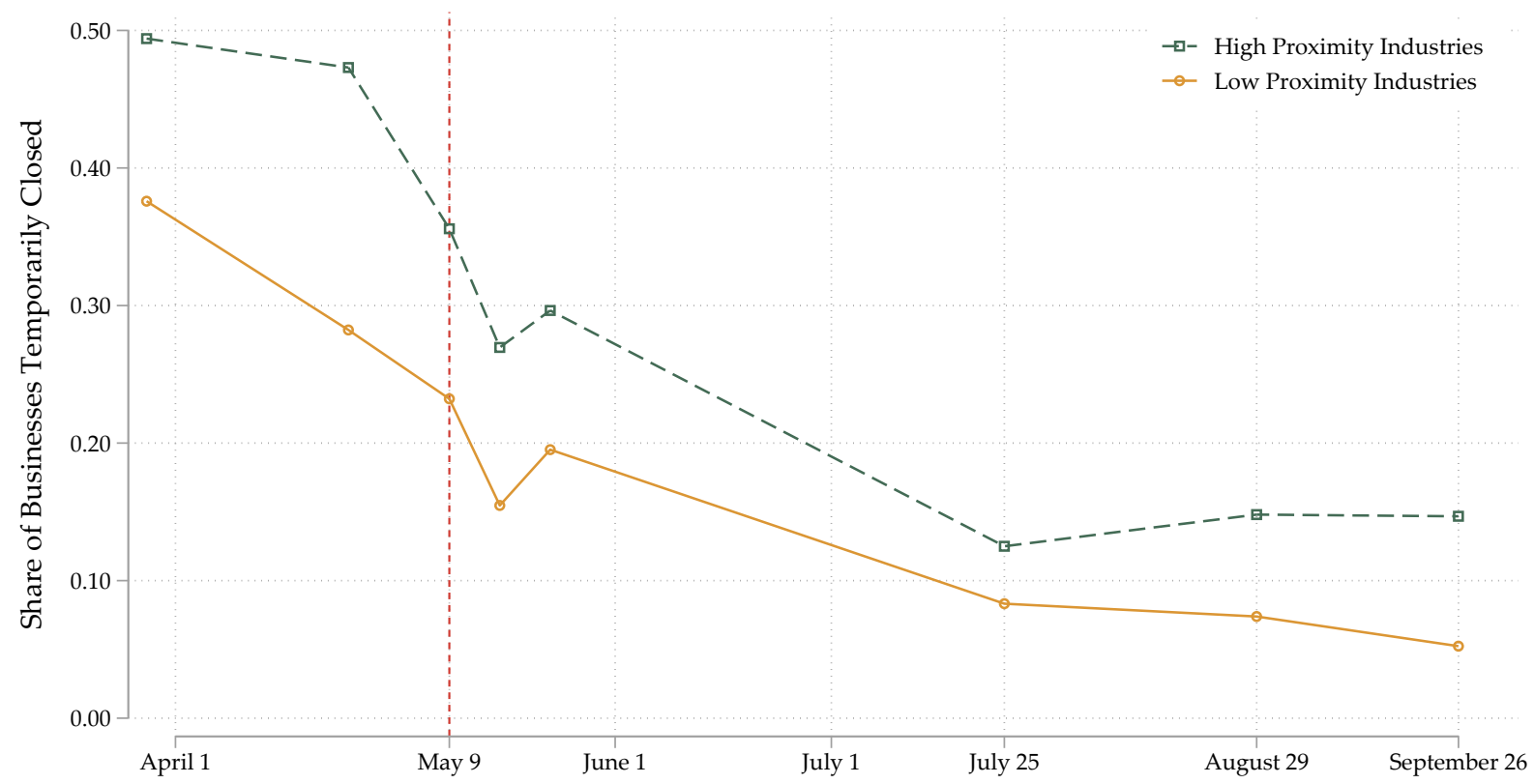

Panel B: Shares of Businesses by Essential and Non-Essential Industry Classifications

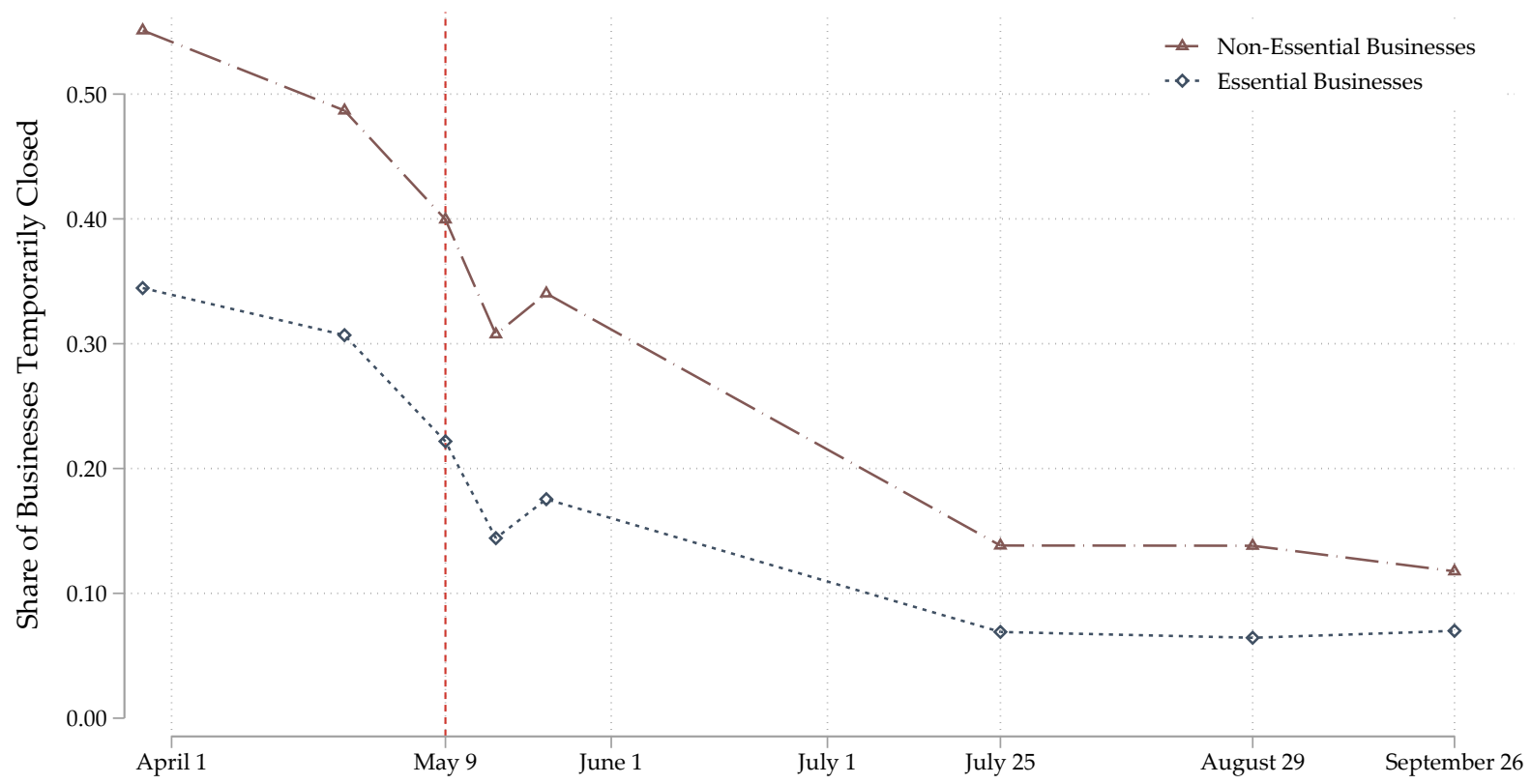

Figure A4. Shares of Businesses that are Temporarily Closed.

Note: This figure plots the share of firms that are temporarily closed across waves of Alignable's data collection, split by whether the business is in an above or below median proximity industry. Proximity is defined by the O-NET Physical Proximity measure "To what extent does this job require the worker to perform job tasks in close physical proximity to other people?" We merge the proximity measure to the OES data based on occupation and then take an employment-weighted average by industry. We thank Simon Mongey and Alex Weinberg for publicly sharing this measure. Industries are classified as essential if they are on the list of essential NAICS codes in both Delaware and Minnesota, two states that have done this classification based on NAICS industries. 
Table A1. Census industry versus survey industry breakdown.

\begin{tabular}{lcc}
\hline \hline Industry & Census Percentage & Survey Percentage \\
\hline Agriculture, Forestry, Fishing and Hunting & 0.4 & 1.1 \\
Mining, Quarrying, and Oil and Gas Extraction & 0.3 & 0.3 \\
Utilities & 0.1 & 0.3 \\
Construction & 11.7 & 7.6 \\
Manufacturing & 4.1 & 6.0 \\
Wholesale and Retail Trade & 15.7 & 13.1 \\
Transportation and Warehousing & 3.1 & 1.2 \\
Information & 1.3 & 2.1 \\
Finance and Insurance & 4.0 & 6.8 \\
Real Estate and Rental and Leasing & 5.2 & 8.8 \\
Professional, Scientific, and Technical Services & 13.5 & 14.6 \\
Management of Companies and Enterprises & 0.3 & 0.0 \\
Administrative and Support and Waste Remediation Svcs & 5.8 & 3.8 \\
Educational Services & 1.5 & 3.3 \\
Health Care and Social Assistance & 10.9 & 8.8 \\
Arts, Entertainment, and Recreation & 2.2 & 6.9 \\
Accommodation and Food Services & 9.0 & 5.2 \\
Other Services (except Public Administration) & 11.6 & 9.2 \\
\hline \hline
\end{tabular}

Note: This table reports results of Census and Survey shares by industry for firms with fewer than 500 employees. Survey response shares are conditional on being able to classify industries, with unavailable or "Other" industry classifications omitted from the denominator. We combine wholesale and retail trade. 
Table A2. Expected demand by industry (NAICS 2-digit).

\begin{tabular}{|c|c|c|c|c|c|c|c|c|c|}
\hline Industry & \multicolumn{2}{|c|}{ May } & \multicolumn{2}{|c|}{ June } & \multicolumn{2}{|c|}{ July } & \multicolumn{2}{|c|}{ September } & $\mathrm{N}$ \\
\hline Share Expecting & $>90 \%$ & Mean & $>90 \%$ & Mean & $>90 \%$ & Mean & $>90 \%$ & Mean & \\
\hline Arts, Entertainment, \& Recreation & 0.07 & 0.37 & 0.07 & 0.43 & 0.07 & 0.44 & 0.11 & 0.55 & 1851 \\
\hline Educational Services & 0.08 & 0.47 & 0.07 & 0.47 & 0.11 & 0.53 & 0.13 & 0.60 & 832 \\
\hline Accommodation \& Food Services & 0.02 & 0.42 & 0.05 & 0.48 & 0.06 & 0.50 & 0.14 & 0.58 & 1452 \\
\hline Retail Trade & 0.10 & 0.51 & 0.13 & 0.55 & 0.15 & 0.57 & 0.17 & 0.64 & 3057 \\
\hline Admin. and Waste Services & 0.14 & 0.47 & 0.13 & 0.48 & 0.18 & 0.51 & 0.18 & 0.60 & 1085 \\
\hline Real Estate \& Leasing & 0.14 & 0.54 & 0.16 & 0.57 & 0.20 & 0.60 & 0.20 & 0.61 & 2162 \\
\hline Inform & 0.15 & 0.53 & 0.19 & 0.57 & 0.22 & 0.59 & 0.20 & 0.65 & 586 \\
\hline Manufacturing & 0.12 & 0.56 & 0.14 & 0.60 & 0.13 & 0.59 & 0.21 & 0.67 & 1744 \\
\hline Health Care \& Social Assistance & 0.07 & 0.55 & 0.13 & 0.58 & 0.15 & 0.61 & 0.22 & 0.70 & 2331 \\
\hline Professional \& Technical Services & 0.18 & 0.54 & 0.18 & 0.58 & 0.19 & 0.62 & 0.24 & 0.67 & 3985 \\
\hline Other Services, Except Public Admin. & 0.12 & 0.54 & 0.15 & 0.58 & 0.16 & 0.60 & 0.24 & 0.68 & 2322 \\
\hline Constr & 0.17 & 0.59 & 0.18 & 0.60 & 0.19 & 0.63 & 0.25 & 0.69 & 1998 \\
\hline Finance and Insurance & 0.19 & 0.66 & 0.28 & 0.66 & 0.26 & 0.65 & 0.27 & 0.70 & 1629 \\
\hline
\end{tabular}

Note: This table reports answers to a question about the expected share of customers returning by a certain randomly chosen date in the future. Each cell reports a share of customers relative to pre-COVID customers conditional on being able to classify industries. Columns are the share of respondents who report having greater than $90 \%$ of pre-COVID customers (the highest category) and then mean share of pre-COVID customers using the mid-point of categorical answers. 
Table A3. Tobit: Contribution of Various Factors to the Small Business Reopen Decision

\begin{tabular}{|c|c|c|c|c|c|c|c|c|}
\hline & \multicolumn{4}{|c|}{ All Businesses } & \multicolumn{4}{|c|}{ Excluding Fully Open Businesses } \\
\hline & $\begin{array}{c}(1) \\
\text { Reopen }\end{array}$ & $\begin{array}{c}(2) \\
\text { Restrictions }\end{array}$ & $\begin{array}{c}\text { (3) } \\
\text { Reopen }\end{array}$ & $\mathrm{Lag} \stackrel{(4)}{\geq} 4 \mathrm{wk}$ & $\begin{array}{c}(5) \\
\text { Reopen }\end{array}$ & $\begin{array}{c}(6) \\
\text { Restrictions }\end{array}$ & $\begin{array}{l}\text { (7) } \\
\text { Reopen }\end{array}$ & $\mathrm{Lag} \stackrel{(8)}{\geq} 4 \mathrm{wk}$ \\
\hline $\ln ($ COVID cases per cap.) & $\begin{array}{c}0.1772^{* * *} \\
(0.0438)\end{array}$ & $\begin{array}{c}0.1665^{* * *} \\
(0.0488)\end{array}$ & $\begin{array}{c}0.0533^{* * *} \\
(0.0155)\end{array}$ & $\begin{array}{l}0.0059^{*} \\
(0.0033)\end{array}$ & $\begin{array}{l}0.0249^{*} \\
(0.0128)\end{array}$ & $\begin{array}{c}0.0449^{* *} \\
(0.0214)\end{array}$ & $\begin{array}{c}0.0149 \\
(0.0122)\end{array}$ & $\begin{array}{c}0.0001 \\
(0.0044)\end{array}$ \\
\hline Emp. Physical Proximity & $\begin{array}{c}0.4343^{* * *} \\
(0.0894)\end{array}$ & $\begin{array}{c}0.5125^{* * *} \\
(0.0990)\end{array}$ & $\begin{array}{c}0.0488 \\
(0.0462)\end{array}$ & $\begin{array}{c}0.0124 \\
(0.0088)\end{array}$ & $\begin{array}{l}-0.0126 \\
(0.0615)\end{array}$ & $\begin{array}{c}0.1382 \\
(0.0874)\end{array}$ & $\begin{array}{c}-0.0598 \\
(0.0412)\end{array}$ & $\begin{array}{c}-0.0078 \\
(0.0096)\end{array}$ \\
\hline$\times \ln ($ COVID cases p.c. $)$ & $\begin{array}{l}-0.0161 \\
(0.0145)\end{array}$ & $\begin{array}{l}-0.0142 \\
(0.0166)\end{array}$ & $\begin{array}{l}-0.0060 \\
(0.0082)\end{array}$ & $\begin{array}{c}0.0005 \\
(0.0016)\end{array}$ & $\begin{array}{c}0.0032 \\
(0.0099)\end{array}$ & $\begin{array}{l}-0.0041 \\
(0.0152)\end{array}$ & $\begin{array}{c}0.0020 \\
(0.0076)\end{array}$ & $\begin{array}{c}0.0019 \\
(0.0018)\end{array}$ \\
\hline Owner Age & $\begin{array}{l}-0.0020 \\
(0.0041)\end{array}$ & $\begin{array}{c}-0.0077^{* * *} * \\
(0.0030)\end{array}$ & $\begin{array}{c}0.0052 \\
(0.0036)\end{array}$ & $\begin{array}{c}0.0006 \\
(0.0006)\end{array}$ & $\begin{array}{c}0.0008 \\
(0.0039)\end{array}$ & $\begin{array}{c}-0.0068^{* * *} * \\
(0.0022)\end{array}$ & $\begin{array}{c}0.0026 \\
(0.0034)\end{array}$ & $\begin{array}{c}0.0003 \\
(0.0008)\end{array}$ \\
\hline$\times \ln ($ COVID cases p.c. $)$ & $\begin{array}{c}0.0002 \\
(0.0004)\end{array}$ & $\begin{array}{c}-0.0001 \\
(0.0004)\end{array}$ & $\begin{array}{c}0.0003 \\
(0.0003)\end{array}$ & $\begin{array}{c}0.0000 \\
(0.0001)\end{array}$ & $\begin{array}{c}0.0000 \\
(0.0003)\end{array}$ & $\begin{array}{c}-0.0002 \\
(0.0004)\end{array}$ & $\begin{array}{c}0.0000 \\
(0.0003)\end{array}$ & $\begin{array}{l}-0.0000 \\
(0.0001)\end{array}$ \\
\hline Customers Over 65 & $\begin{array}{c}-0.1934^{* * *} \\
(0.0569)\end{array}$ & $\begin{array}{c}-0.1346^{* *} \\
(0.0598)\end{array}$ & $\begin{array}{l}-0.0780 \\
(0.0527)\end{array}$ & $\begin{array}{l}-0.0099 \\
(0.0116)\end{array}$ & $\begin{array}{c}-0.1100^{* *} \\
(0.0435)\end{array}$ & $\begin{array}{l}-0.0605 \\
(0.0708)\end{array}$ & $\begin{array}{c}-0.1022 * * * \\
(0.0329)\end{array}$ & $\begin{array}{l}-0.0171 \\
(0.0156)\end{array}$ \\
\hline$\times \ln ($ COVID cases p.c. $)$ & $\begin{array}{c}-0.0227^{* *} \\
(0.0106)\end{array}$ & $\begin{array}{c}-0.0115 \\
(0.0106)\end{array}$ & $\begin{array}{l}-0.0143 \\
(0.0093)\end{array}$ & $\begin{array}{l}-0.0024 \\
(0.0019)\end{array}$ & $\begin{array}{l}-0.0051 \\
(0.0074)\end{array}$ & $\begin{array}{c}0.0059 \\
(0.0120)\end{array}$ & $\begin{array}{c}-0.0104^{*} \\
(0.0057)\end{array}$ & $\begin{array}{l}-0.0026 \\
(0.0027)\end{array}$ \\
\hline Essential Business & $\begin{array}{c}-0.6071^{* * *} \\
(0.0433)\end{array}$ & $\begin{array}{c}-0.6139^{* * *} \\
(0.0449)\end{array}$ & $\begin{array}{c}-0.1462^{* * *} \\
(0.0270)\end{array}$ & $\begin{array}{c}-0.0268^{* * * *} \\
(0.0044)\end{array}$ & $\begin{array}{c}-0.1476^{* * *} \\
(0.0353)\end{array}$ & $\begin{array}{c}-0.2588^{* * *} \\
(0.0355)\end{array}$ & $\begin{array}{c}-0.0616^{* *} \\
(0.0264)\end{array}$ & $\begin{array}{c}-0.0186^{* * *} \\
(0.0055)\end{array}$ \\
\hline Ease Operating Online & $\begin{array}{c}0.0965 * * * \\
(0.0264)\end{array}$ & $\begin{array}{c}0.0660^{* * *} \\
(0.0203)\end{array}$ & $\begin{array}{c}0.0497^{* * *} \\
(0.0190)\end{array}$ & $\begin{array}{c}0.0049 \\
(0.0034)\end{array}$ & $\begin{array}{l}0.0272^{*} \\
(0.0165)\end{array}$ & $\begin{array}{c}0.0054 \\
(0.0151)\end{array}$ & $\begin{array}{c}0.0333^{* * *} \\
(0.0124)\end{array}$ & $\begin{array}{c}0.0033 \\
(0.0036)\end{array}$ \\
\hline $\ln$ (Pop. Density) & $\begin{array}{c}-0.0908^{* * *} \\
(0.0309)\end{array}$ & $\begin{array}{c}-0.0945^{* * *} \\
(0.0301)\end{array}$ & $\begin{array}{l}-0.0211 \\
(0.0129)\end{array}$ & $\begin{array}{l}-0.0025 \\
(0.0023)\end{array}$ & $\begin{array}{l}-0.0193 \\
(0.0145)\end{array}$ & $\begin{array}{c}-0.0409^{* *} \\
(0.0169)\end{array}$ & $\begin{array}{c}-0.0071 \\
(0.0107)\end{array}$ & $\begin{array}{l}-0.0005 \\
(0.0029)\end{array}$ \\
\hline GOP Vote Share (County) & $\begin{array}{c}-2.4685^{* * *} \\
(0.2686)\end{array}$ & $\begin{array}{c}-2.0884^{* * *} \\
(0.3181)\end{array}$ & $\begin{array}{c}-1.0520^{* * *} \\
(0.1132)\end{array}$ & $\begin{array}{c}-0.1694^{* * *} \\
(0.0243)\end{array}$ & $\begin{array}{c}-1.1728^{* * *} \\
(0.1091)\end{array}$ & $\begin{array}{c}-0.9962^{* * *} \\
(0.1835)\end{array}$ & $\begin{array}{c}-0.7041^{* * *} \\
(0.1142)\end{array}$ & $\begin{array}{c}-0.1556^{* * *} \\
(0.0363)\end{array}$ \\
\hline Restriction Expectation FE & No & No & Yes & Yes & No & No & Yes & Yes \\
\hline DV Mean & 1.309 & 1.053 & 1.309 & 0.177 & 2.076 & 1.670 & 2.076 & 0.281 \\
\hline DV SD & 1.489 & 1.409 & 1.489 & 0.382 & 1.386 & 1.456 & 1.386 & 0.449 \\
\hline Psuedo $R^{2}$ & 0.0211 & 0.0251 & 0.1762 & 0.0413 & 0.0091 & 0.0097 & 0.1024 & 0.2783 \\
\hline $\mathrm{N}$ & 28,449 & 28,449 & 28,449 & 28,449 & 17,932 & 17,932 & 17,932 & 17,932 \\
\hline
\end{tabular}

Note: Reopen is the expected months to reopen. Restriction is the estimated months until restrictions are lifted. Lag $\geq 4 w k$ is a indicator variable that evaluates to 1 if the firm's estimated reopening date is at least one month/four weeks after the estimated date restrictions are lifted. Businesses that were permanently closed at the time of the survey are excluded from these regressions; businesses that were fully open at the time of the survey are excluded from columns 5-8. Employee Physical Proximity, Customers Over 65, and Ease Operating Online are converted to z-scores. Restriction expectation fixed effects are included in the indicated models and are a vector of fixed effects corresponding to the date at which respondents believe that restrictions will be lifted. Standard errors in parentheses, clustered at county level. Note that the survey questions in which reopening and restriction beliefs are elicited is mid-way through the survey, thus in some columns we are able to have more observations than we have complete survey responses. ${ }^{*} p<0.1,{ }^{* *} p<0.05,{ }^{* * *} p<0.01$ 
Table A4. Contribution of Various Factors to the Small Business Reopen Decision, County Fixed Effects

\begin{tabular}{|c|c|c|c|c|c|c|c|c|}
\hline & \multicolumn{4}{|c|}{ All Businesses } & \multicolumn{4}{|c|}{ Excluding Fully Open Businesses } \\
\hline & $\begin{array}{c}(1) \\
\text { Reopen }\end{array}$ & $\begin{array}{c}(2) \\
\text { Restrictions }\end{array}$ & $\begin{array}{c}(3) \\
\text { Reopen }\end{array}$ & $\stackrel{\text { Lag }}{\stackrel{(4)}{\geq} 4 \mathrm{wk}}$ & $\begin{array}{c}(5) \\
\text { Reopen }\end{array}$ & $\begin{array}{c}(6) \\
\text { Restrictions }\end{array}$ & $\begin{array}{c}\text { (7) } \\
\text { Reopen }\end{array}$ & $\mathrm{Lag} \stackrel{(8)}{\geq} 4 \mathrm{wk}$ \\
\hline Emp. Physical Proximity & $\begin{array}{c}0.325^{* * *} \\
(0.0623)\end{array}$ & $\begin{array}{c}0.416^{* * *} \\
(0.0657)\end{array}$ & $\begin{array}{c}0.0373 \\
(0.0475)\end{array}$ & $\begin{array}{c}-0.00218 \\
(0.0187)\end{array}$ & $\begin{array}{c}0.0551 \\
(0.0831)\end{array}$ & $\begin{array}{c}0.225^{* *} \\
(0.104)\end{array}$ & $\begin{array}{l}-0.0157 \\
(0.0697)\end{array}$ & $\begin{array}{l}-0.0244 \\
(0.0214)\end{array}$ \\
\hline$\times \ln ($ COVID cases p.c. $)$ & $\begin{array}{c}0.0144 \\
(0.0110)\end{array}$ & $\begin{array}{c}0.0189 \\
(0.0114)\end{array}$ & $\begin{array}{c}0.00270 \\
(0.00838)\end{array}$ & $\begin{array}{c}-0.00162 \\
(0.00313)\end{array}$ & $\begin{array}{c}0.0120 \\
(0.0135)\end{array}$ & $\begin{array}{c}0.0123 \\
(0.0181)\end{array}$ & $\begin{array}{l}0.00636 \\
(0.0123)\end{array}$ & $\begin{array}{c}-0.000739 \\
(0.00378)\end{array}$ \\
\hline Owner Age & $\begin{array}{r}-0.000389 \\
(0.00301)\end{array}$ & $\begin{array}{c}-0.00716^{* * *} \\
(0.00202)\end{array}$ & $\begin{array}{c}0.00464 \\
(0.00301)\end{array}$ & $\begin{array}{c}0.00111 \\
(0.000905)\end{array}$ & $\begin{array}{c}0.00189 \\
(0.00455)\end{array}$ & $\begin{array}{c}-0.00823^{* * *} \\
(0.00224)\end{array}$ & $\begin{array}{c}0.00433 \\
(0.00411)\end{array}$ & $\begin{array}{l}0.000808 \\
(0.00107)\end{array}$ \\
\hline$\times \ln ($ COVID cases p.c. $)$ & $\begin{array}{c}0.000220 \\
(0.000328)\end{array}$ & $\begin{array}{l}-0.000306 \\
(0.000415)\end{array}$ & $\begin{array}{c}0.000451 \\
(0.000364)\end{array}$ & $\begin{array}{c}0.000116 \\
(0.000119)\end{array}$ & $\begin{array}{c}0.000307 \\
(0.000400)\end{array}$ & $\begin{array}{c}-0.000348 \\
(0.000493)\end{array}$ & $\begin{array}{c}0.000398 \\
(0.000441)\end{array}$ & $\begin{array}{l}0.0000769 \\
(0.000135)\end{array}$ \\
\hline Customers Over 65 & $\begin{array}{c}-0.169^{* * *} \\
(0.0436)\end{array}$ & $\begin{array}{c}-0.175^{* * * *} \\
(0.0559)\end{array}$ & $\begin{array}{l}-0.0420 \\
(0.0379)\end{array}$ & $\begin{array}{r}-0.00548 \\
(0.0192)\end{array}$ & $\begin{array}{c}-0.112^{* *} \\
(0.0491)\end{array}$ & $\begin{array}{c}-0.130 \\
(0.0779)\end{array}$ & $\begin{array}{c}-0.0921^{*} \\
(0.0462)\end{array}$ & $\begin{array}{l}-0.0263 \\
(0.0240)\end{array}$ \\
\hline$\times \ln ($ COVID cases p.c. $)$ & $\begin{array}{c}-0.0209^{* * *} \\
(0.00759)\end{array}$ & $\begin{array}{c}-0.0196^{* *} \\
(0.00912)\end{array}$ & $\begin{array}{l}-0.00639 \\
(0.00629)\end{array}$ & $\begin{array}{l}-0.00172 \\
(0.00312)\end{array}$ & $\begin{array}{c}-0.00779 \\
(0.00862)\end{array}$ & $\begin{array}{l}-0.00707 \\
(0.0129)\end{array}$ & $\begin{array}{c}-0.0102 \\
(0.00807)\end{array}$ & $\begin{array}{c}-0.00423 \\
(0.00414)\end{array}$ \\
\hline Essential Business & $\begin{array}{c}-0.302^{* * *} \\
(0.0286)\end{array}$ & $\begin{array}{c}-0.329^{* * *} * \\
(0.0302)\end{array}$ & $\begin{array}{c}-0.0703 * * * \\
(0.0169)\end{array}$ & $\begin{array}{c}-0.0263 * * * \\
(0.00482)\end{array}$ & $\begin{array}{c}-0.121^{* * *} \\
(0.0330)\end{array}$ & $\begin{array}{c}-0.235^{* * *} \\
(0.0311)\end{array}$ & $\begin{array}{c}-0.0471^{*} \\
(0.0239)\end{array}$ & $\begin{array}{c}-0.0183^{* * *} \\
(0.00611)\end{array}$ \\
\hline Ease Operating Online & $\begin{array}{c}0.0516^{* * *} \\
(0.0137)\end{array}$ & $\begin{array}{c}0.0379^{* * *} \\
(0.00978)\end{array}$ & $\begin{array}{c}0.0234^{* *} \\
(0.0107)\end{array}$ & $\begin{array}{c}0.00406 \\
(0.00345)\end{array}$ & $\begin{array}{l}0.0288^{*} \\
(0.0151)\end{array}$ & $\begin{array}{c}0.0201 \\
(0.0141)\end{array}$ & $\begin{array}{c}0.0268^{* *} \\
(0.0120)\end{array}$ & $\begin{array}{c}0.00176 \\
(0.00361)\end{array}$ \\
\hline Restriction Expectation FE & No & No & Yes & Yes & No & No & Yes & Yes \\
\hline County FE & Yes & Yes & Yes & Yes & Yes & Yes & Yes & Yes \\
\hline DV Mean & 1.302 & 1.047 & 1.302 & 0.177 & 2.076 & 1.671 & 2.076 & 0.282 \\
\hline DV SD & 1.486 & 1.406 & 1.486 & 0.382 & 1.386 & 1.455 & 1.386 & 0.450 \\
\hline Residual SD & 1.414 & 1.323 & 1.092 & 0.366 & 1.331 & 1.387 & 1.127 & 0.366 \\
\hline$R^{2}$ & .0946 & .115 & .46 & .0806 & .0782 & .091 & .339 & .337 \\
\hline $\mathrm{N}$ & 27,266 & 27,266 & 27,266 & 27,266 & 16,890 & 16,890 & 16,890 & 16,890 \\
\hline
\end{tabular}

Note: Reopen is the expected months to reopen. Restriction is the estimated months until restrictions are lifted. Lag $\geq 4 w k$ is a indicator variable that evaluates to 1 if the firm's estimated reopening date is at least one month/four weeks after the estimated date restrictions are lifted. Businesses that were permanently closed at the time of the survey are excluded from these regressions; businesses that were fully open at the time of the survey are excluded from columns 5-8. Employee Physical Proximity, Customers Over 65, and Ease Operating Online are converted to z-scores. Restriction expectation fixed effects are included in the indicated models and are a vector of fixed effects corresponding to the date at which respondents believe that restrictions will be lifted. Standard errors in parentheses, clustered at county level. Note that the survey questions in which reopening and restriction beliefs are elicited is mid-way through the survey, thus in some columns we are able to have more observations than we have complete survey responses. ${ }^{*} p<0.1,{ }^{* *} p<0.05,{ }^{* * *} p<0.01$ 
Table A5. Customers returning and business reopening: projected vs realized.

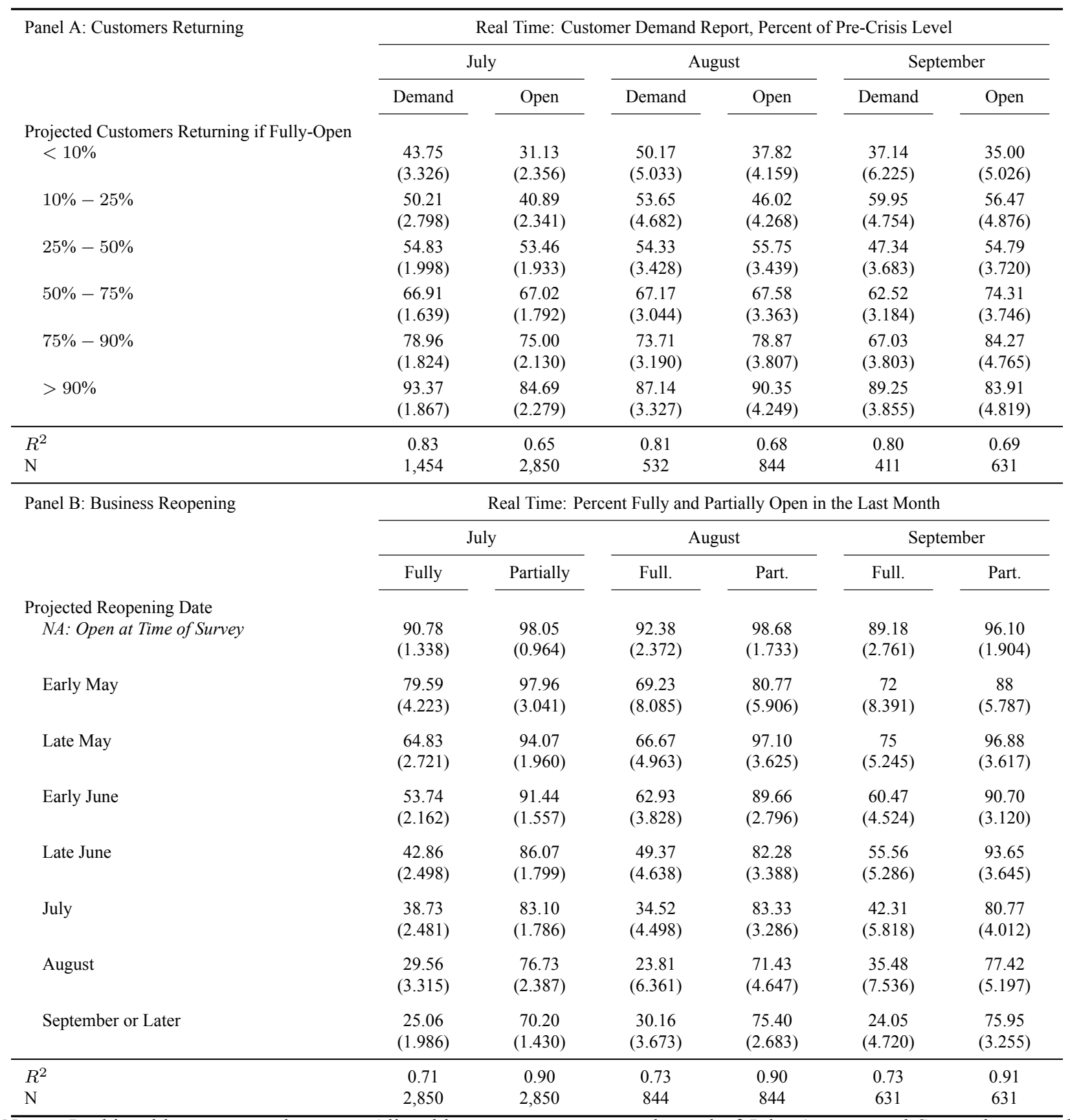

Notes: In this table, we use subsequent Alignable surveys sent out at the end of July, August, and September to validate demand expectations (Panel A) and reopening plans (Panel B). In Panel A, we plot the mean share of customers returning relative to the pre-crisis level (Demand) and the share of businesses that are fully open (Open). We estimate these means conditional on the respondent's projected share of customers returning by a given date in the initial May survey. The realized demand is only available for firms that report being fully open at the time of the later survey; therefore for each survey round we have more observations for the business status (Open) than for the realized demand measure (Demand). Finally, in pair of columns, we restrict to the set of respondents that appear in both the initial May survey, and the subsequent survey. In Panel B, we report the share of businesses that are open at the time of the subsequent survey. We show both the share that are fully open (Fully) and the share that are either fully open or partially open (Partially). Each row reports these means conditional on the respondent's projected reopening date at the time of the initial survey. 
Table A6. Attrition Analysis

\begin{tabular}{|c|c|c|c|c|c|c|c|}
\hline \multirow{4}{*}{ Number of Respondents } & \multirow{4}{*}{$\begin{array}{c}\frac{\text { Full Survey Sample }}{(\text { May, 2020) }} \\
27,340 \\
\text { Share of Respondents }\end{array}$} & \multicolumn{6}{|c|}{ Re-Surveyed } \\
\hline & & \multicolumn{2}{|c|}{ July } & \multicolumn{2}{|c|}{ August } & \multicolumn{2}{|c|}{ September } \\
\hline & & \multicolumn{2}{|c|}{2,893} & \multicolumn{2}{|c|}{859} & \multicolumn{2}{|c|}{641} \\
\hline & & Share & p-value & Share & p-value & Share & $\mathrm{p}$-value \\
\hline \multicolumn{8}{|l|}{ Five Largest Industries } \\
\hline Professional and Technical Services & 0.160 & 0.167 & 0.305 & 0.127 & 0.024 & 0.137 & 0.178 \\
\hline Retail Trade & 0.129 & 0.128 & 0.874 & 0.155 & 0.060 & 0.152 & 0.141 \\
\hline Finance and Insurance & 0.084 & 0.054 & $<0.001$ & 0.066 & 0.094 & 0.071 & 0.287 \\
\hline Health Care and Social Assistance & 0.081 & 0.083 & 0.818 & 0.056 & 0.020 & 0.071 & 0.402 \\
\hline Real Estate and Rental and Leasing & 0.074 & 0.053 & $<0.001$ & 0.049 & 0.018 & 0.044 & 0.014 \\
\hline \multicolumn{8}{|l|}{ Five Largest States } \\
\hline California & 0.122 & 0.129 & 0.248 & 0.116 & 0.583 & 0.139 & 0.168 \\
\hline New York & 0.071 & 0.077 & 0.190 & 0.078 & 0.429 & 0.067 & 0.684 \\
\hline Florida & 0.066 & 0.072 & 0.202 & 0.070 & 0.614 & 0.072 & 0.527 \\
\hline Pennsylvania & 0.050 & 0.042 & 0.031 & 0.041 & 0.217 & 0.038 & 0.147 \\
\hline Texas & 0.050 & 0.051 & 0.807 & 0.047 & 0.683 & 0.041 & 0.289 \\
\hline \multicolumn{8}{|l|}{ Business Status } \\
\hline Fully Open & 0.322 & 0.337 & 0.062 & 0.352 & 0.060 & 0.360 & 0.036 \\
\hline Partially Open & 0.332 & 0.299 & $<0.001$ & 0.313 & 0.222 & 0.324 & 0.665 \\
\hline Temporarily Closed & 0.319 & 0.348 & $<0.001$ & 0.318 & 0.939 & 0.300 & 0.285 \\
\hline Permanently Closed & 0.026 & 0.015 & $<0.001$ & 0.017 & 0.094 & 0.016 & 0.082 \\
\hline \multicolumn{8}{|l|}{ (Predicted) Share of Customers Returning } \\
\hline$<10 \%$ & 0.099 & 0.133 & $<0.001$ & 0.141 & $<0.001$ & 0.127 & 0.018 \\
\hline $10 \%-25 \%$ & 0.122 & 0.135 & 0.027 & 0.134 & 0.279 & 0.135 & 0.319 \\
\hline $25 \%-50 \%$ & 0.211 & 0.198 & 0.060 & 0.206 & 0.718 & 0.231 & 0.208 \\
\hline $50 \%-75 \%$ & 0.252 & 0.230 & 0.005 & 0.216 & 0.014 & 0.228 & 0.170 \\
\hline $75 \%-90 \%$ & 0.168 & 0.163 & 0.431 & 0.168 & 0.987 & 0.141 & 0.067 \\
\hline$>90 \%$ & 0.148 & 0.142 & 0.330 & 0.135 & 0.274 & 0.138 & 0.458 \\
\hline
\end{tabular}

Notes: In this table, we test for differential attrition across the subsequent survey waves. In the first column, we present the share of respondents with a given attribute (industry, state) or response ( business status, predicted share of customers returning) in the initial May survey. We report the share of businesses with each attribute or response in the subsample of the original survey that can be matched to the later survey round. We also report the p-value of the difference between the share of respondents in the subsequent round and in the initial May round. The last two sections, business status and share of customers returning, are collectively exhaustive, though may not sum to one due to rounding. 
Table A7. Time to Reopen by Industry (2-digit NAICS), excluding Fully Open in May 9 Survey

\begin{tabular}{lccc}
\hline & Reopen & Lag & Lag $\geq 4$ weeks \\
\hline Management of Companies and Enterprises & 0.750 & 0.500 & 0.000 \\
Accommodation and Food Services & 2.235 & 0.556 & 0.204 \\
Real Estate and Rental and Leasing & 1.928 & 0.670 & 0.275 \\
Arts, Entertainment, and Recreation & 2.654 & 0.673 & 0.241 \\
Other Services, Except Public Administration & 1.832 & 0.684 & 0.219 \\
Construction & 1.750 & 0.692 & 0.277 \\
Retail Trade & 1.755 & 0.706 & 0.228 \\
Manufacturing & 2.006 & 0.813 & 0.306 \\
Public Administration & 2.527 & 0.840 & 0.342 \\
Health Care and Social Assistance & 1.985 & 0.868 & 0.316 \\
Educational Services & 2.473 & 0.879 & 0.269 \\
Agriculture, Forestry, Fishing and Hunting & 2.034 & 0.912 & 0.311 \\
Wholesale Trade & 1.872 & 0.929 & 0.332 \\
Utilities & 1.938 & 0.969 & 0.348 \\
Professional and Technical Services & 2.158 & 0.992 & 0.355 \\
Administrative and Waste Services & 2.388 & 1.012 & 0.337 \\
Information & 2.698 & 1.049 & 0.383 \\
Finance and Insurance & 1.786 & 1.086 & 0.278 \\
Transportation and Warehousing & 2.371 & 1.113 & 0.416 \\
Mining, Quarrying, and Oil and Gas Extraction & 1.884 & 1.304 & 0.308 \\
\hline
\end{tabular}

Note: This table presents average time to reopen by 2-digit NAICS code for the subset of firms that are not fully open at the time of the survey. Reopen is the predicted time to reopen in months, Lag is the difference between the predicted time to reopen and the predicted end of restrictions, and $L a g \geq 4$ weeks is an indicator that evaluates to one when the predicted reopening time is more than four weeks after the predicted end of restrictions. 
Table A8. Time to Reopen by Industry (3-digit NAICS), excluding Fully Open in May 9 Survey

\begin{tabular}{|c|c|c|c|}
\hline & Reopen & Lag & $\mathrm{Lag} \geq 4$ weeks \\
\hline Accommodation and Food Services: Accommodation & 2.129 & 0.700 & 0.300 \\
\hline Accommodation and Food Services: Food Services and Drinking Places & 2.270 & 0.509 & 0.172 \\
\hline Administrative and Waste Services: Administrative and Support Services & 2.400 & 1.009 & 0.339 \\
\hline Agriculture, Forestry, Fishing and Hunting: Animal Production and Aquaculture & 2.154 & 1.023 & 0.314 \\
\hline Arts, Entertainment, and Recreation: Amusement, Gambling, and Recreation Industries & 2.023 & 0.461 & 0.173 \\
\hline Arts, Entertainment, and Recreation: Museums, Historical Sites, and Similar Institutions & 2.238 & 0.844 & 0.214 \\
\hline Arts, Entertainment, and Recreation: Performing Arts, Spectator Sports, and Related Industries & 3.183 & 0.815 & 0.299 \\
\hline Construction: Construction of Buildings & 1.784 & 0.678 & 0.265 \\
\hline Construction: Specialty Trade Contractors & 1.705 & 0.687 & 0.297 \\
\hline Educational Services: Educational Services & 2.480 & 0.846 & 0.270 \\
\hline Finance and Insurance: Credit Intermediation and Related Activities & 1.771 & 1.187 & 0.246 \\
\hline Finance and Insurance: Funds, Trusts, and Other Financial Vehicles & 1.964 & 1.455 & 0.268 \\
\hline Finance and Insurance: Insurance Carriers and Related Activities & 1.810 & 0.866 & 0.331 \\
\hline Finance and Insurance: Securities, Commodity Contracts, and Other Financial Investments and Related Activities & 1.610 & 0.794 & 0.310 \\
\hline Health Care and Social Assistance: Ambulatory Health Care Services & 1.920 & 0.887 & 0.325 \\
\hline Health Care and Social Assistance: Social Assistance & 2.233 & 0.692 & 0.244 \\
\hline Information: Motion Picture and Sound Recording Industries & 3.093 & 0.844 & 0.327 \\
\hline Information: Publishing Industries (except Internet) & 2.455 & 1.455 & 0.519 \\
\hline Manufacturing: Beverage and Tobacco Product Manufacturing & 2.075 & 0.488 & 0.163 \\
\hline Manufacturing: Food Manufacturing & 2.353 & 1.176 & 0.344 \\
\hline Manufacturing: Machinery Manufacturing & 1.823 & 0.746 & 0.328 \\
\hline Manufacturing: Miscellaneous Manufacturing & 2.051 & 0.720 & 0.265 \\
\hline Manufacturing: Printing and Related Support Activities & 1.833 & 0.654 & 0.330 \\
\hline Other Services, Except Public Administration: Personal and Laundry Services & 1.696 & 0.532 & 0.171 \\
\hline Other Services, Except Public Administration: Religious, Grantmaking, Civic, Professional, and Similar Organizations & 2.340 & 1.010 & 0.340 \\
\hline Other Services, Except Public Administration: Repair and Maintenance & 1.546 & 0.819 & 0.252 \\
\hline Professional and Technical Services: Professional, Scientific, and Technical Services & 2.159 & 0.994 & 0.356 \\
\hline Public Administration: Administration of Human Resource Programs & 2.882 & 0.779 & 0.309 \\
\hline Real Estate and Rental and Leasing: Real Estate & 1.916 & 0.648 & 0.278 \\
\hline Real Estate and Rental and Leasing: Rental and Leasing Services & 2.041 & 0.912 & 0.250 \\
\hline Retail Trade: Clothing and Clothing Accessories Stores & 1.576 & 0.507 & 0.136 \\
\hline Retail Trade: Food and Beverage Stores & 1.911 & 0.998 & 0.270 \\
\hline Retail Trade: Furniture and Home Furnishings Stores & 1.471 & 0.695 & 0.224 \\
\hline Retail Trade: Health and Personal Care Stores & 1.776 & 0.595 & 0.242 \\
\hline Retail Trade: Miscellaneous Store Retailers & 1.782 & 0.628 & 0.225 \\
\hline Retail Trade: Motor Vehicle and Parts Dealers & 1.378 & 0.448 & 0.120 \\
\hline Retail Trade: Sporting Goods, Hobby, Musical Instrument, and Book Stores & 2.014 & 0.797 & 0.269 \\
\hline Transportation and Warehousing: Transit and Ground Passenger Transportation & 2.647 & 1.016 & 0.381 \\
\hline Wholesale Trade: Merchant Wholesalers, Durable Goods & 1.767 & 0.822 & 0.276 \\
\hline
\end{tabular}

Note: This table presents average time to reopen by 3-digit NAICS code for the subset of firms that are not fully open at the time of the survey. Reopen is the predicted time to reopen in months, Lag is the difference between the predicted time to reopen and the predicted end of restrictions, and $L a g \geq 4$ weeks is an indicator that evaluates to one when the predicted reopening time is more than four weeks after the predicted end of restrictions. 